\title{
Synthesis of Antimycobacterial Agents that Harness Mycothiol and Cysteine conjugate $\beta$-lyase Metabolic Pathways
}

by

Scott W. Riordan

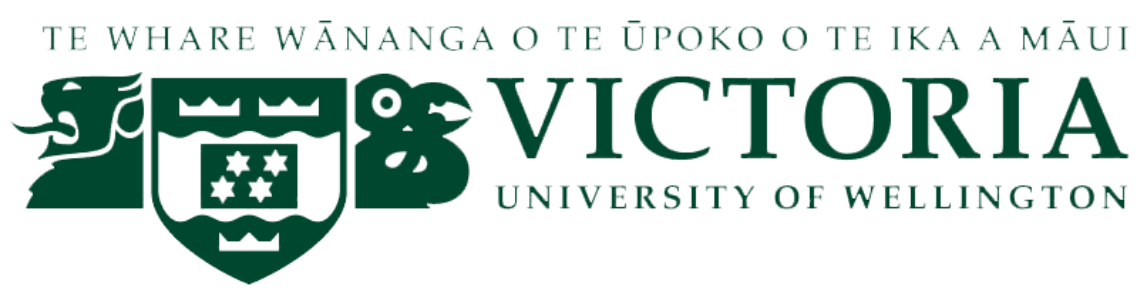

\author{
A thesis submitted to \\ Victoria University of Wellington \\ in fulfilment of the requirements for the \\ degree of Master of Biomedical Science
}

Victoria University of Wellington

2015 


\section{Abstract}

Mycobacterium tuberculosis kills approximately two million people each year and is second only to HIV/AIDs in terms of death from infectious disease. The most pertinent problem in regards to Mycobacterium tuberculosis today is the increasing prevalence of drug resistant strains. Thus, there is a great need for the development of new drugs with novel targets. This thesis aimed to address this problem by synthesizing a compound that could exploit the mycothiol detoxification pathway, unique to Mycobacterium, in order to cause cell death, through the release of a harmful halothioketene.

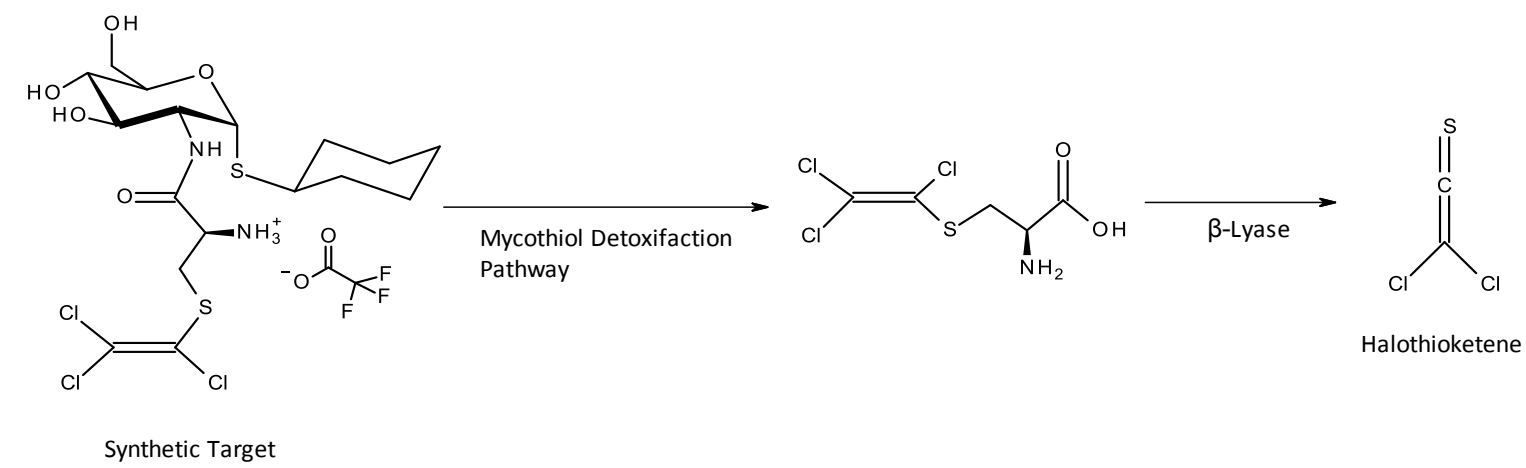

The research described herein involved the successful synthesis of the desired mycothiol analogue, along with three other related compounds. The target compounds were synthesised via protection of $\mathrm{N}$-acetyl glucosamine, followed by thioglycosidation with cyclohexane thiol. Subsequent deprotection and coupling to Boc protected Strichlorovinyl cysteine provided access to the synthetic target and its $\beta$-anomer, as well as their Boc protected precursors.

The original synthetic target demonstrated weak antimycobacterial activity against Mycobacterium smegmatis and an encouraging sub $100 \mu \mathrm{M}$ MIC against Mycobacterium bovis derived Bacillus Calmette-Guérin. Unexpectedly the beta anomer of the synthetic target also displayed antimycobacterial activity against Bacillus Calmette-Guérin (MIC 125 - $250 \mu \mathrm{M})$. All compounds proved to be active against HL60 cells (16-114 $\mu \mathrm{M})$. 
Whilst further work is required to improve efficacy, the work presented here demonstrates the potential of these compounds as leads for the generation of new antimycobacterial agents. 


\section{Acknowledgements}

There are many people I would like to thank. Firstly, Paul, I could not have asked for a better supervisor. Throughout the course of my studies your office door was always open and you were always happy to discuss results, no matter how busy you might have been. While your knowledge in both biochemistry and organic chemistry made these talks invaluable. I would also like to take the time to thank my co-supervisor Joanne. Your positive outlook, eye for detail and vast organic chemistry knowledge was a huge help. To all the people who occupied 205 east end during the course of my thesis, thanks for the all the good times and helpful discussions that took place.

Specifically regarding my thesis, it was fantastic to have my synthesised compounds tested. So thanks to Jessica, Hilary and Nathaniel for making this possible.

I would like to thank my family for all the moral support over the years and for showing an interest in my study, despite the fact my answers probably did not make much sense. For their financial support, I would like to thank my nana Alison and granddad Tony, it was a great help. Aunty Carolyn, uncle Niven and Robbie, thanks for letting me stay your at your place while I finished of my thesis, it saved me a lot of hassle, towards to the end of my thesis. Finally, to my parents, to you I owe my biggest gratitude, for without your support and encouragement none of this would be possible. 


\section{Table of Contents}

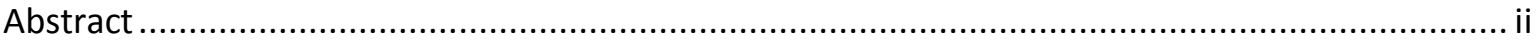



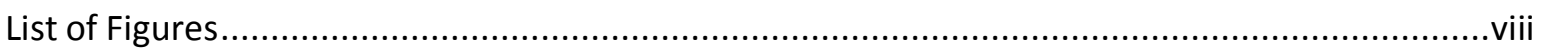

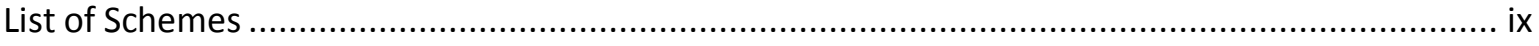

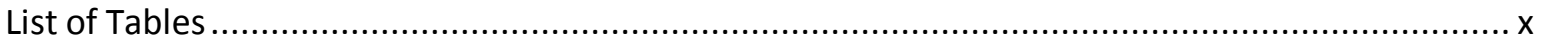



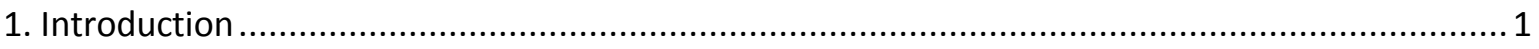



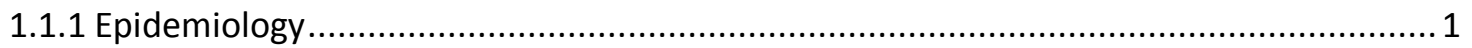

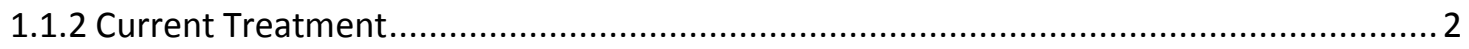

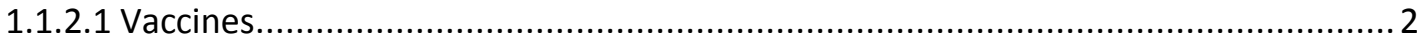

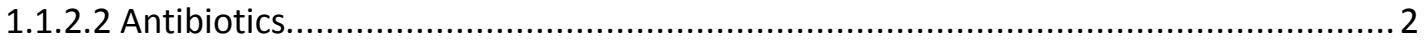



1.1.3.1 Phenotypic Resistance ............................................................................. 3

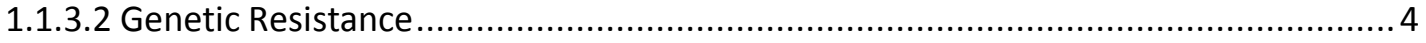

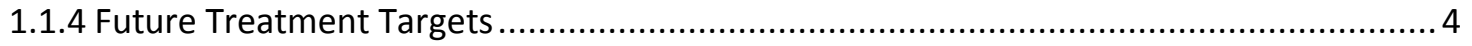

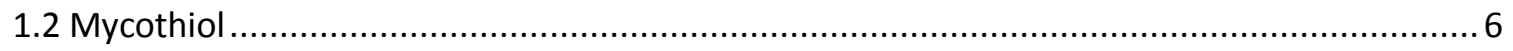

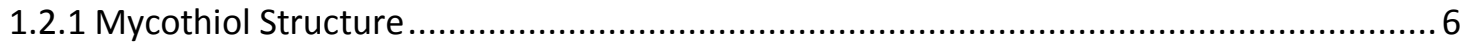

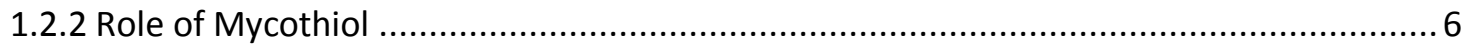

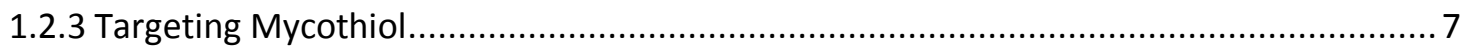

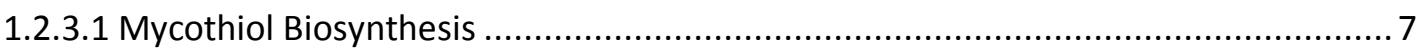

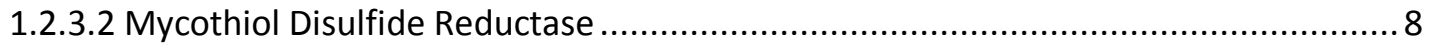

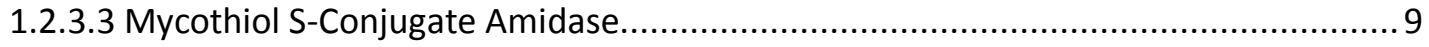

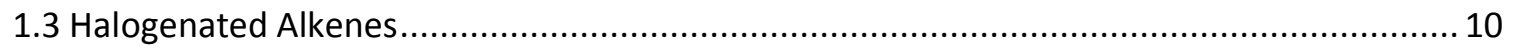

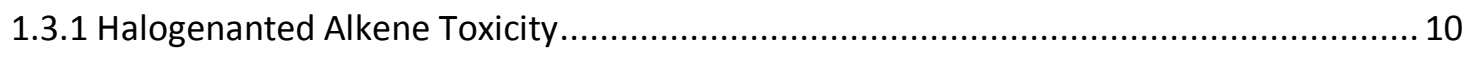

1.3.1.1 Halogenated Alkenes and their Uses ............................................................. 10

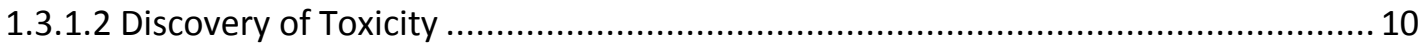

1.3.1.3 Animal studies and Human studies on Toxicity and Carcinogenicity...................... 11

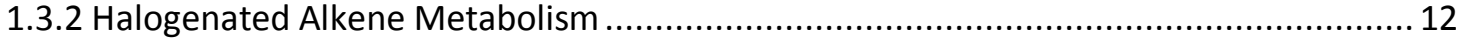




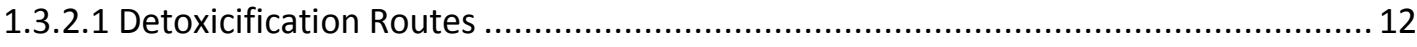

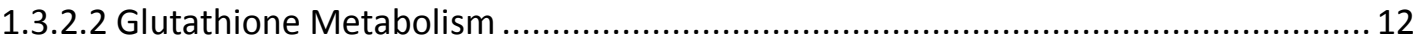

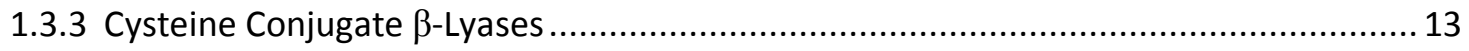



1.3.3.2 Cysteine S-Conjugate Metabolism by $\beta$-Lyases ................................................... 14

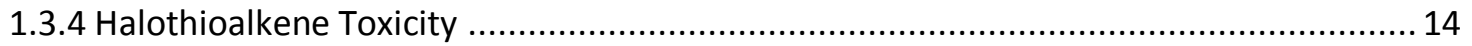

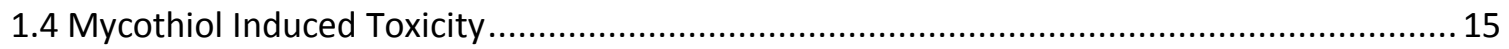



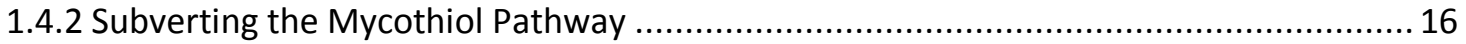

1.4.3 Proposed Mechanism for Conjugated Mycothiol Analogue ......................................... 16

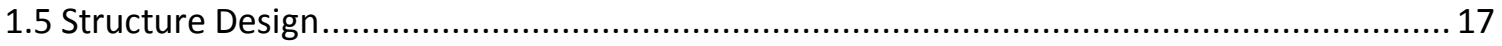

1.5.1 Cysteine $N$-Acetylation and Hydroxyl Removal ....................................................... 17

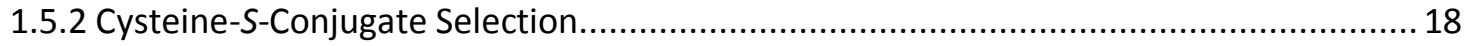

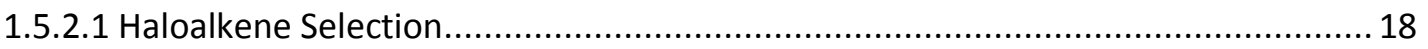

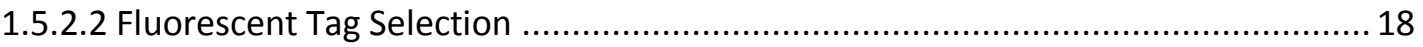

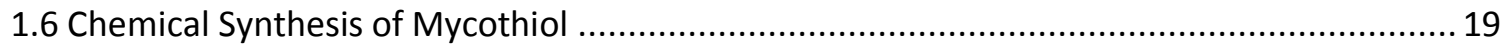

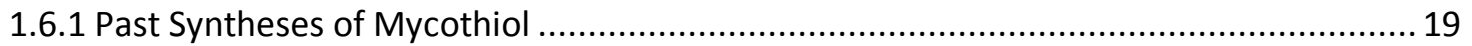

1.6.2 Knapp et al. (2002) Synthesis of a Mycothiol Analogue .......................................... 20

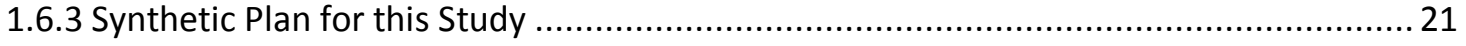

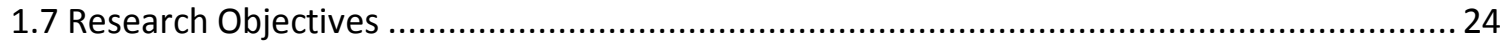

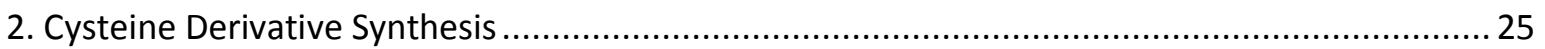

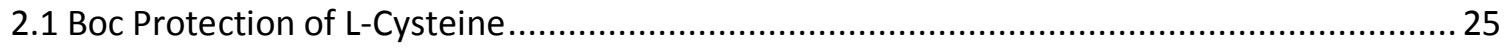

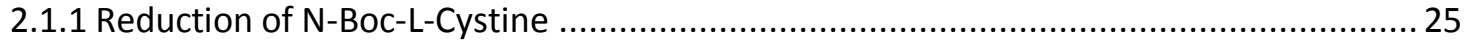

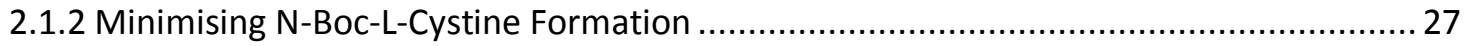

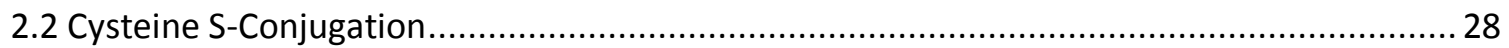

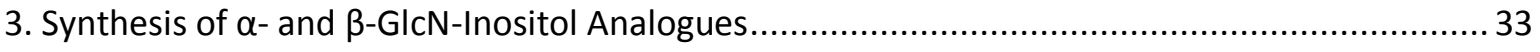

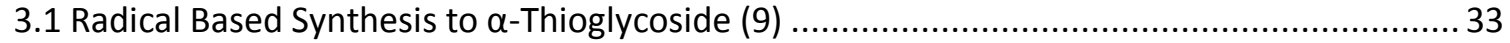

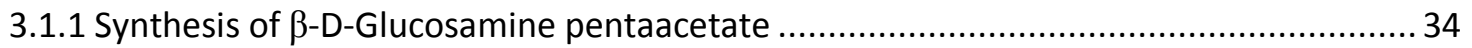

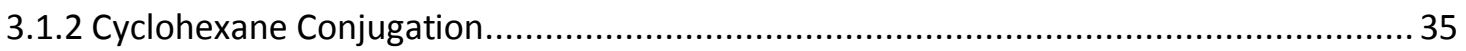

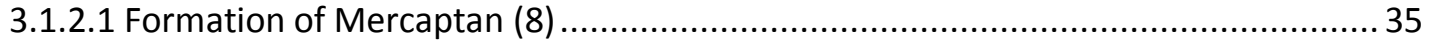

3.1.2.2 Radical Induced Thioglycoside Formation........................................................ 36 


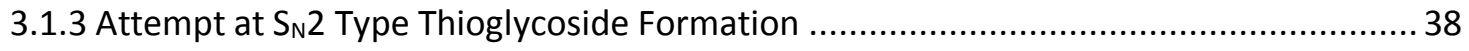

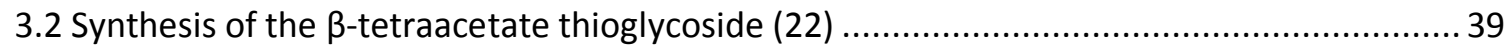

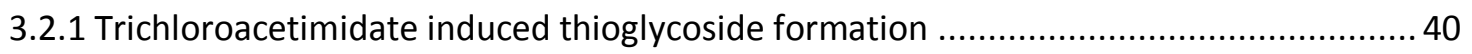

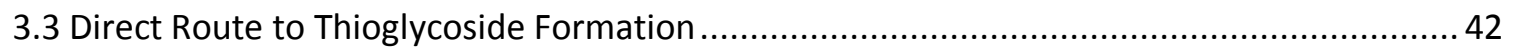

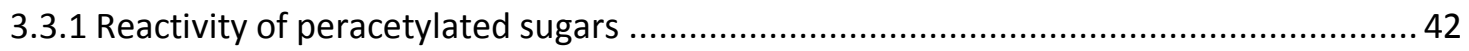

3.3.2 Synthesis of $\alpha$ - and $\beta$-Thioglycoside Directly from $\alpha$-Glucosamine pentaacetate .......... 43

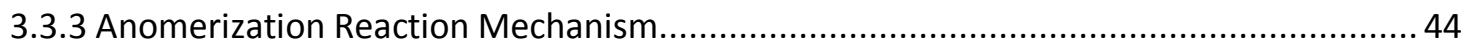

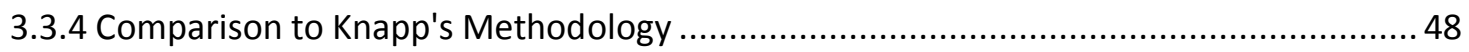

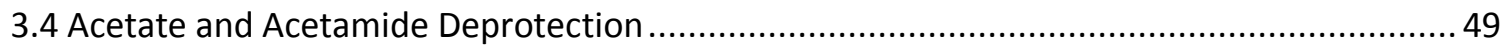

3.4.1 Addition of the Boc Group to Acetate Protected Thioglycosides (9) and (22) .............. 49

3.4.2 Deprotection of Boc, Acetamide and Acetate Protecting Groups from (23) and (24) ....53

4. Synthesis of Mycothiol Analogues and Biological Studies....................................................... 54

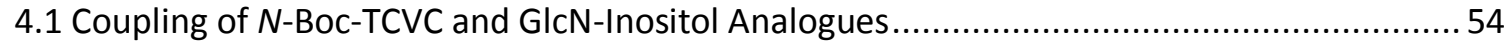

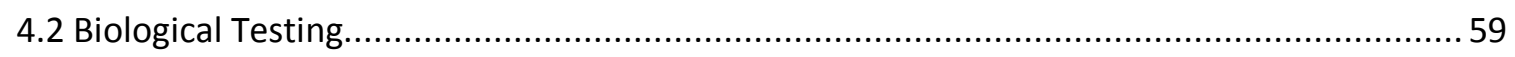

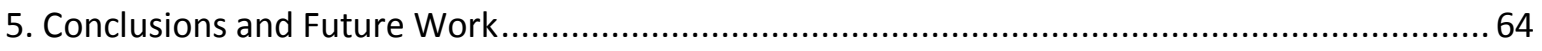

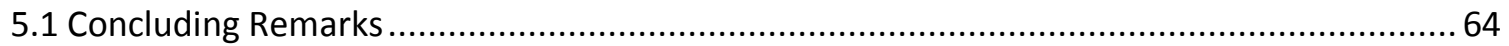

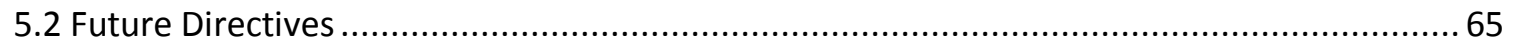

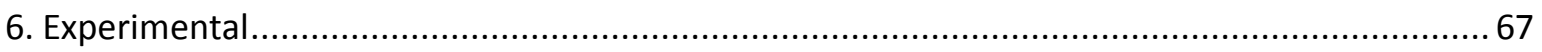

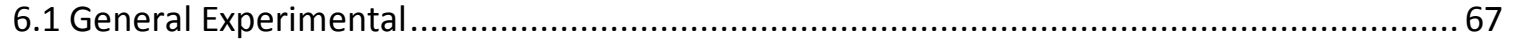

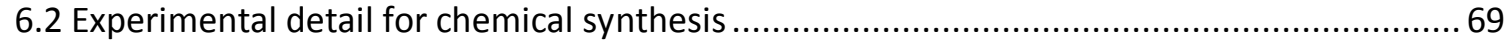

6.3 Experimental Details for Macromodel Calculations............................................................... 83

6.4 Experimental Detail for MTT Cell Proliferation Assay ....................................................... 84

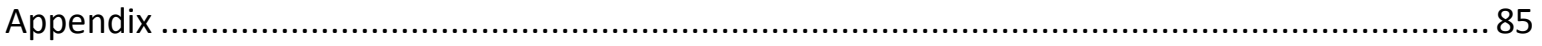

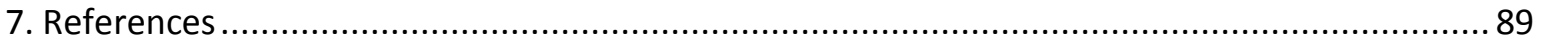




\section{List of Figures}

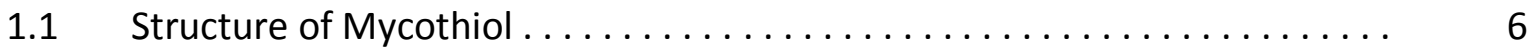

$1.2 \quad$ Structure of Mycothione $\ldots \ldots \ldots \ldots \ldots \ldots \ldots \ldots \ldots \ldots \ldots \ldots \ldots \ldots \ldots$

$1.3 \quad \beta$-lysis of cysteine-S-conjugate $\ldots \ldots \ldots \ldots \ldots \ldots \ldots \ldots \ldots \ldots \ldots \ldots$

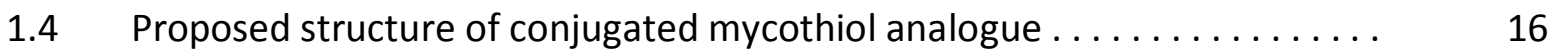

1.5 Structure of proposed fluorescent mycothiol analogue . . . . . . . . . 19

2.1 Species formed during the Boc protection of $L$-cysteine $\ldots \ldots \ldots \ldots \ldots \ldots$

2.2 ${ }^{1} \mathrm{H}$ NMR spectrum comparing the $\alpha$ and $\beta$ protons of Boc-TCVC

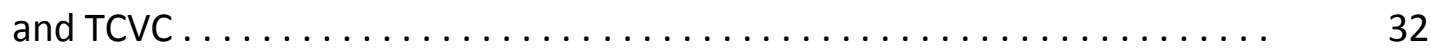

3.1 ${ }^{1} \mathrm{H}$ NMR of the $\alpha$-Boc 23 and $\beta$-Boc $24 \ldots \ldots \ldots \ldots \ldots \ldots \ldots \ldots \ldots$

3.2 Molecular models of the lowest energy Boc-up and Boc-down conformations for the $\alpha$-Boc 23 and $\beta$-Boc $24 \ldots \ldots \ldots \ldots \ldots \ldots \ldots \ldots \ldots \ldots$ 


\section{List of Schemes}

1.1 Knapp et al. (2002) synthesis of a simplified mycothiol analogue . . . . . . 21

1.2 Proposed synthesis of cysteine-S-conjugates $\ldots \ldots \ldots \ldots \ldots \ldots \ldots \ldots$

1.3 Proposed synthesis of mycothiol analogues 13 and $14 \ldots \ldots \ldots \ldots \ldots$

$2.1 \quad$ Attempted synthesis of $N$-Boc-L-cysteine $\ldots \ldots \ldots \ldots \ldots \ldots \ldots \ldots \ldots$

3.1 Synthesis of $\beta$-D-glucosamine pentaacetate $\ldots \ldots \ldots \ldots \ldots \ldots \ldots \ldots \ldots$

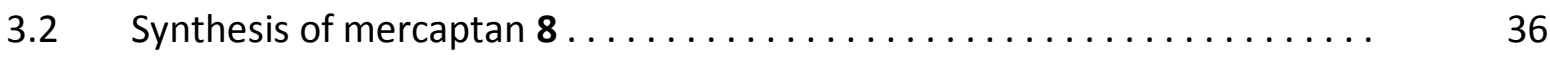

3.3 Attempted formation of thioglycoside 9 through $\mathrm{S}_{\mathrm{N}} 2$ type reaction $\ldots \ldots \quad 39$

3.4 Synthesis of $\beta$-Thioglycoside 22 via trichloroacetimidate $21 \ldots \ldots \ldots \ldots .41$

3.5 Synthesis of $\alpha$ - and $\beta$-thioglycosides $\mathbf{9}$ and $\mathbf{2 2}$ directly from peracetylated glucosamine $\ldots \ldots \ldots \ldots \ldots \ldots \ldots \ldots \ldots \ldots \ldots \ldots \ldots \ldots$

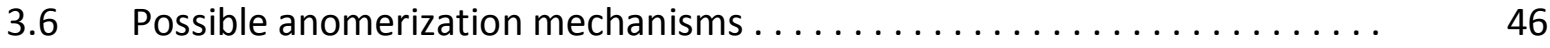

3.7 Boc activation of $N$-acetyl thioglycosides 9 and $22 \ldots \ldots \ldots \ldots \ldots \ldots$

3.8 One-pot deprotection of $N$-Boc thioglycosides 23 and $24 \ldots \ldots \ldots \ldots \ldots$

4.1 Formation of mycothiol analogues through N-Boc-TCVC conjugation and

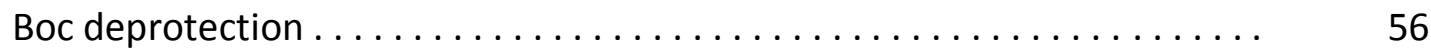

4.2 Synthesis of mycothiol analogues $\mathbf{1 1}, \mathbf{2 7}, \mathbf{1 3}$, and $28 \ldots \ldots \ldots \ldots \ldots$ 


\section{List of Tables}

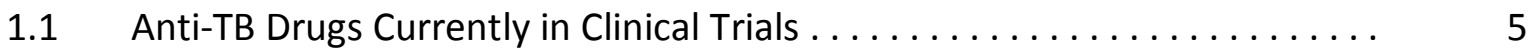

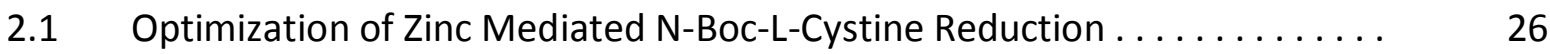

2.2 Optimization of L-Cysteine Boc Protection $\ldots \ldots \ldots \ldots \ldots \ldots \ldots \ldots \ldots$

2.3 Reaction of L-Cysteine with Tetrachloroethylene $\ldots \ldots \ldots \ldots \ldots \ldots \ldots \ldots$

3.1 Optimization of Radical Induced Thioglycoside Formation . . . . . . . 37

4.1 Activity of Synthesized Compounds Against Varying Cell Lines . . . . . . . 60 


\section{List of Abbreviations}

\begin{tabular}{|c|c|}
\hline Ac & acetyl \\
\hline aq. & aqueous \\
\hline Boc & $-\mathrm{COOC}\left(\mathrm{CH}_{3}\right)_{3}$ \\
\hline AIBN & azobisisobutyronitrile \\
\hline BCG & bacille Calmette-Guerin \\
\hline $\mathrm{BF}_{3} \cdot \mathrm{OEt}_{2}$ & boron trifluoride diethyl etherate \\
\hline $\mathrm{Boc}_{2} \mathrm{O}$ & di-tert-butyl dicarbonate \\
\hline brsm & based on recovered starting material \\
\hline COSY & correlation spectroscopy \\
\hline cy & cyclohexane \\
\hline$d$ & doublet \\
\hline DCC & N,N'-Dicyclohexylcarbodiimide \\
\hline DCM & dichloromethane \\
\hline DBN & 1,5-diazabicyclo[4.3.0]non-5-ene \\
\hline DBU & 1,8-Diazabicyclo[5.4.0]undec-7-ene \\
\hline DCVC & 1,2-Dichlorovinyl L-cysteine \\
\hline DMAP & 4-(Dimethylamino)pyridine \\
\hline DMF & $N, N$-Dimethylformamide \\
\hline DMSO & dimethyl sulfoxide \\
\hline $\mathrm{EDCl}$ & 1-(3- dimethylaminopropyl)-3-ethylcarbodiimide hydrochloride \\
\hline eq. & equivalent(s) \\
\hline
\end{tabular}




\begin{tabular}{|c|c|}
\hline ESI & electrospray ionisation \\
\hline Et & ethyl \\
\hline et al. & et alia (and others) \\
\hline EtOAc & ethyl acetate \\
\hline GFP & green fluorescent protein \\
\hline GlcN & Glucosamine \\
\hline GST & Glutathione-S-transferase \\
\hline HATU & $\begin{array}{l}\text { 1-[Bis(dimethylamino)methylene]-1H-1,2,3-triazolo[4,5- } b] \text { pyridinium 3-oxid } \\
\text { hexafluorophosphate }\end{array}$ \\
\hline HRMS & high resolution mass spectrometry \\
\hline HL60 & human promyelocytic leukemia cells \\
\hline HOAt & 1-Hydroxy-7-Azabenzotriazole \\
\hline IARC & International Agency for Research on Cancer \\
\hline $\mathrm{IC}_{50}$ & the concentration required to inhibit call/organism growth by $50 \%$ \\
\hline IR & infrared \\
\hline LA & Lewis acid \\
\hline $\mathrm{m}$ & multiplet \\
\hline Mca & mycothiol-S-conjugate amidase \\
\hline Me & methyl \\
\hline MIC & minimum inhibitory concentration \\
\hline m.p. & melting point \\
\hline Mtr & mycothiol disulfide reductase \\
\hline MTT & 3-(4,5-Dimethyl-2-thiazolyl)-2,5-diphenyl-2H-tetrazolium bromide \\
\hline OD & optical density \\
\hline
\end{tabular}




$\begin{array}{ll}\text { PMP } & \text { pyridoxamine 5'-phosphate } \\ \text { PLP } & \text { pyridoxal 5'-phosphate } \\ \text { q } & \text { quartet } \\ \mathrm{R}_{f} & \text { retention factor } \\ \mathrm{rt} & \text { room temp } \\ \mathrm{S} & \text { singlet } \\ \mathrm{t} & \text { triplet } \\ \text { TB } & \text { tuberculosis } \\ \text { TBAHS } & \text { tetrabutylammonium hydrogen sulfate } \\ \text { TCVC } & \text { trichlorovinyl L-cystiene } \\ \text { THF } & \text { tetrahydrofuran } \\ \text { TFA } & \text { triflouroacetic acid } \\ \text { TLC } & \text { Thin layer chromatography } \\ \text { UV } & \text { ultra violet } \\ \text { VUW } & \text { Victoria University of Wellington } \\ \end{array}$




\section{Chapter 1}

\section{Introduction}

The aim of this thesis is to explore whether the mycothiol pathway, in combination with cysteine conjugate $\beta$-lyases, could be exploited in order to activate a prodrug to produce an accumulation of harmful halothioketenes selectively in Mycobacterium Tuberculosis. This should ultimately result in cell death and thus provide a novel target and mechanism of action for the treatment of tuberculosis.

\subsection{Mycobacterium tuberculosis}

\subsubsection{Epidemiology}

Mycobacterium tuberculosis is the major causative agent for tuberculosis (TB). TB is primarily an infection of the lung, although it may be localized elsewhere, particularly in immunocompromized people. Clinical symptoms include fatigue, anorexia, weight loss, fevers and potentially death ${ }^{1}$. On a worldwide basis there are an estimated eight million new cases of TB each year, of which approximately two million are lethal; making it second only to HIV/AIDs in terms of deaths from an infectious disease ${ }^{2}$.

There are two possible outcomes that occur upon infection by Mycobacterium tuberculosis: Less frequently, the host will develop the clinical symptoms associated with the disease (active TB). Alternatively, which is more often the case, the immune system will control and isolate the pathogen, progressing to what is known as latent TB. This state represents a stalemate between the host's immune system and the Mycobacterium tuberculosis, where the pathogen population is not able to actively grow, nor is the immune system able completely eradicate the pathogen ${ }^{3}$. It is estimated that approximately one third of the world's population is infected with latent TB. These people will not exhibit any clinical signs 
of TB, nor are they contagious. However they may at any time progress to its active form. The probability of this occurring is estimated at between two and twenty three percent over a lifetime, with the risk of it occurring increasing in diabetic, malnourished or immunocompromized people, as well as though drug use and in cancer sufferers ${ }^{4}$.

\subsubsection{Current Treatment}

\subsubsection{Vaccines}

Prevention can be a very effective form of treatment and with this in mind, an effective vaccine would represent a great step forward in the fight against Mycobacterium tuberculosis. However, although there are a large number of potential vaccines being explored in human clinical trials, there is only one vaccine currently in use, namely bacille Calmette-Guerin $(B C G)^{5,6}$. Despite being the world's most widely administered vaccine, BCG is a long way from being optimal and carries with it some significant drawbacks ${ }^{7}$. BCG's major drawbacks are its highly variable efficacy and its inefficiency in preventing TB in adolescents and adults ${ }^{8}$. Thus, although vaccines may represent an ideal solution for the control of TB, there is currently no reliable vaccine available. Therefore the use of antibiotics in the treatment of tuberculosis remains pertinent.

\subsubsection{Antibiotics}

The current TB treatment regime recommended by the world health organization involves treatment with a combination of four of the first line TB drugs. These drugs include Isoniazid, Rifampicin, Pyrazinamide, Ethambutol and Thioacetazone. After an initial two month treatment patients should continue treatment with Isonazid in combination with either Rifampicin and/or Ethambutol for a further four to six months. The combination of

drugs used and the time they are used for is dependent on factors such as the severity of 
the infection, whether it is a reoccurring infection, or whether the patients has a concomitant HIV infection ${ }^{2}$. Patients in which Mycobacterium tuberculosis is resistant to the first line drugs, can be given second line drugs. However, these drugs often come with major drawbacks, such as decreased efficacy and more severe side effects ${ }^{2}$. The treatment complexity, time required and multitude of drugs needed demonstrates just how difficult TB is to treat. This difficulty stems from the perseverance of drug resistant strains of Mycobacterium tuberculosis.

\subsubsection{Drug Resistance}

\subsubsection{Phenotypic Resistance}

Mycobacterium tuberculosis possesses many mechanisms that lead to drug resistance. From a phenotypic perspective, Mycobacterium tuberculosis has a highly impervious cell wall that confers resistance to the vast majority of available antibiotics ${ }^{9}$. Resistance is further exacerbated by its ability to reside in multiple metabolic states. In the latent form described above (section 1.1.1) the Mycobacterium tuberculosis lies in a dormant, non replicating state. This causes problems, as current antibiotics against TB are most effective when the Mycobacterium tuberculosis is actively replicating ${ }^{10}$. While they provide inherent resistance to a wide range of antibiotics, these phenotypes are not the reason for one of the biggest health concerns in regards to TB today. Instead it is the increasing prevalence of Mycobacterium tuberculosis that possess genetic resistance to the drugs currently used to treat TB, i.e. multi and extensive drug resistant TB. 


\subsubsection{Genetic Resistance}

As many as 440,000 cases of multidrug resistant TB strains were estimated to have occurred in $2008^{11}$ and continued to rise at an alarming rate, reaching 605,000 by $2010^{12}$. Doctors using inadequate treatment regimes and failure of patients to adhere to the regimes that are adequate has added to an increase in multi and extensive drug resistance to TB over the past decade. The multi drug resistant strains demonstrate resistance to the common first line drugs Isoniazid and Rifampicin. Extensive drug resistant strains "exhibit resistance to Rifampicin and Isoniazid, any fluoroquinolone, and one of the three injectable drugs, Capreomycin, Kanamycin, and Amikacin" ${ }^{11 .}$.

Resistant strains in Mycobacterium tuberculosis are a direct result of spontaneous mutations that occur on its genome. Hence, these resistant strains can develop in any population and, over time, drug based selection pressures can cause growth in the resistant strain to the point where it represents the largest portion of Mycobacterium tuberculosis present in the host ${ }^{11}$. It is because of this phenomenon that multiple drugs are required to treat TB and why incorrect treatment strategies can quickly cause a proliferation in multidrug and extensive drug resistant strains.

Multi and extensive drug resistant strains of TB are of serious concern. Although treatment is available, they pose problems due to their increased costs and fatality rates. Recently there has been incidence of a strain resistant to all forms of tuberculosis drugs ${ }^{13}$. With drug resistance to tuberculosis becoming more prevalent, the search for new treatments to combat the disease becomes more pertinent.

\subsubsection{Future Treatment Targets}

The need for new and novel TB treatments has increased interest and research in the area,

with anti-TB drugs in clinical and preclinical trials currently at its highest point in 40 years ${ }^{12}$. Advancements made in drug screening has led to the identification of a plethora of new 
compounds that exhibit high levels of toxicity toward Mycobacterium tuberculosis. Between 2006 and 2011 alone, 278 natural products and their derivatives have been found that have a minimum inhibitory concentration (MIC) of less than $50 \mu \mathrm{g} / \mathrm{mL}$ against Mycobacterium tuberculosis or the closely related Mycobacterium smegmatis ${ }^{14}$. However there is a high attrition rate in the progression of these compounds into clinical evaluation. At the time of writing, there are only ten drugs in clinical development (table 1.1). Of these just six drugs are novel, while three have been repurposed from other disease treatments to test their viability against TB. The remaining one is currently being re-evaluated to see if its efficacy can be enhanced ${ }^{9,12,15}$.

The small number of anti-TB drugs currently in clinical development demonstrates the need for a sustained effort in the development of new drugs to combat TB. Of particular importance are drugs that work through novel targets and metabolic pathways. These drugs will have a higher chance of success against drug resistant strains as well as a decreased risk of drug-drug interactions ${ }^{10}$. One such pathway that meets this criteria is the mycothiol pathway and for this reason much interest has been generated by considering the mycothiol pathway in Mycobacterium tuberculosis ${ }^{16-18}$.

Table 1.1. Anti-TB Drugs Currently in Clinical Trials

\begin{tabular}{llll}
\hline Drug & Novel & Phase of Clinical Trial & Chemical Class \\
\hline PA-824 & Nompound & 2 & Nitroimidazole-oxazine \\
Sutezolid & Novel & 2 & Oxazolidinone \\
Bedaquiline & Novel & 2 & Diarylquinoline \\
SQ109 & Novel & 2 & Ethylenediamine \\
Linezolid & Repurposed & 2 & Oxazolidinone \\
Rifapentine & Re-evaluated & 2 and 3 & Rifamycin \\
AZD5847 & Novel & 2 & Oxazolidinone \\
Gatifloxacin & Repurposed & 3 & Fluoroquinolone \\
Moxifloxacin & Repurposed & 3 & Fluoroquinolone \\
Delamanid & Novel & 3 & Nitro-dihydro-Imidazoooxazole \\
\hline
\end{tabular}




\subsection{Mycothiol}

\subsubsection{Mycothiol Structure}

Mycothiol is the major low molecular weight thiol found in the majority of actinomycetes; the most clinically relevant of these being Mycobacterium tuberculosis. It was not discovered until 1993, when Fahey et al. were able to determine its existence in a range of actinomycetes. However they could not fully characterise its structure, with the only thing known about it at that time being that it contained cysteine ${ }^{19}$. Since then it has been demonstrated that its structure is composed of an $\mathrm{N}$-acetylated cysteine linked through an amide bond to glucosamine, which itself is linked to myo-inositol through a glycosidic bond (Figure 1.1) ${ }^{20}$.

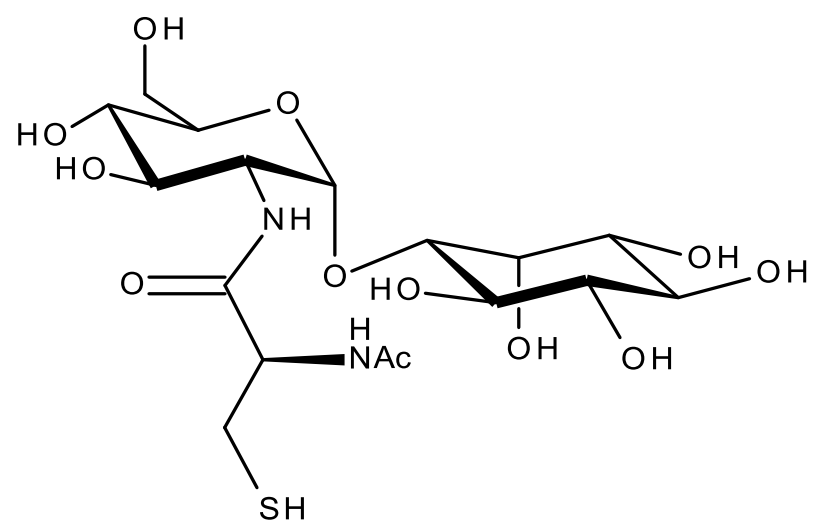

Figure 1.1. Structure of Mycothiol

\subsubsection{Role of Mycothiol}

Mycothiol performs a role analogous to that of the other low molecular weight thiols found in a range of organisms. These include glutathione which is found in eukaryotes and gram negative bacteria, trypanothione in trypanosomatids and coenzyme $A$ in certain gram positive bacteria ${ }^{19}$. The discovery of mycothiol came quite late in comparison to its eukaryotic relative glutathione. 
However, in the two decades since its discovery a large quantity of research has been undertaken, that provides a great wealth of knowledge in regards to its roles and functions. The vast majority of mycothiol-containing actinomycetes do not produce any glutathione, suggesting that mycothiol acts as a direct replacement to glutathione in actinomycetes. Thus, as with glutathione, the main roles of mycothiol are: 1) regulation of the redox potential in the cell in order to maintain a reducing environment and 2) protecting the cell against dangerous electrophilic radicals and xenobiotics ${ }^{21}$. Consequently, due to the important roles mycothiol plays in mycobacteria there has been a large amount of interest in mycothiols biosynthetic and metabolic enzymes as potential drug targets for Mycobacterium tuberculosis. Several of these enzymes have been researched to determine their viability as potential targets. The key ones are described below.

\subsubsection{Targeting Mycothiol}

\subsubsection{Mycothiol Biosynthesis}

There are in total five enzymes involved in the biosynthesis of mycothiol from its $N$-acetyl glucosamine precursor. They include MshA1 and MshA2, which together are responsible for joining the inositol and $\mathrm{N}$-acetyl glucosamine together. Once joined MshB removes the $\mathrm{N}$-acetate from the glucosamine, allowing MshC to conjugate the cysteine portion. The final step in the biosynthesis is the addition of an acetate group to the cysteine amine by MshD, resulting in the completed mycothiol. Of these enzymes, MshA1 and MshC are essential to the growth of Mycobacterium tuberculosis. Disrupting the genes encoding for either of these enzymes causes no mycothiol to be produced and consequently prevents Mycobacterium tuberculosis from growing 22 .

In one study, Newton et al. (2006) screened 2024 compounds looking for MshC inhibition, and discovered a compound, termed NTF1836, that has an $\mathrm{IC}_{50}=100 \mu \mathrm{M}$ against MshC. NTF1836 was able to completely inhibit the growth of Mycobacterium smegmatis at $40 \mu \mathrm{M}$. 
However, the activity may not be a direct result of MshC inhibition, as Mycobacterium smegmatis has been demonstrated to grow in the absence of MshC, suggesting NTF1836 has an alternative target as well ${ }^{23}$. Nevertheless, the importance of MshA1 and MshC enzymes to Mycobacterium tuberculosis suggests a potent inhibitor of either enzyme would be a good candidate for an anti-TB drug.

\subsubsection{Mycothiol Disulfide Reductase}

One of mycothiol's most important roles is to prevent damage from harmful free radicals and oxidants by maintaining a reducing environment inside the cell. To achieve this mycothiol will react with free radicals and oxidants, subsequently causing their reduction as well as the oxidation of mycothiol to its corresponding disulphide mycothione (Figure 1.2). In order to maintain the reducing environment the mycothione needs to be reduced so as to replenish the mycothiol. This is achieved via an NADPH-dependent flavoprotein, mycothiol disulfide reductase (Mtr). Studies have shown that antisense oligonucleoside inhibition of Mtr in Mycobacterium bovis results in a reduction of growth. However, it will not stop growth completely ${ }^{24}$. Thus Mtr may not be a viable anti-TB drug if it is directly

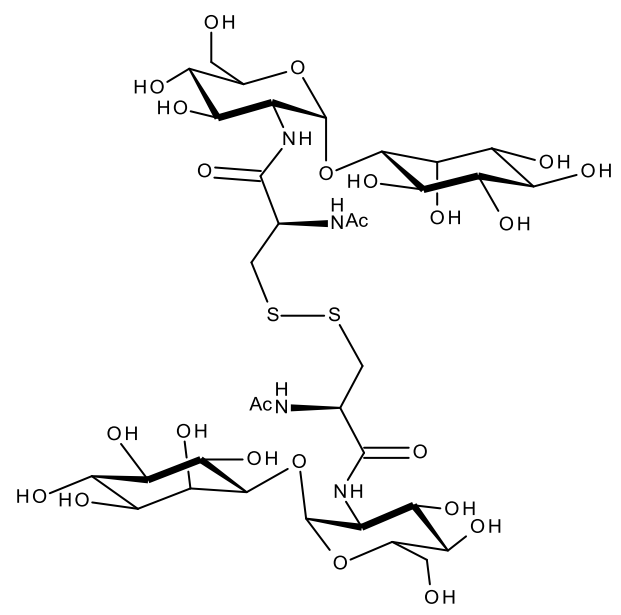

Figure 1.2. Structure of Mycothione 
targeted. Nonetheless, it is known that majority of antibiotics used result in a build up of toxic hydoxyl free radicals, regardless of the drug's target. These hydroxyl free radicals are a major contributor to cell death. Thus, by combining traditional drugs with drugs that inhibit the cell's defence against free radicals, i.e. Mtr in Mycobacterium tuberculosis, it may be possible to synergistically enhance the efficacy of existing antibiotics ${ }^{25}$.

\subsubsection{Mycothiol S-Conjugate Amidase}

Mycothiol S-conjugate amidase plays an important role in the detoxification of harmful electrophilic xenobiotics in actinomycetes. Mycothiol will conjugate electrophilic xenobiotics through its cysteine sulphur. The newly formed conjugate is subsequently cleaved by mycothiol S-conjugate amidase (Mca), releasing the conjugated $N$-acetylated cysteine (mercapturic acid) from the inositol and glucosamine rings (GlcN-Ins). The mercapturic acid is then readily excreted from the cell and GlcN-Ins is recycled back into mycothiol's biosynthetic pathway ${ }^{21}$. Mca has a broad substrate scope in regards to what is conjugated to the cysteine sulphur. Variations range from large to small and polar to non polar, although small and polar compounds, such as mycothiol itself, show substantially reduced activity ${ }^{26}$. This substrate scope can be best exemplified by the different antibiotics Mca is able to metabolise. Substrates range from the large, macrocyclic and complex Rifamycin, to the comparatively small Cerulenin ${ }^{21}$.

The inhibition of Mca has been the focus of a number of studies. Over 1500 compounds have been tested for their activity against Mca, a number of which have $I_{50}$ 's less than 10 $\mu \mathrm{M}^{16,27}$. These studies and the other studies performed to date on mycothiol's other biosynthetic and metabolic enzymes have all been explored for inhibition in order to develop anti-TB drugs. The reasoning behind the focus on inhibition is due to the fact that mycothiol has been shown to be essential to the survival of the Mycobacterium tuberculosis and as it is not present in humans, its metabolic and biosynthetic enzymes provide a good entry point into the development of selective drugs against $\mathrm{TB}^{13}$. However, there is another 
approach that warrants consideration. This is to use one of mycothiol's metabolic pathways, namely Mca detoxification, in the selective killing of mycobacterium tuberculosis through the use of halogenated alkenes.

\subsection{Halogenated Alkenes}

\subsubsection{Halogenanted Alkene Toxicity}

\subsubsection{Halogenated Alkenes and their Uses}

Of the simplest forms of halogenated alkenes, i.e. haloethenes, tetrachloroethylene and trichloroethylene are the most widely used due to their lipophilicity and non-flammability as solvents. These properties make them useful in roles such as degreasing metals and dry in cleaning fabrics ${ }^{28}$. In the 1930's, trichloroethylene was even used as a general anaesthetic. Neither tetrachloroethylene or trichloroethylene occur naturally in nature, though due to their wide spread use they are found as common contaminants in both air and drinking water. As of 1995 an estimated 34\% of America's drinking water was thought to be contaminated with trichloroethene, a figure that would presumably be larger today ${ }^{28}$.

\subsubsection{Discovery of Toxicity}

It was not until over 20 years after its first use as a general aesthetic that toxicity relating to haloalkene exposure was first proposed. This hypothesis manifested out of an observation that calves fed trichloroethylene-extracted soybeans had a high rate of aplastic aneamia $^{29}$. It was later suggested by McKinney et al. (1959) that the cause of the aplastic ameamia was a metabolic product of trichloroethylene, namely 1,2-dichlorovinyl cysteine $(D C V C)^{30}$. The discovery came about through the observation that the administration of DCVC to calves caused the same aplastic anaemia syndrome that was seen in the calves fed 
trichloroethylene-extracted soybeans ${ }^{30}$. There is still much debate around the toxicity and carcinogenicity of halogenated alkenes, trichloroethylene in particular. A lot of ambiguity and scepticism exists in the studies done to date, both in animals and humans ${ }^{28}$.

\subsubsection{Animal studies and Human studies on Toxicity and Carcinogenicity}

Since the initial studies on aplastic anaemia in calves there have been numerous studies looking at the toxicity of trichloroethylene in both animals and humans, particularly in regards to its carcinogenicity. In 1995, on the back of evidence obtained from animal studies, the International Agency for Research on Cancer (IARC) deemed there was "sufficient evidence" to conclude that trichloroethylene does display carcinogenicity in animals. The experiments included four inhalation experiments on mice, all of which indicated an increase risk in various tumours. Rats and hamsters were also tested with varying results ${ }^{31}$. Given that trichloroethylene displayed some carcinogenicity in certain animal models the question remained as to whether the same carcinogenicity would be seen in humans. Most of the case studies into humans have considered people exposed to trichloroethylene at high levels. These studies tend to show a small but statistically significant increase in the amount of urinary proteins and other markers for nephrotoxicity ${ }^{32}$. Further, multiple studies have demonstrated an increase in the risk of contracting renal cancer in people exposed to high levels over a number of years. However, these studies have been criticized due to perceived methodology flaws. Nevertheless, the evidence obtained does suggest a weak correlation between high level trichloroethylene exposure and renal cancer in humans ${ }^{32}$. 


\subsubsection{Halogenated Alkene Metabolism}

\subsubsection{Detoxicification Routes}

In order to gain a better understanding of trichloroethylene toxicity, multiple studies have been performed looking at the metabolic fate of trichloroethylene in human and animals. The results of these studies found the majority of trichloroethylene is metabolized by cytochromes P450 to trichloroethanol, trichloroethanol-glucuronide and trichloroacetic acid. Nonetheless, it is thought that the toxicity caused by trichloroethylene is not a direct result of any of the metabolites formed from cytochrome P450 metabolism ${ }^{33}$. Instead the main culprit is believed to occur through glutathione metabolism. The amount of trichloroethlyene that gets metabolized through this pathway is extremely low, estimated to be less than $0.01 \%$ of the total dose of trichloroethylene in humans. However this small percentage is sufficient to cause damage, due to the high toxicity of some of the metabolites that are produced during this glutathione metabolism ${ }^{34}$.

\subsubsection{Glutathione Metabolism}

As mentioned previously (section 1.2.2), glutathione acts in an analogous manner to mycothiol. As such, one of its more important roles is in the detoxification of harmful electrophilic xenobiotics ${ }^{19}$. There is conclusive evidence that glutathione-mediated metabolism of trichloroethylene does occur. Both human and animal studies have isolated metabolic products consistent with glutathione metabolism present in urine after exposure to trichloroethylene ${ }^{35,36}$. Upon entry into the cell, trichloroethylene is processed by glutathione S-transferases (GSTs) to the corresponding glutathione S-conjugate, which gets metabolized further by $\mathrm{\gamma}$-glutamyltransferase and various dipeptidases to form $\mathrm{DCVC}^{33}$. Unlike trichloroethylene and tetrachloroethylene there is no doubt that DCVC is toxic; a fact that has been proven in numerous studies ${ }^{37-39}$. In the case of trichloroethylene metabolism DCVC can lead to either detoxification or toxicity. Detoxification occurs via $N$-acetylation of 
cysteine's amine. This step is catalysed by amino acylases producing a non-toxic mercapturic acid which is rapidly excreted from the cell ${ }^{40}$. However, without $\mathrm{N}$-acetylation the DCVC's free amine allows metabolism through an alternative route. This route is catalysed by $\beta$-Lyases and results in the formation of extremely toxic metabolites ${ }^{41}$.

\subsubsection{Cysteine Conjugate $\beta$-Lyases}

\subsubsection{Distribution and Discovery}

The name $\beta$-lyases is given to a set of enzymes that catalyse the cleavage of the cysteine $S$ conjugates through the sulphur-carbon bond of cysteine, in a $\beta$-elimination reaction ${ }^{40}$. This reaction was first demonstrated to occur in DCVC by Bhattacharya et al. $(1967)^{42}$. Nonetheless, it was not until 1978 that the term "cysteine conjugate $\beta$-lyase" was first used $^{43}$. There are currently thirteen enzymes containing cysteine conjugate $\beta$-lyase activity that have been identified in mammals, eight of which are cytosolic and five of which reside in the mitochondria ${ }^{44}$. These $\beta$-lyases are particularly prevalent in the kidney and liver, which explains why much of the toxicity associated with trichloroethylene exposure is isolated to the kidney ${ }^{45}$. The primary role of enzymes that exhibit cysteine conjugate $\beta$-lyase activity is not the beta elimination reaction they are usually characterized by, rather the majority of them are amino acid transferases ${ }^{44}$. Amino acid transferases are found widely throughout nature, including in bacteria and as such $\beta$-lyases should be prevalent in bacteria as well. A study by Dekant et al. (1986) supports this as it demonstrated Salmonella typhimurium have a significantly higher $\beta$-lyase concentration than mammalian cells ${ }^{46}$. 


\subsubsection{Cysteine S-Conjugate Metabolism by $\beta$-Lyases}

Both the $\beta$-elimination and transamination reactions require pyridoxal 5'-phosphate (PLP) as a coenzyme. The transamination reaction results in the conversion of an amino acid to it's corresponding $\alpha$-ketoacid. In this reaction, the PLP will be converted to pyridoxamine 5'-phospahate (PMP). In this form the enzyme is unable to catalyze a $\beta$-elimination reaction, though may be converted back to its PLP form through the reverse reaction, i.e. conversion of $\alpha$-ketoacid to amino acid $^{44}$. Thus, the addition of $\alpha$-ketoacid can increase $\beta$-lyase mediated toxicity by converting the inactive PMP to PLP, allowing $\beta$-elimination to take place $^{47}$. As mentioned above, the $\beta$-Lyases catalyse the cleavage of the C-S bond of cysteine through a $\beta$-elimination reaction. The $\beta$-elimination reaction performed by $\beta$-lyases ultimately results in the production of pyruvate, ammonia and a halothioalkene (Figure 1.3). It is this halothioalkene that is associated with the toxicity of trichloroethylene and various other halogenated alkenes ${ }^{45}$.

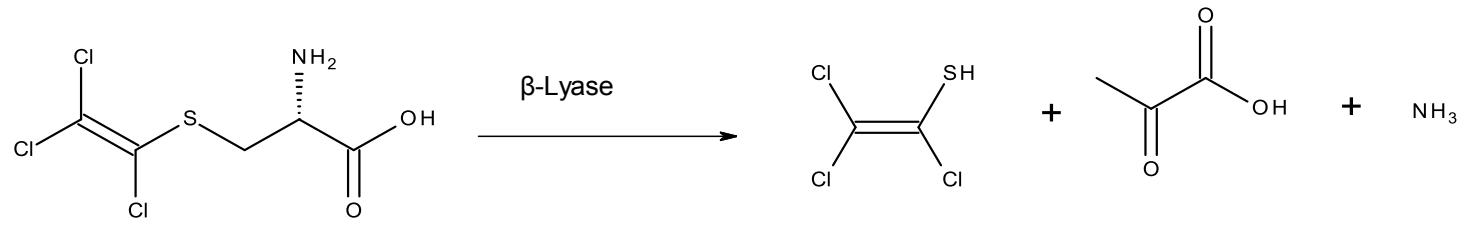

Figure 1.3. $\beta$-lysis of cysteine-S-conjugate

\subsubsection{Halothioalkene Toxicity}

The toxicity of the halothoialkenes are a direct result of their propensity to undergo transformation into a number of highly reactive intermediates including tautomerization to form thionyl acyl chlorides, or the loss of a halogen to form halothioketenes ${ }^{48}$. The halothioketenes in particular have been shown to be highly toxic. Volkel et al. (1998) demonstrated the high reactivity of halothioketenes, namely chlorothioketenes, by showing under optimal conditions chlorothioketenes could react with DNA, though had a higher propensity toward reacting with proteins ${ }^{49}$. Halothioketenes are also capable of 
reacting with the cell's glutathione, causing subsequent depletion of the cell's glutathione stores, resulting in oxidative stress and lipid peroxidation, ultimately leading to cell death ${ }^{50}$. Due to their inherent toxicity, halothioketenes could provide a novel approach to the treatment of TB, provided they can be made to specifically target the pathogen and avoid release in human cells. Utilizing mycothiol metabolism present in Mycobacterium tuberculosis provides an opportunity to induce the same halothioketene toxicity that is seen in mammals exposed to trichloroethylene.

\subsection{Mycothiol Induced Toxicity}

\subsubsection{Mycothiol and Glutathione Pathway}

As stated previously (section 1.2.3.3 and 1.3.2.2), both Mycobacterium tuberculosis and mammals utilize low molecular weight thiols to detoxify harmful electrophilic xenobiotics. In mammals glutathione will conjugate the electrophile to its cysteine's sulphur. The glutathione conjugate will then undergo metabolism by a number of enzymes to produce the corresponding cysteine $S$-conjugate. This can then either get $N$-acetylated to produce a non-toxic mercapturic acid, or alternatively, $\beta$-elimination can take place resulting in the production of a harmful halothioketene. In comparison, Mycobacterium tuberculosis utilizes mycothiol to detoxify electrophilic compounds ${ }^{21}$. This method of detoxification is more efficient than the glutathione based system. The reason being that the cysteine in mycothiol is already $\mathrm{N}$-acetylated, thus once a electrophile is conjugated to the mycothiol it requires just one enzyme, Mca, to produce the same end product of glutathione metabolism, i.e. a mercapturic acid. 


\subsubsection{Subverting the Mycothiol Pathway}

Because mycothiol metabolism is not present in mammals it provides an opportunity to selectivity release halothioketenes into Mycobacterium tuberculosis. However some of the differences between the detoxification pathways could pose problems. The end product of both their detoxifications is mercapturic acid, which excretes the conjugated electrophile out of the cell. The key difference in the two systems in terms of haloalkene toxicity is the $\mathrm{N}$-acetylatation of cysteine. This occurs in the last step of mercapturic acid formation in the glutathione pathway, while is present before conjugation in the case of the mycothiol pathway ${ }^{20}$. The activation and release of the toxic halothioketene is dependent on the

cysteine not being acetylated so $\beta$-elimination can occur. Thus, the halothioketene if conjugated to mycothiol would not released ${ }^{40}$. Taking this into consideration, the structure of a proposed mycothiol analogue (Figure 1.4) is suggested as a possible carrier for selective release of toxic haloalkenes in Mycobacterium tuberculosis.

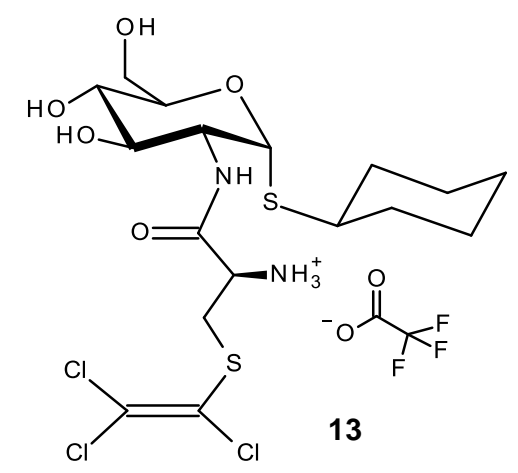

Figure 1.4. Proposed structure of conjugated mycothiol analogue

\subsubsection{Proposed Mechanism for Conjugated Mycothiol Analogue}

The proposed mechanism for the analogue causing Mycobacterium tuberculosis death is as follows: Upon entry into the mycobacterial cell, the analogue is recognized by Mca and subsequent cleavage of the amide bond occurs. This results in the release of the cysteine $S$-conjugate. The conjugate is then cleaved by $\beta$-lyases and the haloalkene sulfur fragment 
is released. The unstable haloalkene sulfur fragment then converts to a halothioketene and this results in the binding and disruption of macromolecules, as well as potentially reacting with the mycothiol, resulting in oxidative stress and a decrease in cell viability.

\subsection{Structure Design}

The proposed structure above (Figure 1.4) was based on an analogue produced by Knapp et al. (2002). However, it differs in two key areas; 1 ) the removal of the $N$-acetyl group from the cysteine and 2) the conjugation of the cysteine sulphur with a haloalkene.

\subsubsection{Cysteine N-Acetylation and Hydroxyl Removal}

The mycothiol analogue proposed by Knapp et al. (2002) had good activity for Mca, around half of what is observed with mycothiol (MSH), indicating that the simplification of the inositol ring by the removal of hydroxyl groups should not be too detrimental to its activity ${ }^{18}$. However, the removal of the $N$-acetyl group to allow for $\beta$-elimination to take place will have a greater effect on Mca recognition and activity. Newton et al. (2000) investigated the effect of removing the $\mathrm{N}$-acetyl group from the cysteine and found a significant decrease in the activity of Mca toward the substrate, with it showing just $0.1 \%$ of the activity shown by the $\mathrm{N}$-acetylated mycothiol ${ }^{20,51}$. Furthermore, a later study noted that the mycothiol biosynthetic enzyme MshB, which cleaves the $\mathrm{N}$-acetyl amide bond of GlcN-inositol (section 1.2.3.1), demonstrated a 500\% increase in activity toward the same des- $\mathrm{N}$-acetyl substrate than it's native GlcN-inositol substrate. Thus, removal of the $\mathrm{N}$ acetate from cysteine may not cause a significant decrease in the amide cleavage of the

proposed mycothiol analogue ${ }^{20,51}$. The other structural variation on mycothiol and the analogue developed by Knapp et al. (2002) is the conjugation of the haloalkene ${ }^{18}$. 


\subsubsection{Cysteine-S-Conjugate Selection}

\subsubsection{Haloalkene Selection}

The haloalkene initially chosen is tetrachloroethene, which would produce $S-(1,2,2-$ tricholorvinyl)-L-cysteine (TCVC) upon cleavage by Mca. Birner et al. (1997) looked at the toxicity of TCVC, S-(1,2-dichlorovinyl)-L-cysteine, S-(2,2-dichlorovinyl)-L-cysteine and S$(1,2,3,4,4-$ pentachlorobutadienyl)-L-cysteine (PCBC) in rat kidneys and found that TCVC produced the greatest amount of damage to the kidney cells ${ }^{41}$. This result suggests TCVC should be effective in disrupting the viability of the Mycobacterium tuberculosis and avoids the problem of regioselectivity that would be seen with trichloroethylene.

\subsubsection{Fluorescent Tag Selection}

A compound containing a fluorescent tag (Figure 1.5) was chosen to be synthesized alongside the compound seen in (Figure 1.4) in order to track cell entry and enzymatic activity. Tracking of mycothiol is typically done with the use of monobromobimane. Bimane is a fluorophore that gets conjugated to cysteine of mycothiol in the same way as the haloalkenes. The bimane conjugate has been shown to elicit the highest activity towards Mca to date, making it ideal for the tracking of the mycothiol detoxification pathway ${ }^{21}$. The application of the bimane conjugate's use in tracking the activity of the substrate with Mca was demonstrated by Knapp et al. (2002). They used fluorescence-detected HPLC to detect the mycothiol conjugate with bimane, and its corresponding mercapturic acid, demonstrating the potential to use monobromobimane in the study of the proposed mycothiol analogue uptake and degradation ${ }^{18}$. 


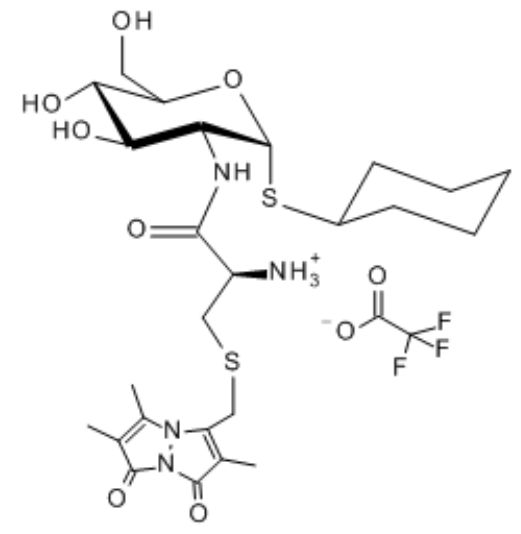

Figure 1.5. Structure of proposed fluorescent mycothiol analogue

\subsection{Chemical Synthesis of Mycothiol}

\subsubsection{Past Syntheses of Mycothiol}

In past studies involving mycothiol, two approaches are taken to obtaining mycothiol. They are whole cell extraction and chemical synthesis. Mycothiol is a difficult compound to isolate through whole cell extracts; it takes 1 litre of Mycothiol smegmatis cell culture to produce just $1.5 \mathrm{mg}$ of mycothiol. In many cases this method is impractical, especially when a scale up is required ${ }^{21}$. It is therefore not surprising that a lot of effort has been dedicated in to producing mycothiol through chemical synthesis.

There have been a number of mycothiol syntheses to date, which from a synthetic view point contain many challenging structural features. These include $\alpha / \beta$ selectivity at the anomeric centre, avoiding racemisation when conjugating cysteine, as well as desymmetrisation and protection of the inositol ${ }^{52-54}$. The first synthesis of mycothiol was developed by Bornemann et al. $(1997)^{54}$. It required a cumbersome five step protection/deprotection sequence to produce the appropriately protected insitol . Once formed, this functionalized inositol was coupled to a derivatized glucosamine in a silver 
triflate mediated reaction. Sixty percent of the conjugated adduct was obtained in a 1:1 mixture of $\alpha / \beta$ anomers. This synthesis was in fact a semi-synthesis utilizing a undialysed Mycothiol smegmatis cell extract in the final step of their synthesis to conjugate the cysteine and GIcN-Inositol. The final step resulted in a $40 \%$ yield containing both mycothiol and its des-acetyl cysteine analogue in a 4:1 mixture respectively ${ }^{54}$. A later synthesis was developed by Lee et al. $(2004)^{53}$. They employed an Me 3 SiOTf-promoted coupling of a trichloroacetimidate functionalized glucosamine and derivatized inositol, resulting in a 9:1 $(\alpha: \beta)$ ratio in a $45 \%$ yield. The conjugation of the GlcN-Inositol to $N$-acetyl cysteine however proved problematic, with both carbodiimide coupling reagents $\mathrm{EDCl}$ and $\mathrm{DCC}$ resulting in racemization. Nonetheless a diastereomerically pure product was achieved using HATU/HOAt and collidine, though a poor yield of $21 \%$ was obtained ${ }^{53}$. The two syntheses outlined above demonstrate some of the key structural challenges in regards to mycothiol synthesis. A number of other syntheses have also been completed ${ }^{13,52,55}$. However, none of these have managed to synthesise mycothiol on a scale that could not be easily reached via whole cell extracts and thus a higher yielding and more scalable synthesis was required ${ }^{21}$.

\subsubsection{Knapp et al. (2002) Synthesis of a Mycothiol Analogue}

Knapp et al. (2002) bypassed the problem of low yielding mycothiol syntheses by producing a mycothiol analogue (Scheme 1.1) that is biologically active toward Mca and can be readily synthesized in large quantities. The compound itself can be synthesized in seven steps from $\beta$-glucosamine pentaacetate. The synthesis involves the formation of a thiazoline through treatment of $\beta$-glucosamine pentaacetate with Lawesson's reagent, followed by the opening of the thiazoline with TFA to yield an anomeric $\alpha$-mercaptan. Conjugating of a cyclohexane ring was achieved through an $\mathrm{AIBN}$-induced radical reaction between cyclohexene and the mercaptan. Subsequent acetate deprotection using hydrazine afforded a GIcN-Inositol derivative. By stripping the hydroxyls of the inositol and using a sulphur linker, the issue of $\alpha / \beta$ selectivity was solved and the need for cumbersome 
protection/deprotection to obtain the properly derived inositol was removed. The production of the mycothiol derivative was achieved by coupling the GlcN-Inositol derivative to $\mathrm{N}$-Boc-S-Acetyl cysteine using EDCl, followed by TFA treatment to remove the Boc protecting group. The use of a Boc protecting group allowed no racemisation to take place during conjugation, despite the use of the carbodiimide coupling reagent EDCI. Treatment of the coupled product with pyridine caused acetate transfer from the sulphur to nitrogen, resulting in the formation of the mycothiol analogue (Scheme 1.1). The overall yield of this synthesis was 53\%, significantly greater than the other syntheses of mycothiol. Therefore the compound synthesized by Knapp et al. (2002) will be the starting point in regards to the synthesis of the mycothiol analogue described herein.

\subsubsection{Synthetic Plan for this Study}

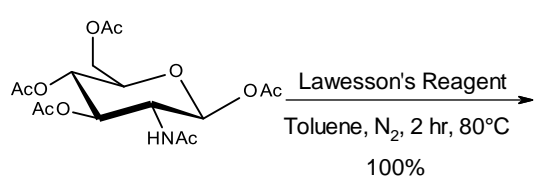

rt, 2 hrs, $100 \%$
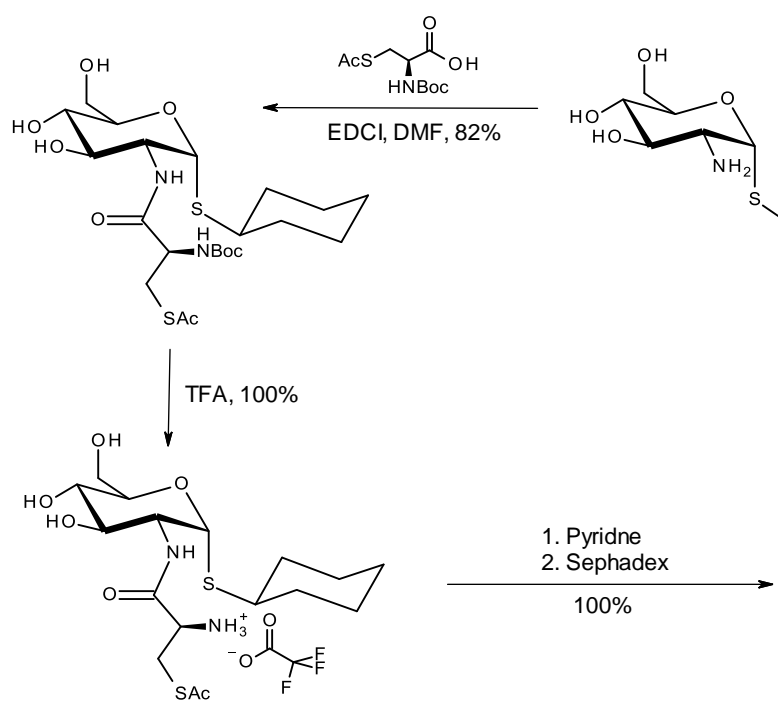
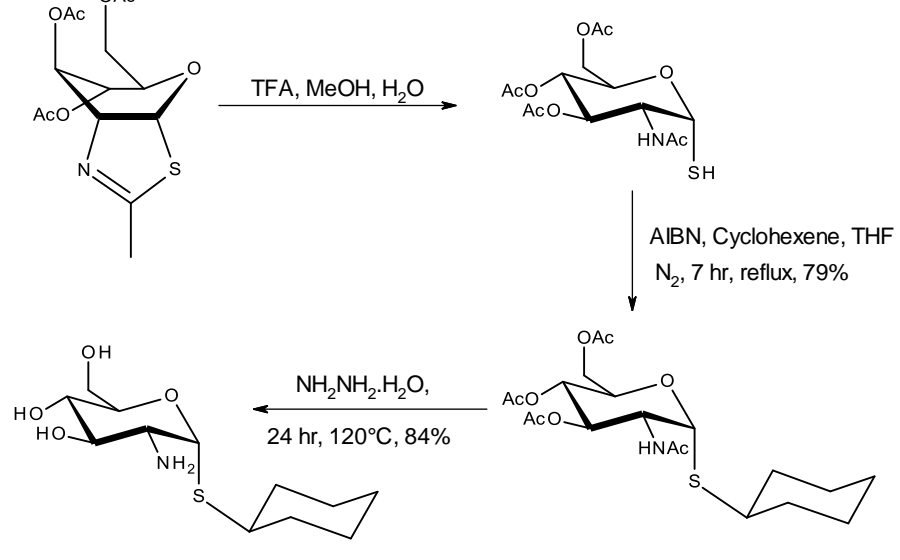

Scheme 1.1. Knapp et al. (2002) synthesis of a simplified mycothiol analogue ${ }^{18}$ 
Knapp's (2002) synthetic strategy will provide the basis from which the desired compounds will synthesized. The proposed synthesis of both the haloalkene and bimane derivitives can be seen in schemes 1.2 and 1.3. The cysteine derivatives will be synthesized firstly by Boc protection of the L-cysteine's amine with di-tert-butyl dicarbonate forming $\mathrm{N}$-Boc cysteine 2. The $N$-Boc cysteine can then be conjugated through cysteine's sulphur to either tertrachloroethylene, forming $\mathrm{N}$-Boc-TCVC 3, or monobromobiamane, forming the bimane derivative 4. The formation of 5-10 will follow Knapp's synthesis. However the synthesis will deviate from this point in regards to the derivatization added at cysteine's sulphur, though will stay true to Knapp's coupling conditions employing EDCI in DMF producing coupled products 11 and 12. As well the deprotection of Boc using TFA to yield products 13 and 14 as the desired mycothiol analogues.

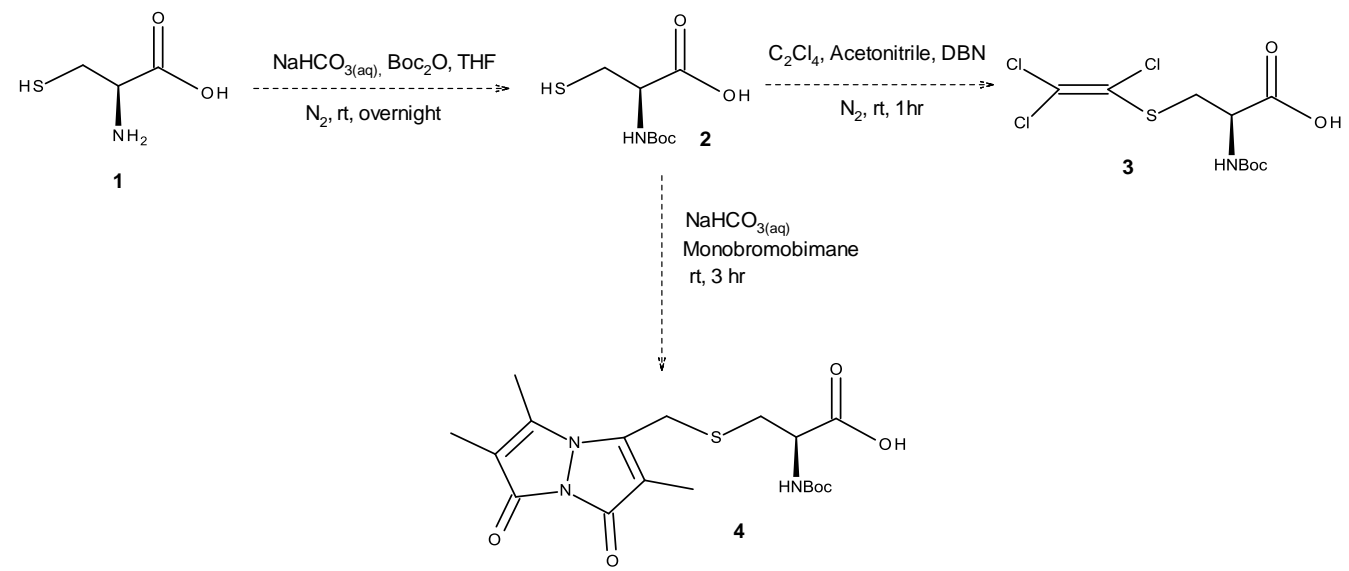

Scheme 1.2. Proposed synthesis of the cysteine-S-conjugates 


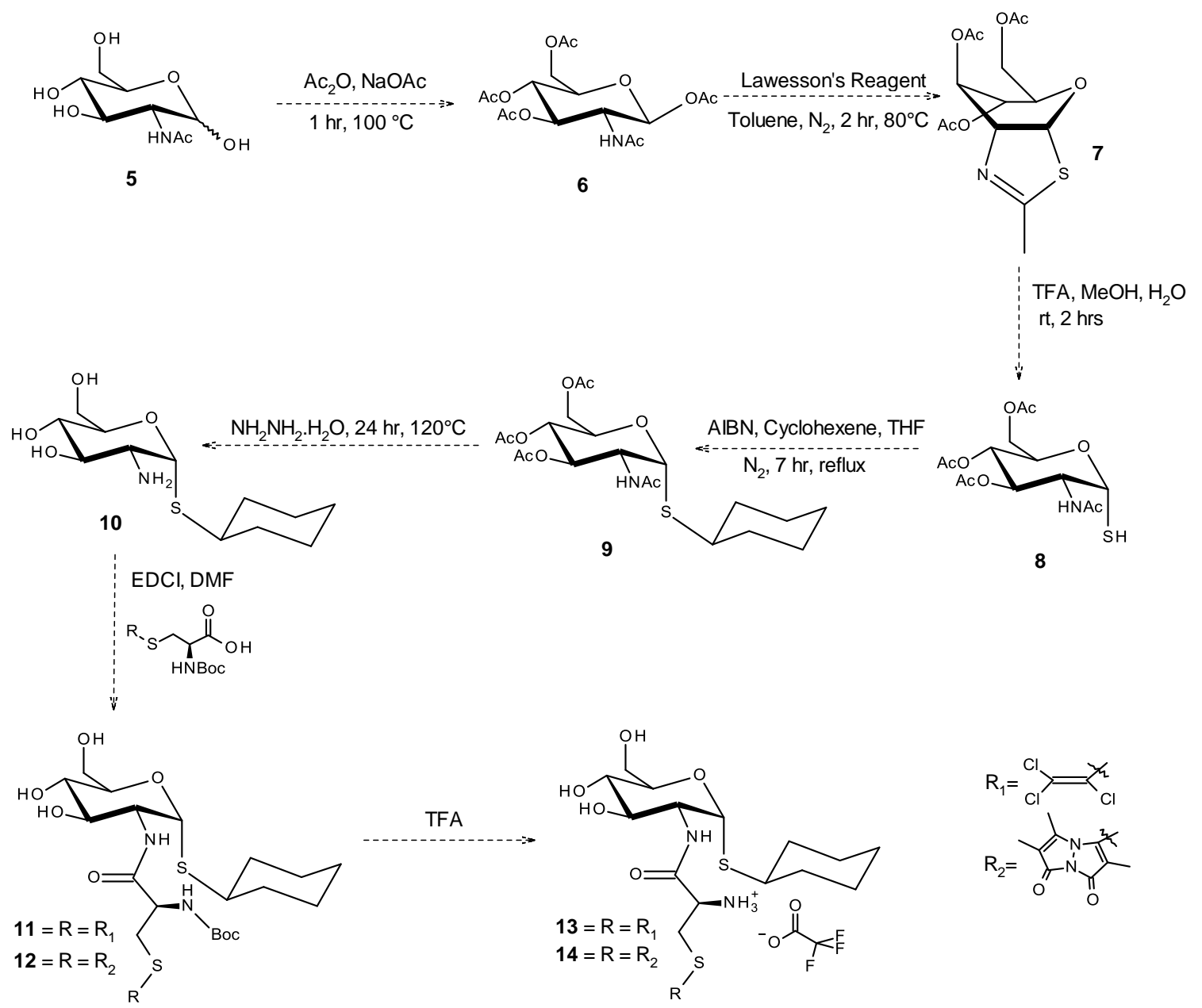

Scheme 1.3. Proposed synthesis of mycothiol analogues 13 and 14 


\subsection{Research Objectives}

The thesis described herein set out to determine whether the mycothiol detoxification pathway, present Mycobacterium tuberculosis, can be exploited, in conjugation with $\beta$ lyases, to cause a build-up of harmful halothioketenes and subsequent cell death. To this end, the major aim was the synthesis and biological evaluation of mycothiol analogue 13.

The objectives required to achieve this aim were:

1) Synthesis of N-Boc-TCVC

2) Synthesis of the simplified GIcN-Inositol 10

3) Conjugation of fragments made from objectives 1 and 2 and deprotection to form 13

4) Synthesis of fluorophore $\mathbf{1 4}$ to evaluate cell entry

5) Synthesis of the $\beta$-anomer of $\mathbf{1 3}$ (became an objective part way through thesis, for reasons discussed in chapter 3) 


\section{Chapter 2}

\section{Cysteine Derivative Synthesis}

One of the overarching goals in this thesis was the synthesis of the mycothiol analogue 13, for which, the formation of $\mathrm{N}$-Boc-TCVC represents an important objective. This chapter outlines the successful synthesis of $N$-Boc-TCVC, through $N$-Boc protection of L-cysteine and subsequent tetrachloroethylene conjugation.

\subsection{Boc Protection of L-Cysteine}

\subsubsection{Reduction of N-Boc-L-Cystine}

Based on previous literature, the $N$-Boc protection of L-cysteine was thought to be obtainable through treatment of L-cysteine with di-tert-butyl dicarbonate under alkaline conditions ${ }^{56,57}$. However, these conditions promoted the production of both the desired $N$ Boc-L-cysteine and its oxidized form N-Boc-L-cystine (Scheme 2.1). This reaction mixture was subjected to sodium borohydride reducing conditions in an attempt to reduce the unwanted $\mathrm{N}$-Boc-L-cystine into the desired N-Boc-L-cysteine ${ }^{58}$. Based on ${ }^{1} \mathrm{H}$ NMR evidence, a portion of the $\mathrm{N}$-Boc-L-cystine was reduced, however, a significant quantity still remained. In order to gain a better indication of the effectiveness of this reaction, L-cystine was doubly

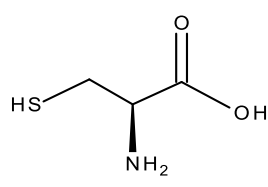

1

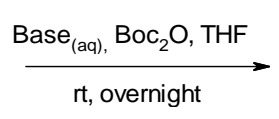

rt, overnight

Scheme 2.1. Attempted synthesis of $N$-Boc-L-cysteine 
protected with di-tert-butyl dicarbonate to afford N-Boc-L-cystine in 93\% yield after isolation ${ }^{56}$. The newly obtained $N$-Boc-L-cystine was then reacted with a larger excess of sodium borohydride in an attempt to push the reaction to completion. Once again this resulted in only partial reduction. With sodium borohydride unable to promote the complete reduction of $\mathrm{N}$-Boc-L-cystine, an alternative literature method was examined using zinc and acetic acid in ether (Table 2.1 $)^{59}$. The first attempt resulted in no reduction occurring at all, which was put down to a lack solubility in diethyl ether. With this in mind, the subsequent reaction employed THF as the solvent, in which cysteine demonstrated much better solubility. This resulted in a partial reduction of N-Boc-L-cystine, demonstrating solubility as the probable culprit for the failure of the first attempt. On the basis of another literature method, which demonstrated that a temperature of up to $60{ }^{\circ} \mathrm{C}$ could be used without causing the deprotection of Boc protecting groups, a higher temperature was applied in order to promote the complete reduction (Reaction 3$)^{60}$. This involved initially cooling the reaction to $0{ }^{\circ} \mathrm{C}$ then allowing it to warm up to room temperature over a $1 \mathrm{~h}$ period, followed by an additional $3 \mathrm{hrs}$ at room temperature. This resulted in the complete reduction of the $N$-Boc-L-Cystine to the desired N-Boc-L-Cysteine. However, this set of reaction conditions proved unreliable, with the subsequent two reduction attempts resulting in complex reaction mixtures.

Table 2.1. Optimization of Zinc Mediated N-Boc-L-Cystine Reduction

\begin{tabular}{cccccc}
\hline Reaction & Reagents & Quantity & Time & Temperature & $\begin{array}{c}\text { Level of } \\
\text { Reduction }^{a}\end{array}$ \\
\hline 1 & Boc-Cystine & $447 \mathrm{mg}$ & & & \\
& Zinc dust & $3.29 \mathrm{~g}$ & $2 \mathrm{hr}$ & $0{ }^{\circ} \mathrm{C}$ & Partial \\
\hline 2 & Boc-Cystine & $376 \mathrm{mg}$ & & & \\
& Zinc dust & $2.75 \mathrm{~g}$ & $2 \mathrm{hr}$ & $0{ }^{\circ} \mathrm{C}$ & Partial \\
& $5 \%$ Acetic acid in THF & $14 \mathrm{~mL}$ & & & \\
\hline 3 & Boc-Cystine & $270 \mathrm{mg}$ & & & \\
& Zinc dust & $2.27 \mathrm{~g}$ & $4 \mathrm{hr}$ & $0{ }^{\circ} \mathrm{C}$ up to $20{ }^{\circ} \mathrm{C}$ & Inconsistent $^{b}$ \\
& $5 \%$ Acetic acid in THF & $10 \mathrm{~mL}$ & & & \\
\hline
\end{tabular}

${ }^{a}$ Determined from ${ }^{1} \mathrm{H}$ NMR. ${ }^{b}$ This reaction resulted in $100 \%$ reduction in first attempt, however subsequent attempts yielded complex mixtures 


\subsubsection{Minimising N-Boc-L-Cystine Formation}

In order to bypass problems associated with the reduction of $\mathrm{N}$-Boc-L-cystine, an effort was made to minimize the isolation of $\mathrm{N}$-Boc-L-cystine following the protection of L-cysteine. Variations in the reaction time, base used and number of equivalents of L-cysteine were investigated (Table 2.2). It was hypothesised that by shortening the reaction length the formation of $\mathrm{N}$-Boc-L-cystine may be minimized (provided that the rate of L-cystine formation was significantly lower than the rate of the Boc protection of cysteine). This did prove to be the case, with these reaction conditions providing a reduction in the amount of $\mathrm{N}$-Boc-Cystine formed. However, because the reaction was stopped prior to completion, there was also a corresponding decrease in yield.

Table 2.2. Optimization of L-Cysteine Boc Protection

\begin{tabular}{ccccccc}
\hline Reaction & Time (hrs) & Cysteine (eq) & Nitrogen & Base & $\begin{array}{c}\text { Boc-Cysteine : }^{\text {Boc-Cystine }}{ }^{a} \\
\text { Boreld }\end{array}$ \\
\hline 2 & 18 & 1 & Yes & NaOH & $42: 58$ & $87 \%$ \\
\hline 3 & 3 & 1 & Yes & $\mathrm{NaOH}$ & $62: 38$ & $57 \%$ \\
\hline 4 & 30 & 4 & Yes & $\mathrm{NaOH}$ & $59: 41$ & $59 \%$ \\
\hline
\end{tabular}

$a$ Determined by ${ }^{1} \mathrm{H}$ NMR. ${ }^{b}$ Combined yield of Boc-cysteine and Boc-cystine

It was also hypothesized that the use of excess cysteine, relative to di-tert-butyl dicarbonate, should ensure that the majority of the oxidized L-cystine is present in either the unprotected or incompletely Boc-protected form. The vast majority should therefore remain in the aqueous layer (Figure 2.1). Based on this theory, 4 equivalents of L-cysteine were used, relative to di-tert-butyl dicarbonate, as expected this resulted in an increase in the $\mathrm{N}$-Boc-L-cysteine to $\mathrm{N}$-Boc-L-cystine ratio, such that $\mathrm{N}$-Boc-L-cysteine represented the major product. Like the reaction involving a shorter reaction time, a decrease in combined yield was observed. It is important to note that in both cases the quantity of $N$-Boc-Lcysteine obtained remained constant. Thus, the decrease in combined yield is entirely due to a substantial decrease in the amount of $\mathrm{N}$-Boc-cystine formed. 
Gratifyingly, almost no N-Boc-L-cystine was isolated when sodium bicarbonate was used with 4 eq. of L-cysteine, producing the desired N-Boc-L-cysteine in $66 \%$ yield.

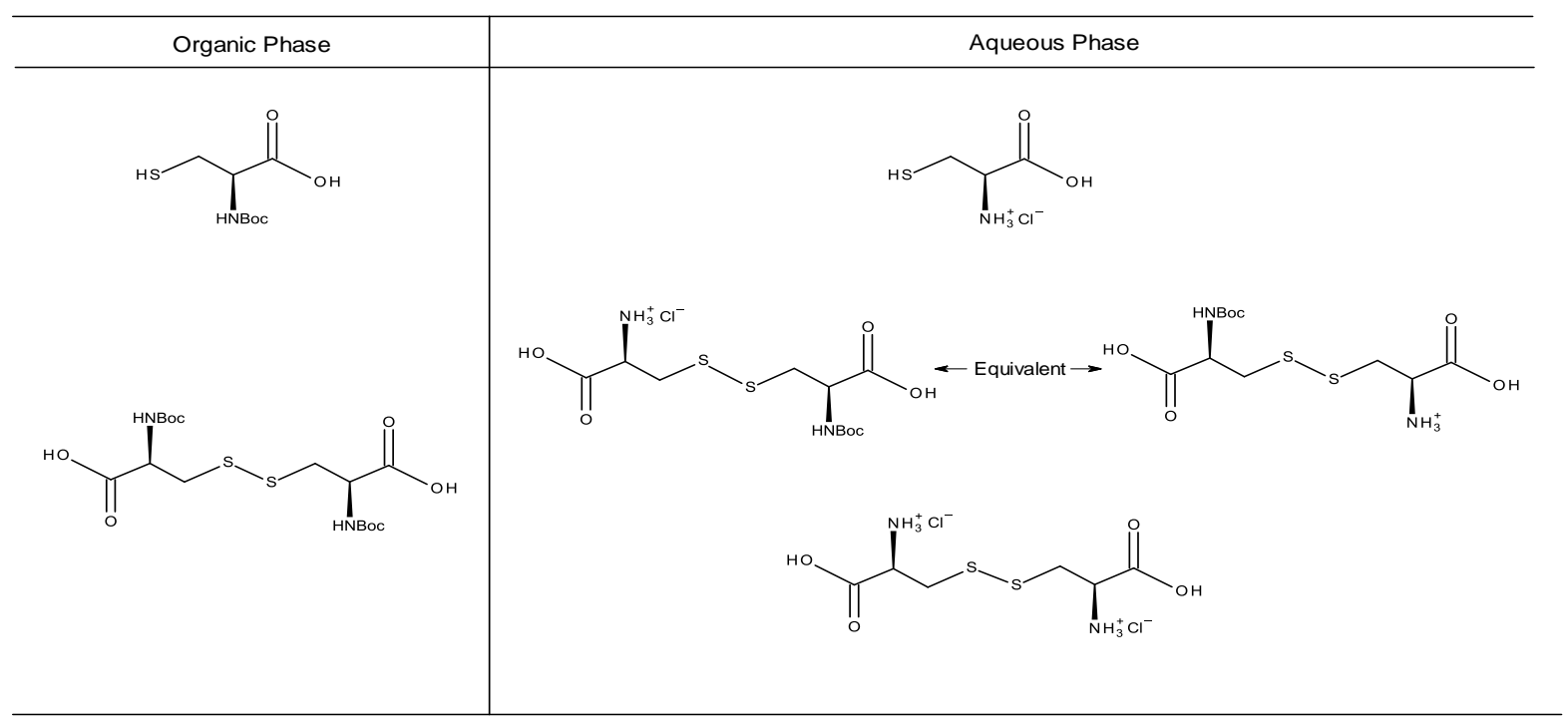

Figure 2.1. Species formed during the Boc protection of L-cysteine

\subsection{Cysteine S-Conjugation}

The initial plan for the synthesis of $\mathrm{N}$-Boc-TCVC 3 was to utilise methodology by Bartels and Miner (1990) to synthesise trichlorovinyl cysteine $(T C V C)^{61}$, then subsequently protect the amine with a Boc protecting group to afford compound 3. This sequence was initially undertaken due to the propensity of cysteine to oxidise to the corresponding disulfide under Boc protection conditions (Section 2.1). By conjugating the cysteine with tetrachloroethylene initially, the ability of the product to oxidise during the subsequent Boc protection is removed. However, the reaction proposed by Bartels and Miner (1990) proved troublesome in the current setting, due to formation of an inseparable impurity. The synthetic methodology consisted of a reaction between L-cysteine and tetrachloroethylene 
in the presence of the base 1,5-diazabicyclo[4.3.0]non-5-ene (DBN), with the desired TCVC rapidly crystallizing upon addition of $\operatorname{acid}^{61}$. Attempts to purify the product proved unsuccessful. The problem stems from the insolubility demonstrated by TCVC and the impurity in essentially all solvents tested. Solubility was observed only in DMSO, $100{ }^{\circ} \mathrm{C}$ water and aqueous base. This effectively ruled out column chromatography as a viable option. Both $\mathrm{pH}$ dependent, and hot water recrystalization failed to yield any improvement in purity. Hence attempts were made to remove the impurity altogether. The impurity obtained had a similar ${ }^{1} \mathrm{H}$ NMR spectrum to the desired product and as such it was initially thought to be a disubstituted tetrachloroethylene.

The attempts to minimise the formation of the impurity are outlined in Table 2.3. Performing the literature method described by Bartels and Miner (1990) resulted in a $2: 1$ mixture of desired product to impurity. If the impurity present was the disubstituted tetrachloroethylene, it stands to reason, that by increasing the amount of tetrachloroethylene relative to cysteine the probability of disubstitution would be reduced. With this in mind, the equivalents of tetrachloroethylene were doubled to eighteen. This resulted in an improved ratio of TCVC to impurity $(4: 1)$. Following this promising result the equivalents of tetrachloroethylene were increased further to 24 and the cysteine added dropwise to further dilute the cysteine relative to tetrachloroethylene. Surprisingly these reaction conditions caused an increase in the amount of the impurity produced such that it represented the majority of product formed (TCVC : impurity, $3: 7)$. Increasing the equivalents of tetrachloroethylene to 200 and adding dropwise resulted in a similar ratio (TCVC : impurity, $1: 3$ ). The reversal in the selectivity towards the impurity upon dropwise addition suggests that a disubstituted tetrachloroethylene is not the impurity and also indicates there may be additional factors, independent of dilution, governing selectivity. Apart from the dilution of cysteine (relative to tetrachloroethylene), the major change in regards to reaction conditions in the dropwise addition is the solvent system. Although both the dropwise and bulk addition reactions contained an overall equal quantity of DMSO relative to tetrachloroethylene, the variation occurs during the initial stage of the reaction. Upon addition of the first drop of cysteine in DMSO, the DMSO concentration is very low, 
gradually rising in to reach its peak concentration upon addition of the last drop. At this point the DMSO concentration will be the same as the bulk addition reaction. This means the initial stages of the dropwise reaction will have a significantly lower polarity solvent system, which may be the cause of the observed changes in product ratios. Unable to remove or separate the impurity, the mixture was then subjected to Boc protection. Successful purification was achieved at this stage, albeit in a low $15 \%$ yield.

The troubles with the inseparable impurity and a low yielding Boc protection prompted investigation into an alternative route for the formation of $\mathrm{N}$-Boc-TCVC. This new route involved a reversal of the tetrachloroethylene conjugation and Boc protection steps, whereby the Boc-group is added prior to tetrachloroethylene conjugation. Using the previously synthesized Boc-Cysteine (Section 2.1), the synthesis of the desired N-Boc-TCVC was achieved through tetrachloroethylene conjugation, via an analogous method to that of Bartels and Miner (1990). Initial attempts involved using the same reaction conditions used previously for TCVC formation ${ }^{61}$. Although ${ }^{1} \mathrm{H}$ NMR evidence indicated the reaction was successful, the desired product was unable to be efficiently isolated from the DMSO as, unlike TCVC, it could not be recrystallized. In an attempt to simplify the workup and allow for easier purification the reaction was trialled in dichloromethane. Unfortunately, the
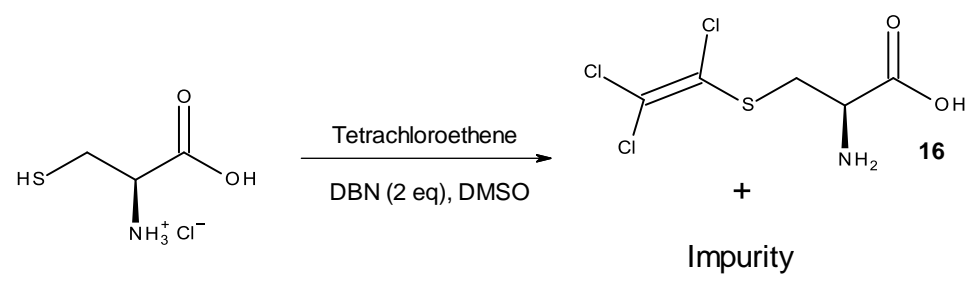

Table 2.3. Reaction of L-Cysteine with Tetrachloroethylene

\begin{tabular}{|c|c|c|c|}
\hline Reaction & Tetrachloroethylene (eq.) & Dropwise Addition $^{a}$ & TCVC : Impurity ${ }^{b}$ \\
\hline 1 & 9 & No & $2: 1$ \\
\hline 2 & 18 & No & $4: 1$ \\
\hline 3 & 24 & Yes & $3: 7$ \\
\hline 4 & 200 & Yes & $1: 3$ \\
\hline
\end{tabular}


reaction did not proceed in this solvent. The reason for the lack of reactivity was put down to the lower polarity of dichloromethane in comparison to DMSO and, as such, a reduced ability to stabilise the dipolar transition state. With this in mind the more polar acetonitrile was trialled, which gratifyingly gave the desired $N$-Boc-TCVC in $74 \%$ yield.

The ${ }^{1} \mathrm{H}$ NMR of this reaction showed two sets of peaks. These peaks were also seen in the spectrum of $\mathrm{N}$-Boc-L-cysteine and were thought to be a result of rotamers caused by the steric bulk of the Boc group. To confirm this was the case, $N$-Boc-TCVC was subjected to treatment with $20 \%$ TFA in dichloromethane for 30 minutes, after which time, the solvent was evaporated off. Subsequent ${ }^{1} \mathrm{H}$ NMR analysis revealed a single set of peaks, confirming the second set of peaks present in the ${ }^{1} \mathrm{H}$ NMR spectrum of $\mathrm{N}$-Boc-TCVC was due to the presence of rotamers (Figure 2.2).

In summary, the successful synthesis of $N$-Boc-TCVC was achieved in two steps (46\%), through the Boc-protection of L-cysteine and subsequent conjugation of tetrachloroethylene. Thus completing one of the initial objectives required to complete the main aim, i.e. the synthesis of mycothiol analogue 13. 

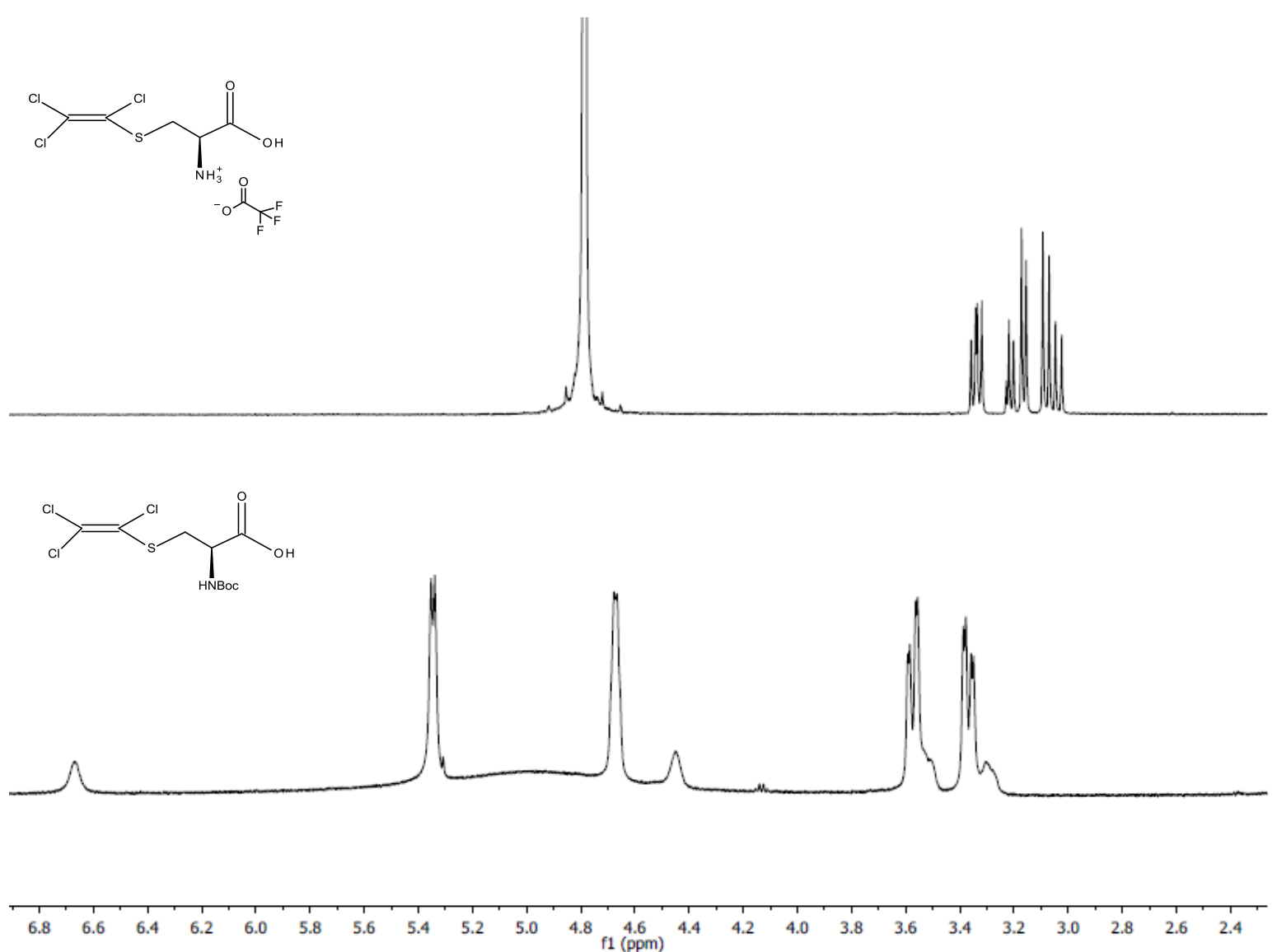

Figure 2.2. ${ }^{1} \mathrm{H}$ NMR spectrum comparing the $\alpha$ and $\beta$ protons of Boc-TCVC and TCVC 


\section{Chapter 3}

\section{Synthesis of $\alpha$ - and $\beta$-GIcN-Inositol Analogues}

Along with the synthesis of $\mathrm{N}$-Boc-TCVC, another objective required to complete the synthesis of the mycothiol analogue $\mathbf{1 3}$ was the synthesis of the $\alpha-\mathrm{GlcN}$-inositol analogue 10. This chapter outlines the successful synthesis of this fragment, while also introducing a new secondary aim, which involves the formation of the $\beta$-anomer of the original synthetic target 13. Thus, this chapter also features the successful synthesis of the $\beta$ version of the $\alpha$-GlcN-inositol analogue 10.

\subsection{Radical Based Synthesis to $\alpha$-Thioglycoside (9)}

As stated previously (Section 1.6.1), there are two key challenges in $\mathrm{GlcN}$-inositol synthesis. These are the formation of the 1,2-cis- $\alpha$-linkage connecting the inositol to the glucosamine and the steroselective derivatization of the inositol ring ${ }^{52-54}$. Knapp et al. (2002) solved these problems by developing a GlcN-Inositol analogue in which the inositol hydroxyls were removed and the glycosidic oxygen linker was replaced by a sulfur ${ }^{18}$. Implementing these changes meant the stereoselective derivatization of inositol was redundant and the substitution of the linker oxygen with sulfur ment the 1,2-cis- $\alpha$-linkage could be obtained selectively through a radical-based mechanism. These changes ultimately resulted in a significantly higher overall yield compared to previous mycothiol syntheses ${ }^{18}$. For these reasons the GlcN-inositol analogue developed by Knapp et al. (2002), as well as the synthetic steps used to make it, were chosen as the primary target. 


\subsubsection{Synthesis of $\beta$-D-Glucosamine pentaacetate}

The starting material used in Knapp's synthesis is $\beta$-D-glucosamine pentaacetate. It was envisioned this could be synthesized from $\mathrm{N}$-acetylglucosamine in a peracetylation reaction $^{62}$. A key challenge in this area is acetylation of six membered sugars so as to stereoselectivly obtain either the $\alpha$ or $\beta$ anomer. In regards to glucosamine peracetylation there are simple stereoselective methodologies for the formation of the $\alpha$-anomer, of which the most widely used is pyridine with acetic anhydride ${ }^{63-67}$. However, there is very little literature regarding high yielding $\beta$-glucosamine pentaacetate procedures to date. In fact, the most common routes to the synthesis of $\beta-D$-glucosamine pentaacetate require multistep processes ${ }^{68-72}$.

Knapp et al. (2007) developed a method for the synthesis of $\beta$-glucosamine pentaacetate from $\mathrm{N}$-acetyl glucosamine in a one step reaction utilizing montmorillonite $\mathrm{K} 10$ and acetic anhydride, albeit in a low yield $(33 \%)^{62}$. Nonetheless, this reaction was chosen as a good starting point due to its simplicity and ability to be performed in a single step. Disappointingly, when the 2007 methodology of Knapp et al. was followed, a complex mixture of products was formed, as demonstrated by ${ }^{1} \mathrm{H}$ NMR analysis of the crude reaction mixture. Present in this mix were the $\alpha$ and $\beta$ anomers of glucosamine pentaacetate in

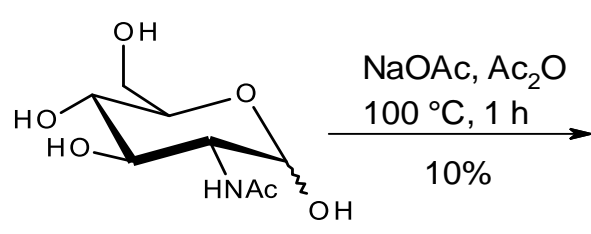

5

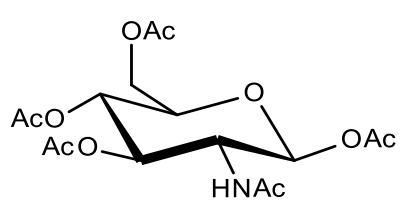

6

Scheme 3.1. Synthesis of $\beta$-D-glucosamine pentaacetate

a 50 : 50 ratio, relative to each other. Recrystallization of the mixture was attempted, though only $1 \%$ yield of the $\beta$-anomer was isolated. The reaction was repeated multiple times; in each case a complex mixture of products resulted. 
In an attempt to produce a cleaner, higher yielding reaction, synthetic methodology used to produce $\beta$-D-glucose pentaacetate was trialled ${ }^{73}$. The reaction involved heating the $N$ acetyl glucosamine at $100^{\circ} \mathrm{C}$ for $1 \mathrm{~h}$ in acetic anhydride and sodium acetate, producing both $\alpha$ - and $\beta$-glucosamine pentaacetate anomers in a ratio of $25: 75(\beta: \alpha)$. The mixture was recrystallized from methanol to give a yield of $10 \%$ for the $\beta$-anomer (Scheme 3.1). Thus, although the ratio of the $\beta$-anomer relative to the $\alpha$-anomer was lower, the overall yield was significantly higher than the montmorillonite $\mathrm{K}-10$ procedure. This is due to the fact that production of the $\alpha$ and $\beta$ glucosamine pentaacetates occurred in the absence of the complex mixture that was obtained from the Knapp methodology.

\subsubsection{Cyclohexane Conjugation}

\subsubsection{Formation of Mercaptan (8)}

The synthesis of the thioglycoside 9 , from $\beta$-D-glucosamine pentaacetate could be achieved through the methodology used by Knapp et al. $(2002)^{18}$. This involved treatment of $\beta-D-$ glucosamine pentaacetate with Lawesson's reagent in toluene at $80{ }^{\circ} \mathrm{C}$. This reaction proceeded to form thiazoline 7 in $68 \%$ yield $^{62}$. The apparent difference in yield seen between Knapp's synthesis (100\%) and the yield obtained may be due to the quality of the Lawesson's reagent. The Lawesson's reagent used was over 5 years old. The thiazoline 7, when treated with TFA and water yielded mercaptan 8 in quantitative yield (Scheme 3.2) ${ }^{74}$. The final step in the formation of thioglycoside $\mathbf{9}$ was the radical induced conjugation of cyclohexene to mercaptan $\mathbf{8}^{18}$. However, this step proved extremely problematic; as discussed below. 

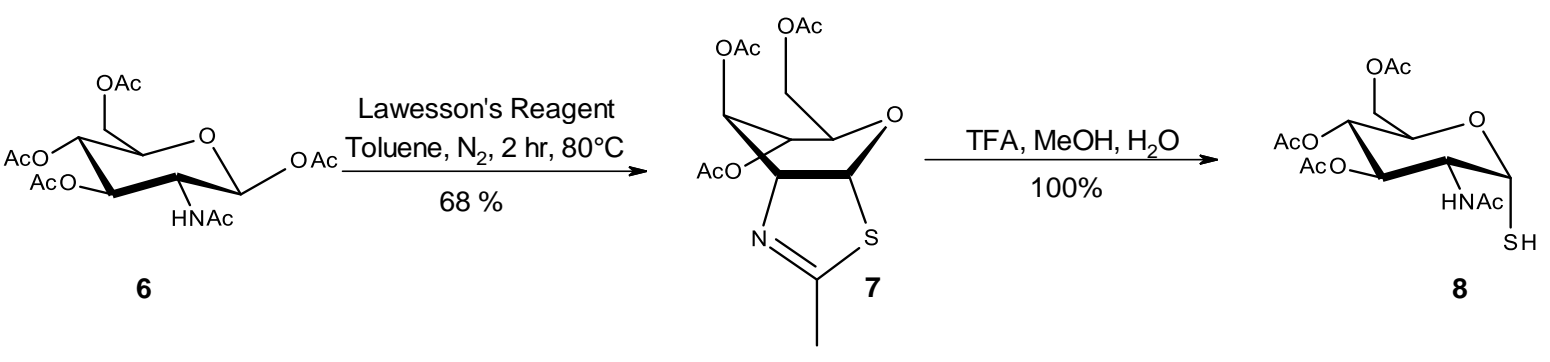

Scheme 3.2. Synthesis of mercaptan 8

\subsubsection{Radical Induced Thioglycoside Formation}

Knapp et al. (2002) reported the synthesis of thioglycoside 9 in $79 \%$ yield via a AIBN-induced radical reaction between mercaptan $\mathbf{8}$ and cyclohexene in chloroform (cyclohexene : chloroform $1: 1 \mathrm{v} / \mathrm{v}$ ) at reflux ${ }^{18}$. However, following this procedure none of the desired product was obtained. ${ }^{1} \mathrm{HNMR}$ and IR spectroscopy of cyclohexene and AIBN, respectively, suggested that both regents were of good quality. Successful reactions using the same batch of AIBN, performed by various members of the research group also suggested that the AIBN was good in quality. Due to the high number of variables in this reaction (i.e. solvent, time, initiator, initiator equivalents, initiator addition sequence, cyclohexene addition sequence, and whether or not the reaction is performed in a nitrogen atmosphere) a series of experiments were performed to identify general trends in an attempt to improve on the yield (Table 3.1). ${ }^{1} \mathrm{HNMR}$ evidence from the reactions performed in the presence of air showed small amounts of the disulfide $\mathbf{1 8}$ was produced (reactions 1 ). In contrast all AIBN reactions that were performed in the presence of nitrogen resulted in the recovery of a portion of starting material, suggesting the 


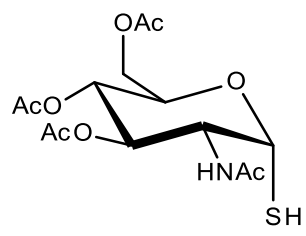

8

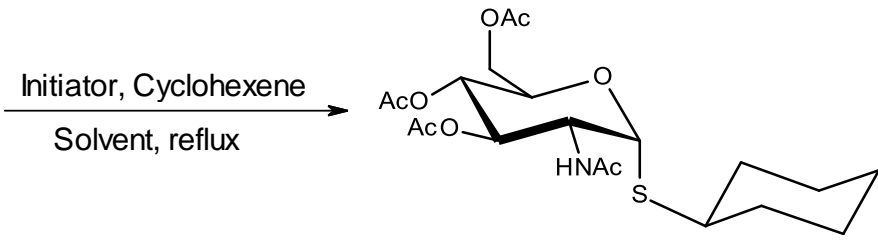

9

Table 3.1 Optimization of Radical Induced Thioglycoside Formation

\begin{tabular}{|c|c|c|c|c|c|c|c|c|c|}
\hline Reaction & Solvent & Time & Initiator & $\begin{array}{l}\text { Initiator } \\
\text { eq. }^{a}\end{array}$ & $\begin{array}{c}\text { Cyclohexene } \\
\text { eq. }{ }^{b}\end{array}$ & Nitrogen & $\%$ Yield & $\begin{array}{c}\text { Recovered } \\
\text { Starting } \\
\text { Material }\end{array}$ & $\begin{array}{l}\text { Yield } \\
\text { brsm }^{c}\end{array}$ \\
\hline 1 & Chloroform & $2 \mathrm{hr}$ & AIBN & $0.65 \times 2$ & 40 & No & - & No & - \\
\hline 2 & Chloroform & $2 \mathrm{hr}$ & AIBN & $0.6 \times 2$ & 40 & Yes & 12 & Yes & 18 \\
\hline 3 & THF & $2 \mathrm{hr}$ & AIBN & $0.7 \times 3$ & 40 & Yes & 17 & Yes & 35 \\
\hline 4 & THF & $5 \mathrm{hr}$ & AIBN & $\begin{array}{l}0.065 \\
\times 2\end{array}$ & 40 & Yes & 19 & Yes & 38 \\
\hline 5 & THF & $5 \mathrm{hr}$ & $\begin{array}{l}\text { Benzoyl } \\
\text { Peroxide }\end{array}$ & $\begin{array}{c}0.25 x \\
5\end{array}$ & 40 & Yes & 25 & No & 25 \\
\hline 6 & THF & $5 \mathrm{hr}$ & $\begin{array}{l}\text { Benzoyl } \\
\text { Peroxide }\end{array}$ & $\begin{array}{l}0.065 \\
\times 2\end{array}$ & 40 & Yes & 15 & Yes & 16 \\
\hline 7 & $\begin{array}{c}1,4 \\
\text { Dioxane }\end{array}$ & $5 \mathrm{hr}$ & $\begin{array}{l}\text { Benzoyl } \\
\text { Peroxide }\end{array}$ & $\begin{array}{l}0.065 \\
\times 2\end{array}$ & 40 & Yes & 12 & Yes & 15 \\
\hline 8 & THF & $7 \mathrm{hr}$ & AIBN & $\begin{array}{r}(0.02 \times \\
5)+(0.6 \\
\times 2)\end{array}$ & $8 \times 5$ & Yes & 29 & Yes & 48 \\
\hline
\end{tabular}

${ }^{a}$ The first aliquot of initiator was added at start of reaction, each subsequent aliquot was added $1 \mathrm{~h}$ after the previous aliquot, with the exception 3 , where it was added in $40 \mathrm{~min}$ intervals. ${ }^{b}$ For reactions with multiple iterations, the first aliquot of cyclohexene was added at start of reaction, each subsequent aliquot was added $1 \mathrm{~h}$ after the previous aliquot. cYield based on recovered starting material.

oxidation may have been a result of atmospheric oxygen and not a radical based mechanism. THF proved to be the solvent of choice, as all AIBN reactions performed in THF saw an improvement in both yield and the amount of starting material recovered. Using a model reaction, both benzoyl peroxide and tertbutylperoxide were investigated as potential initiators for this reaction. They were chosen over the hydroperoxides due to their lower propensity to cause oxidation. Furthermore, as they exhibit lower (tert-butyl peroxide) and higher (benzyl peroxide) decomposition rates relative to AIBN, these initiators enable analysis as to the effect that initiator decomposition has on the reaction ${ }^{75}$. In addition, as amines have been shown to increase the decomposition rate of benzoyl peroxide an extra reaction in which aniline was added to benzoyl peroxide was investigated 
to provide increased scope in regards to rate of decomposition ${ }^{75}$. Of the three sets of reaction conditions, employing benzoyl peroxide in the absence of aniline showed the most promise. However, when benzoyl peroxide was added in place of AIBN, in the thioglycoside formation reaction, there was little improvement in yield, as well as a reduction in recoverable starting material. The total equivalents of initiator appear to have little effect; rather a higher yield is favoured in reactions where multiple iterations of initiator are added over a longer period of time, as seen in reactions 6 and 9 . After canvassing a variety of reaction conditions the yield was ultimately raised from 0 to $29 \%$ (48\% brsm). The highest yield was obtained using THF as a solvent and AIBN as the initiator, under a nitrogen atmosphere. It contained the highest number of AIBN additions over the longest period of time and added cyclohexene in five iterations. While this yield was a significant improvement it was still not ideal. As such alternative methods were sought to form the desired thioglycoside 9 .

\subsubsection{Attempt at $S_{N} 2$ Type Thioglycoside Formation}

A $S_{N} 2$-type reaction was examined in order to circumvent the low yields obtained in the radical induced thioglycosidation. The reaction design was inspired by a paper by Schmidt and Zhu (2004), which conjugated the same mercaptan 8 to peptides in which the primary hydroxyl of serine was derivatized to a bromine ${ }^{76}$. This peptide was then subjected to nucleophilic attack by the sulfur of $\mathbf{8}$ in a biphasic reaction consisting of aqueous sodium bicarbonate, ethyl acetate and the phase-transfer catalyst tetrabutylammonium hydrogen sulfate (TBAHS) ${ }^{76}$. However, when mercaptan 8 was exposed to these conditions, in the presence of bromocyclohexane, none of the desired thioglycoside $\mathbf{9}$ was observed. Instead there was complete conversion to the disulfide 17 (Scheme 3.1). The reason for this disparity is mostly likely due to the steric difference between the primary bromide in the amino acids and the secondary bromide in the bromocyclohexane. This difference is further exaggerated by the cyclohexane ring, in which axial hydrogens will block nucleophilic attack 
of the sulfur (Scheme 3.3). With the $S_{N} 2$ mechanism proving futile and the radical based method not optimal, focus was shifted from synthesising the $\alpha$-thioglycoside $\mathbf{9}$ to the corresponding $\beta$-thioglycoside 22.



Scheme 3.3. Attempted formation of thioglycoside 9 through $\mathrm{S}_{\mathrm{N}} 2$ type reaction

\subsection{Synthesis of the $\beta$-tetraacetate thioglycoside (22)}

Although of no use in the synthesis of the desired compound 13 , the formation of the $\beta$ thioglycoside 22, was deemed advantageous for two reasons. Firstly, it can be used as a model substrate in the radical induced thioglycosidation and subsequent reactions. This would limit the unwanted loss, in future optimizations, of the small amount of the $\alpha$ thioglycoside $\mathbf{9}$ that had been previously obtained. Secondly, $\beta$-thioglycoside 22 provides the opportunity to synthesize the opposite anomer of the desired target 13, which would provide an interesting comparison in biological testing. It was envisioned that the formation of thioglycoside 22 could be obtained via a Lewis acid-catalyzed reaction between trichloroacetimidate $\mathbf{2 0}$ and cyclohexane thiol. 


\subsubsection{Trichloroacetimidate induced thioglycoside formation}

The use of trichloroacetimidates in glycoside synthesis was first demonstrated by Schmidt and Michel $(1980)^{77}$. Since then they have found widespread use, owing to their ease of installation and ability to be activated without the presence of heavy metal salts; as is the case for many halo sugar electrophiles ${ }^{78,79}$. With these advantages in mind, the trichloroacetimidate $\mathbf{2 0}$ was chosen as a potential glycosyl donor for the production of thioglycoside 22 (Scheme 3.4).

The synthesis of trichloroacetimidate $\mathbf{2 0}$ has been reported in the literature ${ }^{65}$. Its formation involves the anomeric deacetylation of $\alpha$-D-glucosamine pentaacetate and subsequent derivatization of the newly formed hemiacetal to the trichloroacetimidate ${ }^{65}$. Following these methods, anomeric deacetylation of $\alpha$-D-glucosamine pentaacetate 18 was achieved using ethylene diamine and acetic acid in THF, proceeding smoothly to afford hemiacetal 19 in 70\% yield. Hemiacetal 19 was subsequently reacted with trichloroacetonitrile in the presence of DBU to afford $\mathbf{2 0}$ in $67 \%$ yield (Scheme 3.4).

The final step in the sequence, involved thioglycoside formation via $\mathrm{BF}_{3} \cdot \mathrm{OEt}_{2}$ catalyzed conjugation of cyclohexanethiol to trichloroacetimidate $\mathbf{2 0}^{80}$. When trichloroacetimidate $\mathbf{2 0}$ was subjected to the $\mathrm{BF}_{3} \cdot \mathrm{OEt}_{2}$ conditions outlined in literature, the $\beta$-D-thioglycoside $\mathbf{2 2}$ represented the majority of product isolated (35\%), followed closely by the oxazoline $\mathbf{2 1}$ (30\%), suggesting that the reaction proceeds through an oxonium ion formation (Scheme 3.4).

As an aside, the observation that it was possible to form the oxazoline under these $\mathrm{BF}_{3} \cdot \mathrm{OEt}_{2}$ catalyzed conditions prompted the testing of the thioamide equivalent of the trichloroacetimidate 20, under the same conditions (minus the cyclohexane thiol). This was looked into as a way to utilize the $\alpha$-glucosamine pentaacetate $\mathbf{1 8}$ in the formation of thiazoline 7. Surprisingly, no thiazoline was detected under these conditions. Thus, this route was never examined further. 
The trichloroacetimidate producedure outlined above did, however, succeed in producing the desired $\beta$-thioglycoside 22, albeit in a disappointing overall yield (17\%), from $\alpha$ glucosamine pentaacetate. As stated above this anomer was of interest as it provides an interesting point of comparison in biological testing (see section 4.2). Hence, the $\beta$-anomer was developed alongside the $\alpha$-anomer for the remainder of the synthesis. However, the ability to use $\beta$-thioglycoside 22 as a model substrate, to prevent unnecessary loss of the $\alpha$ anomer, was hampered due to the poor yield obtained. Thus, a more direct approach was trialled. This involved the use of $\alpha$-glucosamine pentaacetate as a glycosyl donor and cyclohexanethiol as the acceptor.

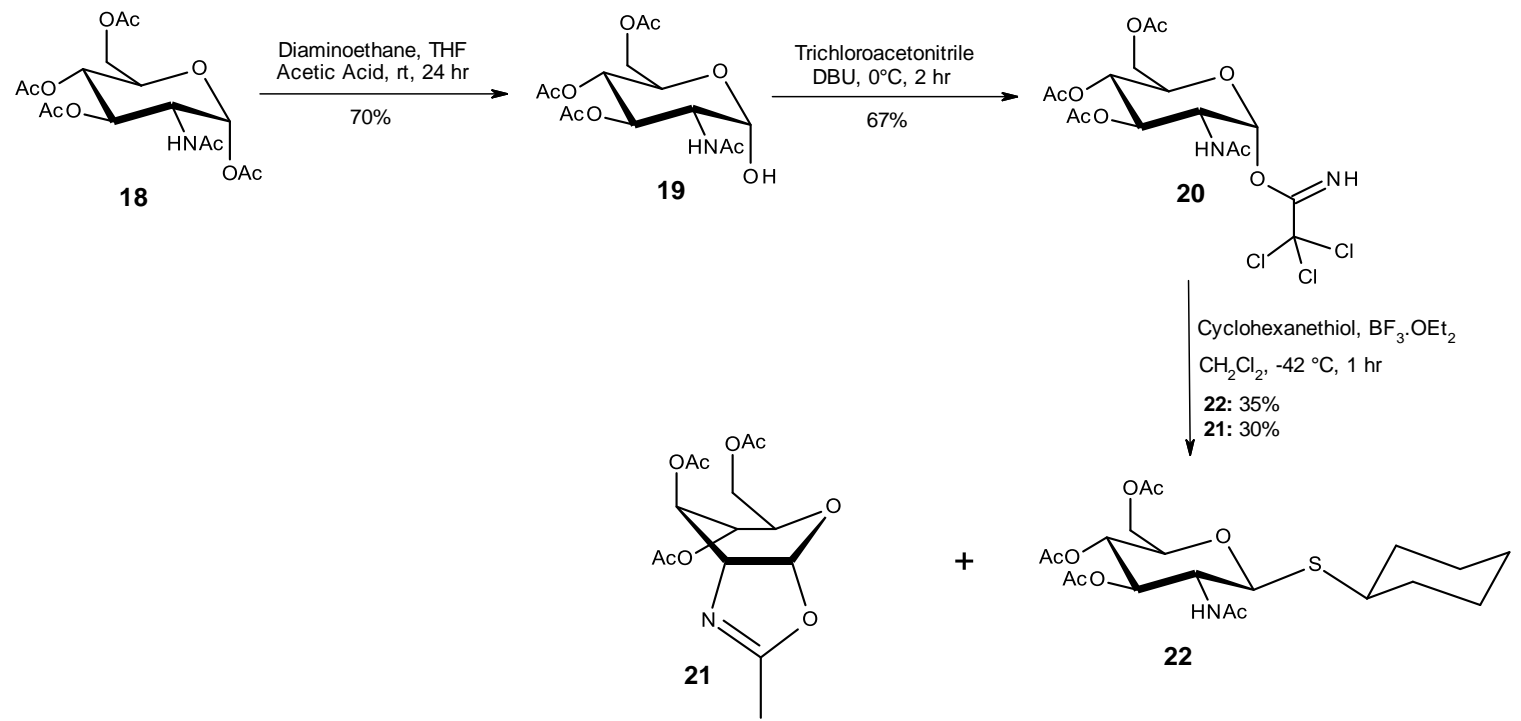

Scheme 3.4. Synthesis of $\beta$-Thioglycoside 22 via trichloroacetimidate 20 


\subsection{Direct Route to Thioglycoside Formation}

\subsubsection{Reactivity of peracetylated sugars}

The formation of thioglycosides from peracetylated sugars is prevalent throughout literature, in most cases the reaction is Lewis acid mediated. The reason for their widespread use is, in part, a result of easy access to the acetate protected precursors ${ }^{81}$. However, although they are easily accessible, peracetylated glycosyl donors are known to be among the most unreactive, particularly in comparison to glycosyl donors with ether protecting groups, e.g. benzyl. Fraser-Reid termed this difference in reactivity the "armeddisarmed theory" 82 . The theory states that glycosyl donors are significantly more reactive when protected with ether groups (armed), as opposed to esters (disarmed). The difference in reactivity is put down to the higher electron withdrawing effects of the ester protecting groups. As a result, this causes a decrease in stability of the oxonium ion intermediate. Consequently, there is an increase in the activation energy and a corresponding decrease in reactivity ${ }^{83}$. The decrease in reactivity is further exacerbated if the acetatylated sugar has a 1,2- $\alpha$-cis configuration. The lack of reactivity demonstrated in 1,2- $\alpha$-cis peractylated donors, in comparison to $1,2-\beta$-trans peracetylated donors, is thought to be due to neighbouring group participation, whereby the $\mathrm{C}-2$ acetate group aids in the departure of the anomeric leaving group in the 1,2- $\beta$-trans configuration; but is unable to do so in the case of the 1,2- $\alpha$-cis configuration ${ }^{84}$.

Li et al. (2011) examined the issue of poor reactivity seen when using 1,2- $\alpha$-cis peractylated sugars as glycosyl donors in Lewis acid catalyzed thioglycosidation reactions. They showed that the reactivity of $1,2-\alpha$-cis peractylated sugars could be enhanced by increasing the reaction temperature ${ }^{85}$. Furthermore, the change in temperature was shown to be more important to activity than the strength of the Lewis acid used. Most importantly, with respect to this thesis, it was found that by increasing the temperature from room temperature to $50^{\circ} \mathrm{C}$, the thioglycosidation reaction utilizing $\alpha$-glucosamine pentaacetate 
and thiophenol was able proceed, producing the $\beta$-thioglycoside in $40 \%$ yield ${ }^{85}$. Unfortunately, Li et al. (2011) did not report any $\alpha$-thioglycoside under these conditions. Nonetheless, as stated previously, the $\beta$-anomer was still desired (3.2) and so a direct thioglycosidation based off of Li et al's (2011) work was attempted to try to improve on the $16 \%$ overall yield obtained through the trichloroacetimidate route ${ }^{85}$.

\subsubsection{Synthesis of $\alpha$ - and $\beta$-Thioglycoside Directly from $\alpha$-Glucosamine pentaacetate}

The synthesis of $\mathbf{2 2}$ was attempted using Li et al's (2011) methodology (Scheme 3.5) ${ }^{85}$. Surprisingly, when $\alpha$-glucosamine pentaacetate 18 and cyclohexanethiol were exposed to these conditions, i.e. 2 eq. of $\mathrm{BF}_{3} . \mathrm{OEt}_{2}$ in dichloroethane at $50{ }^{\circ} \mathrm{C}$, the desired $\alpha$ thioglycoside 9 was the major product formed, in $22 \%$ yield. The $\beta$-thioglycoside 22 was also formed in the reaction, being produced in $11 \%$ yield. This fortuitous result was a contrast to the result obtained by Li et al. (2011), who obtained the $\beta$-anomer in $40 \%$, albeit with thiophenol as the glycosyl acceptor ${ }^{85}$. Interestingly, the major product formed in this reaction contains a 1,2- $\alpha$-cis glycosidic linkage. These are one of the most difficult linkages to make and often require either derivatization of the anomeric leaving group to something that undergoes $S_{N}$ 2-type displacement, such as iodine, or, alternatively, the use of unconventional protecting groups that take multiple steps to put in place ${ }^{86}$. Furthermore, it produced the 1,2- $\alpha$-cis glycosidic linkage in the presence of an acetamide protecting group that typically favours the formation of the $1,2-\beta$-cis glycosidic linkage through neighbouring group participation ${ }^{87}$.

Having produced a somewhat surprising, albeit advantageous result, a re-examination of the literature was performed in order to gain a better understanding of the mechanism that leads to the $\alpha$-thioglycoside being formed preferentially. There is a considerable 


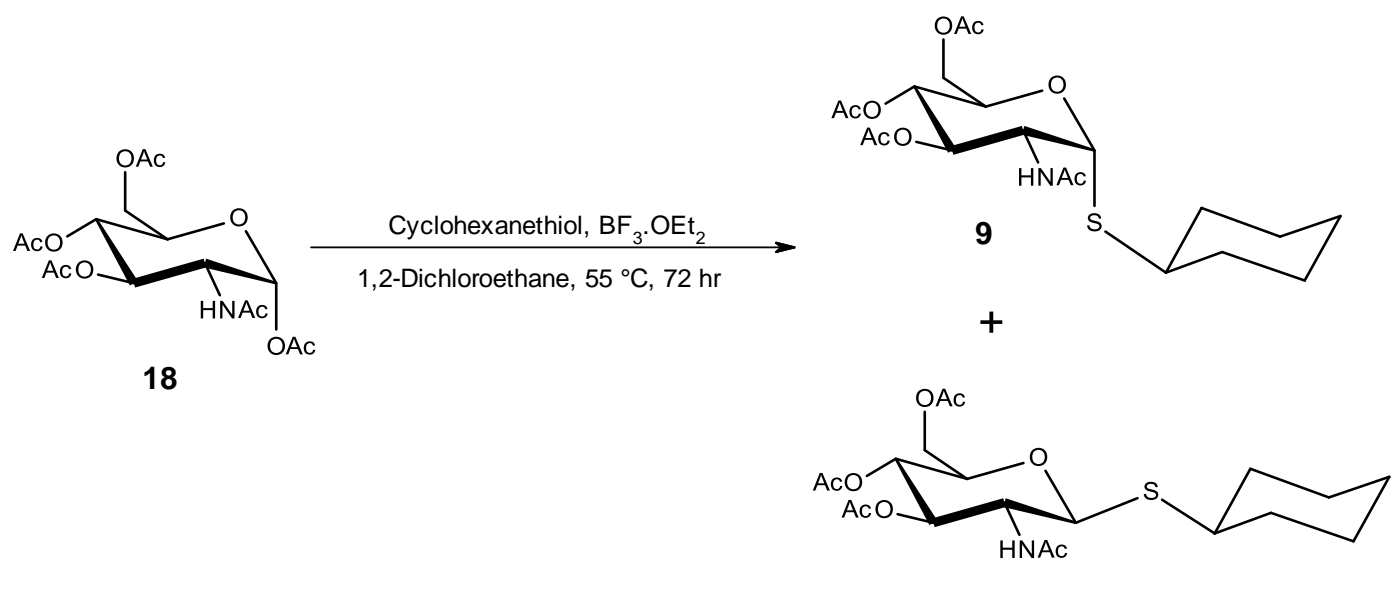

22

Scheme 3.5. Synthesis of $\alpha$ - and $\beta$-thioglycosides $\mathbf{9}$ and $\mathbf{2 2}$ directly from peracetylated glucosamine

amount of literature involving the Lewis acid catalysed glycosidation of peracetylated glucose or glucosamine. The vast majority of these reactions report the exclusive formation of the $\beta$-glycoside ${ }^{88-92}$. However, there are a number of studies that report the preferential formation of the $\alpha$-glycosides through anomerization ${ }^{87,93,94}$.

\subsubsection{Anomerization Reaction Mechanism}

Anomerization is the conversion of one anomer to another over a period of time, in this case conversion of the $\beta$-thioglycoside to the $\alpha$-thioglycoside. This process is reversible and as such will reach an equilibrium between the two anomers if enough time is given ${ }^{95}$. It is widely known that underivatized sugars, such as D-galactose and D-glucose, undergo anomerization in solution through a hemiacetal ring opening mechanism. In contrast, glycosides typically need a Lewis acid catalyst for anomerization to take place ${ }^{95}$. There are two possible mechanisms through which anomerization may take place in glycosides; these are through endocyclic or exocyclic bond breakage ${ }^{93}$. The exocyclic mechanism proceeds 
via breaking of the glycosidic linkage, forming the oxonium ion. The newly formed oxonium ion intermediate can subsequently be attacked from either the top or bottom face, forming the $\beta$-anomer or $\alpha$-anomer respectively. The endocyclic mechanism proceeds through cleavage of the bond between the ring oxygen and anomeric centre. Once broken, what was the glycosidic bond is free to rotate, such that either the $\beta$-anomer or $\alpha$-anomer can be formed depending on the conformation when the ring is reformed (Scheme 3.6) ${ }^{93}$. Evidence for both endo- and exo-anomerization can be found in literature. Xue et al. (2009) looked at tin tetrachloride and silver trifluoroacetate-catalyzed glycosidation reactions involving a range of alcohols ${ }^{87}$. They found that the smaller alcohols (methanol, ethanol and isopropanol) had the propensity to undergo anomerization to form their corresponding $\alpha$ anomers. They suggested that the mechanism itself goes through an exocyclization. This was based on the observation that the $\beta$-methyl glycoside, when subjected to Lewis acid catalysed glycosidation with isopropanol, resulted in the $\alpha$-isopropyl glycoside as the major product ${ }^{87}$. Although this does not rule out the endocyclic anomerization, it does suggest that under these conditions anomerization occurs, at least in part, by exocyclic bond breakage. A paper by Pilgrim and Murphy (2010) looked at the tin and titanium tetrachloride catalyzed anomerization of $O$ - and $S$-glycosides ${ }^{93}$. As they were able to trap and isolate a ring opened intermediate, formed as a consequence of endocyclic ring opening, the study suggested that endocyclic anomerization was the cause of the observed anomerization ${ }^{93}$. However, once again this does not prove there is no anomerization taking place through exocyclization, only that some endocyclic anomerization is taking place. Regardless of which mechanism is taking place, or whether a combination of the two is occurring, these studies demonstrate that anomerization of peracetylated sugars can occur. Furthermore, this anomerization can result in the preferential formation of the $\alpha$ anomer. 


\section{Exo-Cyclic Anomerization}

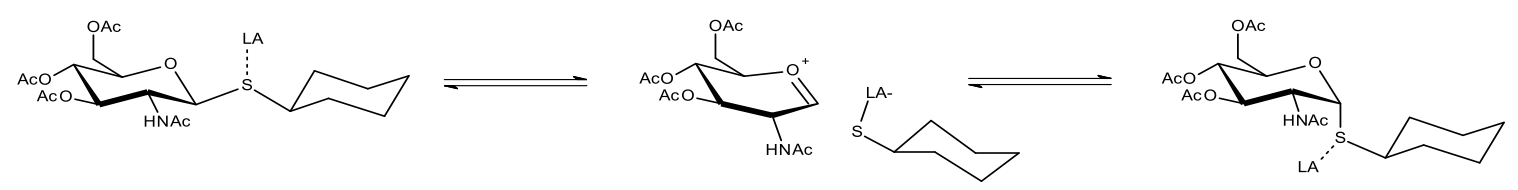

\section{Endo-Cyclic Anomerization}

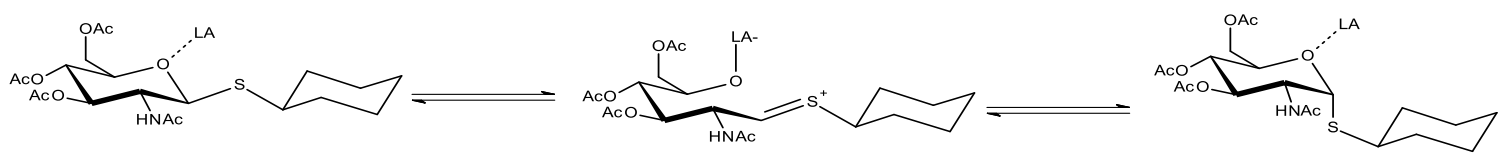

Scheme 3.6. Possible anomerization mechanisms.

LA = Lewis Acid. Adapted from Pilgrim

The study performed by Pilgrim and Murphy (2010) also provided additional information which pointed to anomerization as a likely cause of the selectivity. The study tested a large selection of variables in regards to anomerization, a number of which were of particular interest. It was noted that $S$-glycosides had a higher propensity to undergo anomerization, compared to their corresponding $O$-glycosides, although selectivity towards the $\alpha$-glycoside was significantly lower ${ }^{93}$. Additionally, it was found that higher temperatures resulted in a increase in the rate of anomerization and decrease in $\alpha$-glycoside selectivity. In contrast a higher catalyst loading resulted in a increase in $\alpha$-glycoside, relative to the $\beta$-glycoside. All things considered, the reaction described in this thesis, involving the formation of $\alpha$ thioglycoside 9 from the peracetylated- $\alpha$-D-glucosamine, fits nicely with the observations made by Pilgrim and Murphy $(2010)^{93}$. Although a slightly different starting material, Lewis acid and solvent were used, based on Pilgrim and Murphy's (2010) observations, anomerization would be expected to take place because high temperatures, high catalyst loading and the formation of thioglycosides, all favour anomerization. Furthermore, the $\alpha$ : $\beta$ ratio of 2 : 1 also aligns closely to what was observed by Pilgrim and Murphy $(2010)^{93}$. 
TLCs taken over the course of the reaction also supported anomerization as a likely mechanism. The TLCs showed an initial build up of the $\beta$-anomer. This was followed by an increase in the $\alpha$-thioglycoside, relative to the $\beta$-thioglycoside, as the reaction progressed. All things considered, it is interesting that Li et al. (2011) made no mention of any $\alpha$ thioglycoside formation when using the same conditions described in this thesis, with the only variable being the use of thiophenol in place of cyclohexane thiol ${ }^{85}$.

The contrasting results seen when using cyclohexanethiol instead of thiophenol, may be due to a number of factors. Firstly, Li et al. (2011) may have obtained, but not reported the $\alpha$-thioglycoside. This seems unlikely, given the paper was demonstrating how to improve the reactivity of 1,2-cis- $\alpha$-peracetylated sugars, and not out to synthesise the $\beta$ thioglycoside specifically. Alternatively, it is plausible that the $\beta$-phenylglycoside may be more stable than the corresponding $\alpha$-phenylglycoside, greatly favouring the formation of the $\beta$-phenylglycoside, and resulting in none of the $\alpha$-phenylglycoside being observed. Finally, it is possible that the observed difference in reaction outcomes is down to the $S$ phenyl glycoside having a significantly greater energy barrier to anomerization to overcome, relative to the $S$-cyclohexyl glycoside. Irrespective of how they are occurring, the differing results seen between the experiment performed in this thesis and the one performed by Li et al. (2011) were highly advantageous.

Due to time constraints additional experiments were not able to be performed. However, to confirm anomerization is taking place, the $\beta$-thioglycoside $\mathbf{2 2}$ could be subjected to the same reaction conditions ( $\alpha$-glucosamine pentaacetate excluded) used in the thioglycoside forming reactions. This would ascertain whether $\mathbf{2 2}$ is in fact getting converted to the $\alpha$ thioglycoside 9, as the TLC suggests, or whether it is getting formed in parallel. Secondly, the reaction could be optimized to improve on the modest yield of $33 \%(2: 1, \alpha: \beta)$. As $\mathrm{BF}_{3} \cdot \mathrm{OEt}_{2}$ has been implicated as the main cause of product degradation in a number of studies, its replacement would be a good starting point for optimization ${ }^{85,87}$. Pilgrim and Murphy (2010) found $\mathrm{SnCl}_{4}$ as the best Lewis acid for promoting anomerization in peracetylated glucose thioglycosides, so it would represent a good starting point ${ }^{93}$. Even 
without optimization the reaction provided a very practical means of synthesizing both the $\alpha$ and $\beta$ anomers and possessed many advantages over the syntheses of both the $\alpha$ thioglycoside $\mathbf{9}$ and $\beta$-thioglycoside 22 described previously.

\subsubsection{Comparison to Knapp's Methodology}

There are a number of inherent advantages to utilizing the direct route to thioglycoside formation in place of Knapp's (2002) synthetic route ${ }^{18}$. These advantages include: 1) The reaction can be performed on a large scale, producing gram scale quantities of both the $\alpha$ and $\beta$ thioglycosides; 2 ) It utilizes the significantly more available $\alpha$-glucosamine pentaacetate; 3 ) The desired thioglycosides can be synthesized from the $\alpha$-glucosamine pentaacetate in just a single step, as opposed to the 3 steps for the synthetic routes used to synthesise $\alpha$-thioglycoside 9 and $\beta$-thioglycoside 22 previously; 4) The overall yield (starting from $\mathrm{N}$-acetyl glucosamine) for the formation of $\alpha$-thioglycoside 9 is higher than what was obtained using Knapp's route (12\% vs $1.5 \%)$. However, the overall yield of the $\beta$ thioglycoside 22 was slightly less than the trichloroacetimidate route (6\% vs $9 \%$ ). In conclusion, this reaction, though currently only producing modest yields, upon optimization, may represent an effective way to synthesize the 1,2- $\alpha$-cis-thioglycoside 9 directly from easily accessed peracetylated sugars. Having successfully produced a large quantity of both the $\alpha$-thioglycoside $\mathbf{9}$ and the $\beta$-thioglycoside $\mathbf{2 2}$, all that remained in the synthesis of the GlcN-inositol analogues was to deprotect the alcohols and amine by removing the acetates. 


\subsection{Acetate and Acetamide Deprotection}

The acetate and acetamide deprotection was originally proposed to be achieved through methodology used by Knapp et al. $(2002)^{18}$. However, this reaction required the use of the highly toxic hydrazine at elevated temperatures over an extended period of time. Furthermore, purification required the use of a specific silca gel, namely latrobead silica ${ }^{18}$. With these limitations in mind, an alternative approach to acetate/acetamide deprotection was employed, which involves activating the acetamide, through addition of a Boc group, to allow for a more facile deprotection ${ }^{96}$.

\subsubsection{Addition of the Boc Group to Acetate Protected Thioglycosides (9) and (22)}

Activation of thioglycosides $\mathbf{9}$ and $\mathbf{2 2}$ was achieved by reacting them with di-tert-butyl dicarbonate in the presence of DMAP. The reaction was carried out in THF at $60{ }^{\circ} \mathrm{C}$, producing $N$-Boc- $\alpha$-thioglycoside 23 and $N$-Boc- $\beta$-thioglycoside 24 in 100\% and $80 \%$ yield respectively (Scheme 3.7$)^{96}$. Interestingly, the ${ }^{1} \mathrm{H}$ NMR spectrum of the $N$-Boc- $\beta$ thioglycoside 24 showed an approximately $1: 1$ ratio of two rotamers, which demonstrated different shifts for all protons, with the exception of the cyclohexane ring. In contrast the N-Boc- $\alpha$-thioglycoside 23 showed just a single set of peaks. (Figure 3.1).

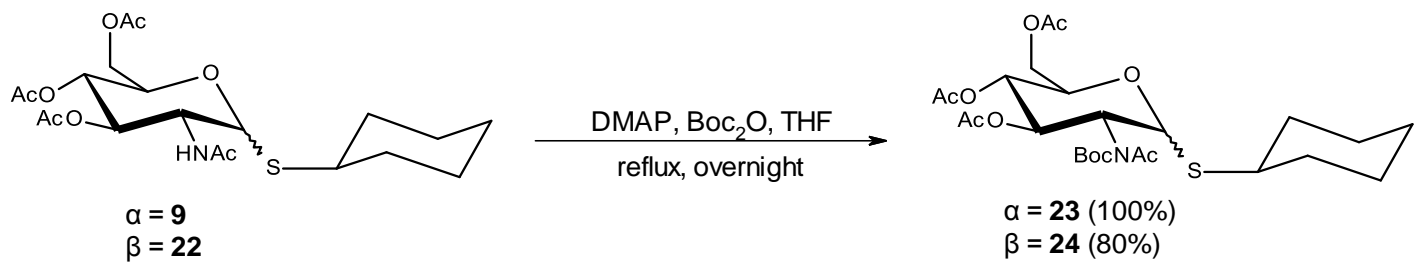

Scheme 3.7. Boc activation of $N$-acetyl thioglycosides $\mathbf{9}$ and $\mathbf{2 2}$ 


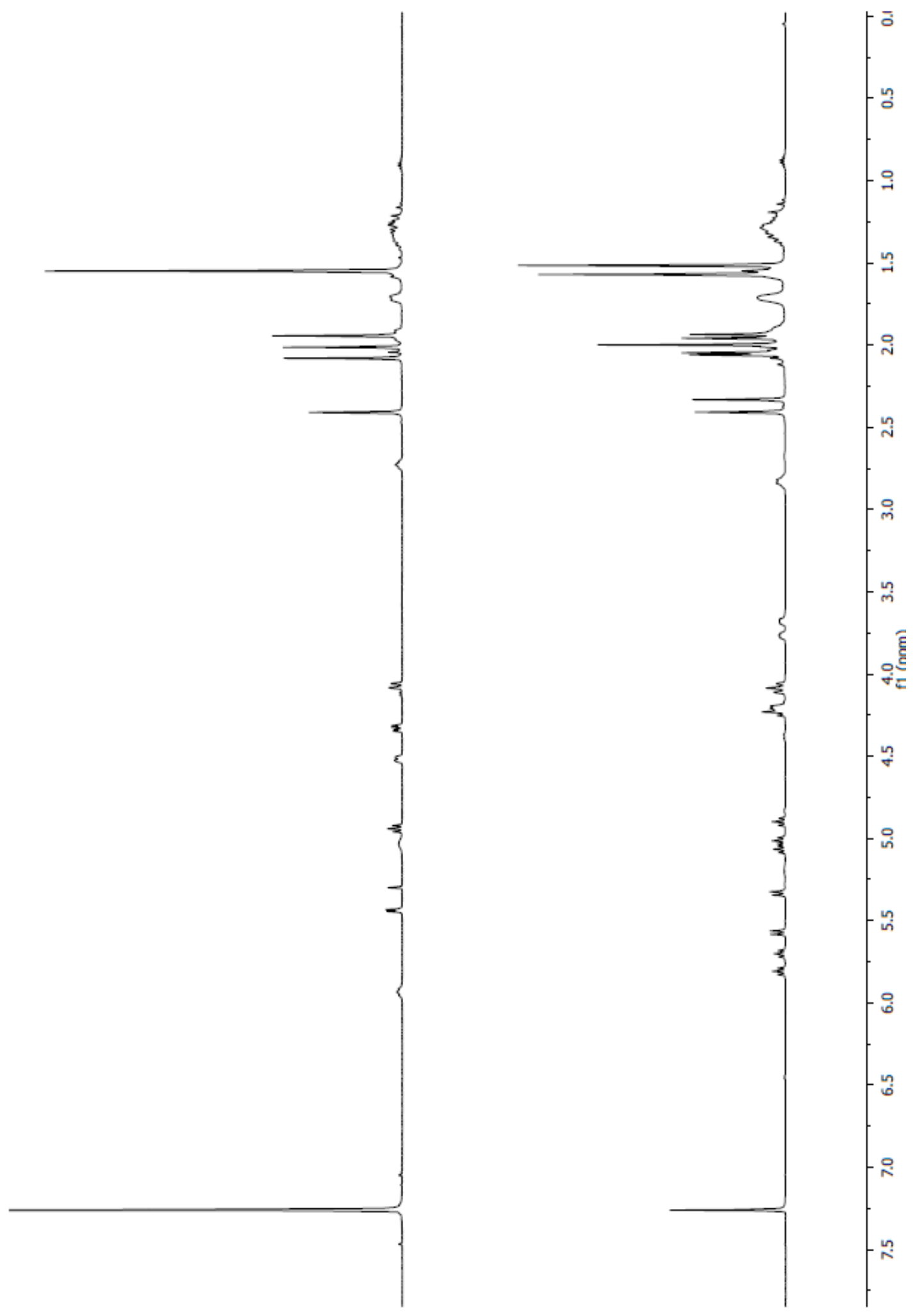

Figure 3.1. ${ }^{1} \mathrm{H}$ NMR of the $\alpha$-Boc 23 and $\beta$-Boc 24 
Interested in the apparent disparity between the two anomers, the structures were subjected to molecular modelling analysis utilizing MacroModel, which allowed examination of the lowest energy conformations for each anomer. The results showed that both the $\alpha$ and $\beta$ anomer had two main populations of conformers; these, broadly, had Bocup or Boc-down features (Figure 3.2). In the $N$-Boc- $\beta$-thioglycoside, both these conformations were essentially the same in regards to their energy. In contrast, there was a difference of approximately $10 \mathrm{~kJ} \mathrm{~mol}^{-1}$ in the Boc-up and Boc-down versions of the $N$ Boc- $\alpha$-thioglycoside. Alongside the lowest energy conformations, the other pertinent point to consider, in regards to the origins of the rotamers in the $\beta$-anomer, is the barrier to rotation between the Boc-up and Boc-down rotamers. An approximate value for this barrier was determined by rotating about the $\mathrm{C} 2-\mathrm{N}$ bond 360 degrees in 5 degree iterations for both the $\alpha$ and $\beta$ anomers. It was found that in both cases the lowest energy pathway the rotation could proceed through had a near identical, and equally significant, energy barrier of approximately $70 \mathrm{~kJ} \mathrm{~mol}^{-1}$. This large value suggests that at room temperature both the $\alpha$ and $\beta$ anomers will be unable to easily switch between conformations, and as such, the reason rotamers are observed in the $\beta$-anomer and absent in the $\alpha$-anomer is likely determined during the course of the reaction. Initially it was thought that, given the high barrier to rotation, the rotamers present in the $\beta$-anomer may just be a representation of the conformation the acetamide was in when the nucleophilic attack took place. However, given the $\alpha$-anomer had an equally high energy barrier to rotation and no rotamers were observed, this option seems unlikely. Furthermore, at the elevated temperatures under which the reaction was performed $\left(60^{\circ} \mathrm{C}\right)$, there is most likely enough energy in the system to overcome the $70 \mathrm{~kJ} \mathrm{~mol}^{-1}$ barrier to rotation and allow for interconversion between the conformers. Thus, it is more likely that production of rotamers in the $\beta$-anomer, and not the $\alpha$-anomer, is due to the difference in energies between the Boc-up and Boc-down conformers of these anomers, i.e. a thermodynamic not a kinetic effect. As stated above there is very little difference between the Boc-up and Boc-down conformation in the $N$ Boc- $\beta$-thioglycoside, whereas, the $N$-Boc- $\alpha$-thioglycoside has a $10 \mathrm{~kJ} \mathrm{~mol}^{-1}$ difference between the two. This difference is 

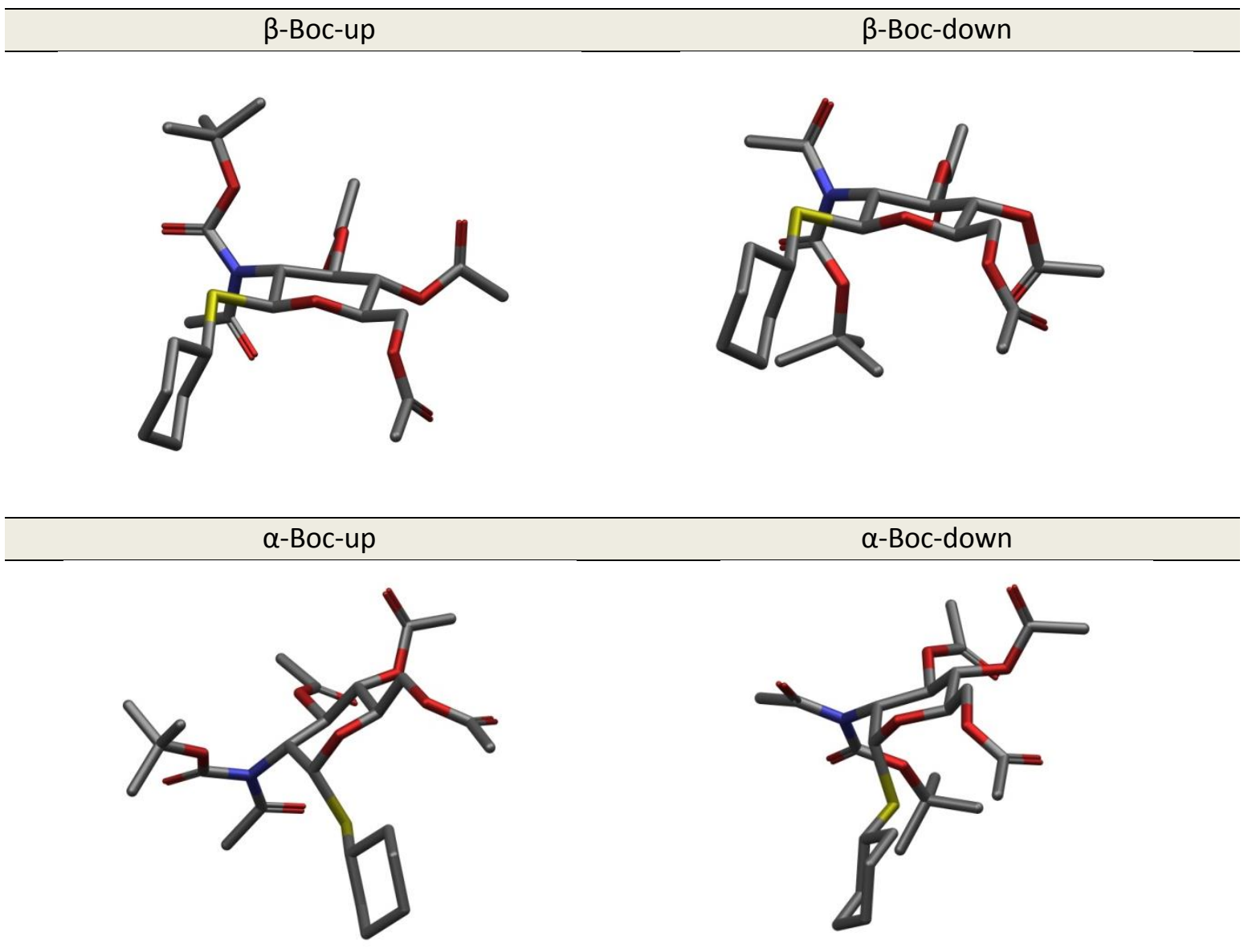

Figure 3.2. Molecular models of the lowest energy Boc-up and Boc-down conformations for the $\alpha$-Boc 23 and $\beta$-Boc 24.

most likely negligible under the $60{ }^{\circ} \mathrm{C}$ reaction conditions; however, once the reaction mixture begins to cool down this difference in energy preferentially favours the lower energy conformer, resulting in the formation of this conformer in isolation. On the other hand, in the $\beta$-anomer there is only a small difference in energy between the two conformations, as such, a 50:50 mix of each conformer would be expected, such as is seen experimentally. Thus, both the experimental observations and molecular modelling suggest that the reason for the disparity between the $\alpha$ and $\beta$ anomers, in regards to rotamers, is due to, firstly, to a high rotational barrier for both anomers, and secondly, the presence of a significant energy difference in the conformations of the $\alpha$-anomer that is not present in the $\beta$-anomer. 
Putting the difference in rotamers aside, the purpose of the placing the Boc group on was to allow for a more facile deprotection of the acetamide. Thus, with it in place, attempts were made to remove all the acetate groups, the acetamide and newly added Boc group in a sequential one-pot deprotection.

\subsubsection{Deprotection of Boc, Acetamide and Acetate Protecting Groups from (23) and (24)}

With the Boc group in place, both the $\mathrm{O}$-acetates and the $\mathrm{N}$-acetate could be removed under relatively mild conditions, using sodium methoxide in methanol at room temperature. Concentration of the reaction mixture, followed by addition of concentrated aqueous hydrochloric acid formed the desired deprotected sugars 25 and 26 as hydrochloride salts ${ }^{96}$. Hence, the removal of the acetates/acetamide and Boc protecting groups, was performed in a one-pot reaction and the only work up that was required was the removal of the solvent in vacuo (Scheme 3.8). This meant there was no loss of material during the deprotection steps. However, this did mean sodium chloride remained mixed in with the desired products. With access to both the GlcN-inositol analogues 25/26 and the cysteine derivative $\mathbf{3}$, all that was required was to conjugate both fragments together. The presence of sodium chloride was deemed not to be a problem in regards to the following conjugation step. Thus no attempt was made to remove it.
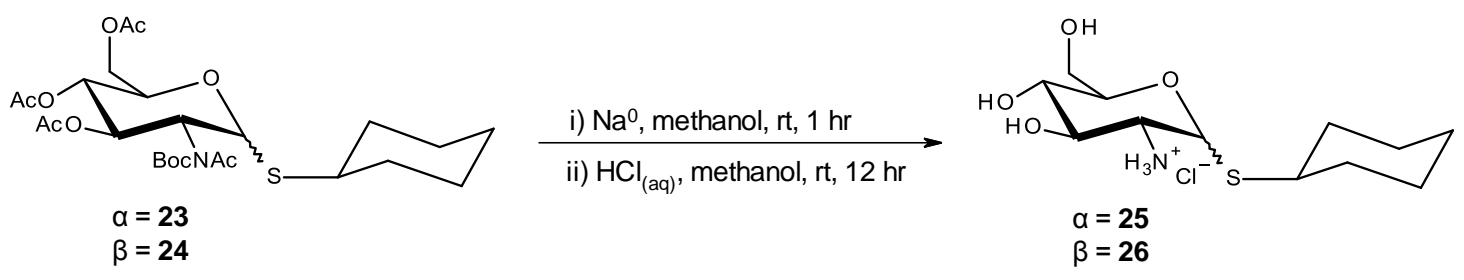

Scheme 3.8. One-pot deprotection of $N$-Boc thioglycosides 23 and 24 


\section{Chapter 4}

\section{Synthesis of Mycothiol Analogues and Biological Studies}

This chapter outlines the successful synthesis of the original synthetic target, mycothiol analogue 13. As well as the structurally related $\beta$-anomer $\mathbf{2 8}$. Thus completing the main aim of this thesis. These compounds, along with two of their precursors, were submitted for testing against Mycobacterium smegmatis, Mycobacterium boivs (BCG strain) and HL60 cells, the results of which are also discussed.

\subsection{Coupling of $N$-Boc-TCVC and GICN-Inositol Analogues}

The coupling of N-Boc-TCVC to the GICN-inositol analogues $\mathbf{2 5}$ and $\mathbf{2 6}$ was modified from the literature procedure by Knapp et al. $(2002)^{18}$. Differences included use of N-Boc-TCVC in place of the $\mathrm{N}$-Boc-S-acetyl cysteine, as well as the use of amine hydrochloride salts for the GIcN-Inositol analogues. In Knapp's (2002) procedure N-Boc-S-acetyl cysteine and the GlcN-inositol analogue $\mathbf{2 5}$ (as the free amine) were coupled in DMF using EDCl, affording an $82 \%$ yield $^{18}$. These same reaction conditions were trialled, albeit with triethylamine added to neutralize the hydrochloride salt, in an attempt to produce the desired $\mathrm{N}$-Bocmycothiol analogue 11 (Scheme 4.1). However under these conditions only a trace amount of product was obtained. TLC analysis throughout the reaction suggested that a significant amount of the starting material $\mathbf{2 5}$ was not reacting. With these observations in mind, an additional two equivalents of triethylamine were used in the next reaction, bringing the total number of equivalents to five. It was thought that this would be sufficient to deprotonate the carboxylic acids from the two equivalents of N-Boc-TCVC, the 
hydrochloride salt from the two equivalents of $\mathrm{EDCl}$ and the hydrochloride salt from 25. However, after $1 \mathrm{hr}$, TLC analysis suggested a large amount of starting material was still present; this prompted a further equivalent of a stronger base, DMAP, to be added in an attempt to progress the reaction. However, once again only trace amounts of the desired product was obtained. These results suggested that the sugar hydrochloride $\mathbf{2 5}$ was not being effectively deprotonated and as a consequence, leading to a reduction in its reactivity. In an effort to try and explore the ability of triethylamine to deprotonate $\mathbf{2 5}$, a large excess was used to quench the reaction in the Boc-deprotection step (section 3.4.2). This was expected to remove the remaining excess $\mathrm{HCl}$ and depronate 25 . Surprisingly, none of the desired free amine of $\mathbf{2 5}$ was produced, instead, triethylamine hydrochloride and the protonated GICN-inositol analogue 25 were the only compounds observed through ${ }^{1} \mathrm{H}$ NMR spectroscopy. This result added further weight to the hypothesis that the low yielding reactions were primarily resulting from the inability of triethylamine to deprotonate the hydrochloride salt of $\mathbf{2 5}$. Due to its low nucleophilicity and higher basicity, potassium tert-butoxide was chosen as a suitable replacement to triethylamine in the coupling reaction. A change in the addition of $\mathbf{2 5}$ was also employed, whereby, $\mathbf{2 5}$ and one equivalent of potassium tert-butoxide were stirred for 30 minutes in DMF, then subsequently added to a mixture of $\mathrm{N}$-Boc-TCVC and EDCI. This change in base and reaction conditions resulted in the complete consumption of $\mathbf{2 5}$ (determined via TLC analysis). Using this method, the desired N-Boc-mycothiol analogues $\mathbf{1 1}$ and $\mathbf{2 7}$ were synthesized in 26\% and 35\% yield respectively (Scheme 4.1) (Note: due the presence of sodium chloride in the starting materials $\mathbf{2 5}$ and 26, these yields are calculated from the Boc-protected sugars $\mathbf{2 3}$ and $\mathbf{2 4}$, see chapter 6 for details). A likely cause of this low yield, despite the consumption of all the starting material, may be due to difficulties in purification. Initial attempts involved the use of flash chromatography on silica, as was used by Knapp et al. (2002) ${ }^{18}$. However, this resulted in substantial loss of product with each pass through the column, suggesting the product may have an undesirable interaction with the silica gel. In an effort to avoid the product spending a lengthy time on the column, a series of quick elutions were performed on a short column of silica. This involved, in order, use of: petroleum ether; 
dichloromethane; diethyl ether; ethyl acetate; and dichloromethane : methanol (3:2) as the eluents. Using this elution system the product was, for the most part, confined to the diethyl ether fraction, with small amount present in the ethyl acetate fraction. Subsequent ${ }^{1} \mathrm{H}$ NMR analysis of these fractions revealed the major impurity to be the excess $N$-BocTCVC, which could be separated by trituration with chloroform. Although this method represented a vast improvement, there is still a lot of room for optimization, with trialling additional coupling agents being the next logical step.

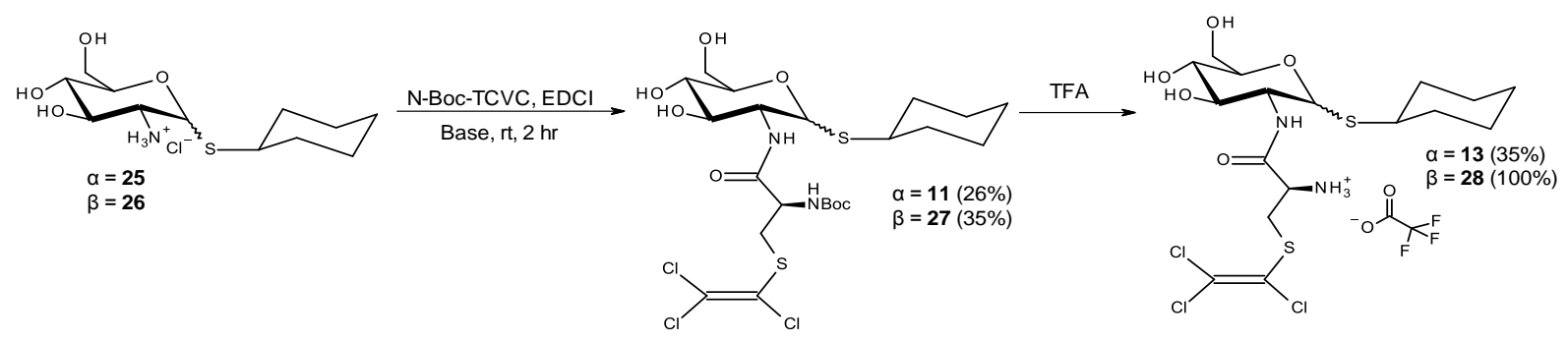

Scheme 4.1. Formation of mycothiol analogues through N-Boc-TCVC conjugation and Boc deprotection

Two papers in the literature have used hydrochloride salts of GlcN-inositol analogues for coupling of cysteine derivatives, in both cases HATU was used as the coupling agent ${ }^{13,53}$. With these studies in mind HATU would be a good choice for further optimization. Time pressures meant this option was never tested.

With sufficient quantities of both the $\alpha$ and $\beta$ anomers, all that remained in the synthesis of the desired mycothiol analogue was removal of the Boc protecting group. To achieve this $\alpha$-Boc 11 was treated with neat TFA for 15 minutes and concentrated in vacuo. However, the subsequent ${ }^{1} \mathrm{H}$ NMR revealed a significant amount of impurities, most of which were concentrated around $0 \mathrm{ppm}$. Given the quantity and positioning of the impurity in the ${ }^{1} \mathrm{H}$ NMR, it was believed that these peaks were a product of degradation of the rubber, present in the vial adapter used to remove the TFA. Fortunately the impurities present were able to 
be removed via chloroform trituration, though as a consequence the yield obtained for this step was only $35 \%$. With only limited time and a small quantity of the starting material $\mathbf{1 1}$ (which was set aside for biological testing), the reaction was never repeated in order to confirm the origin of the impurity. However, when the $\beta-B o c 27$, was tested under the same reaction conditions and concentrated in vacuo (this time without using a vial adapter) the TFA salt 28 was formed in quantitative yield. A subsequent $\mathrm{CDCl}_{3} / \mathrm{TFA}{ }^{1} \mathrm{H}$ NMR spectrum showed no signs of the impurity, although the peaks pertaining to the glucosamine protons showed extreme broadening. Unfortunately, by time a ${ }^{1} \mathrm{H} N M R$ was performed in $\mathrm{CD}_{3} \mathrm{OD}$, the compound showed signs of degradation (see appendix). Compound $\mathbf{2 8}$ will be resynthesized in the future to obtain full characterization data for publication. In regards to biological testing the issue with the degradation of $\mathbf{2 8}$ was deemed not to be a problem, as in each case the sample was prepared on the day of, or the day before, testing. In contrast, the alpha anomer $\mathbf{2 7}$ has exhibited no signs of degradation over storage in $\mathrm{CD}_{3} \mathrm{OD}$ for 2 weeks.

With the successful synthesis of the mycothiol analogues $\mathbf{1 3}$ and $\mathbf{2 8}$ the main aim of this thesis was complete. The optimized scheme leading to the synthesis of these products can be seen in scheme 4.2. Following their synthesis, the compounds were able to be tested for their biological activity. 

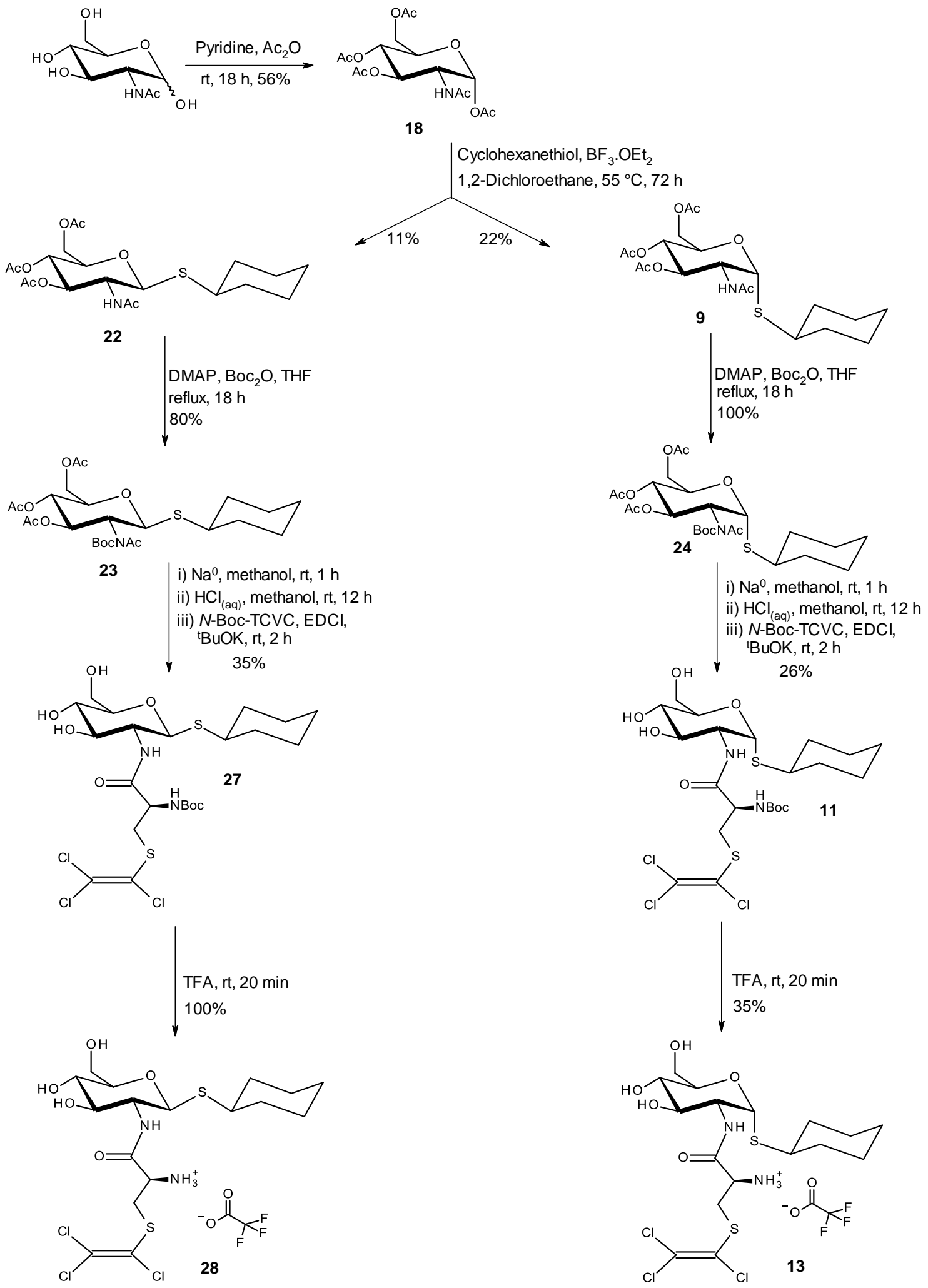

Scheme 4.2. Synthesis of mycothiol analogues $11,27,13$, and 28 


\subsection{Biological Testing}

The original hypothesis stated that the synthesized mycothiol analogue 13 , will be able to cause cell death in Mycobacterium tuberculosis, through an accumulation of harmful halothioketenes. It was theorized that this could occur through metabolism by Mca, or MshB, to form trichlorovinyl cysteine, which has the ability to undergo cleavage by $\beta$-lyases to release the halothioketene, hopefully resulting in cell death (section 1.4.2). Mycobacterium smegmatis and BCG were both chosen to test this hypothesis. These mycobacteria both have the advantage of being non virulent, and as they both express Mca/MshB they should also produce halothioketenes on exposure to 13, making them ideal for initial investigations. The reason two mycobacterial assays were chosen is due to the variance in dependence on the mycothiol pathway exhibited by many mycobacteria. For example, while Mycobacterium tuberculosis is known to require the mycothiol pathway to be viable, while Mycobacterium smegmatis can survive even if the mycothiol pathway is completely absent. Furthermore, Mycobacterium smegmatis, being a soil bacterium, has many mechanisms in place to manage oxidative stress. Since halothioketene exposure, at least in part mediates its toxicity through oxidative stress, Mycobacterium smegmatis may be better suited to cope with the synthesized drug ${ }^{21}$. Thus, by testing against two strains the chance of drawing false conclusions, in regards to potential Mycobacterium tuberculosis activity, is lessened. An HL60 assay was also performed to give an indication of the selectivity of these compounds towards mycobacteria, hence, giving a crude indication of potential toxicity that may be observed in a clinical setting.

Four compounds were chosen to have their activity against Mycobacterium smegmatis, the BCG strain of Mycobacterium Bovis and HL60 cells tested. The $\alpha$-TFA salt 13 was the original synthetic target of this thesis. The $\beta$-TFA salt $\mathbf{2 8}$ was synthesized as it makes, from a biological point of view, an interesting comparison and should in theory act as a negative biological control. Boc-protected precursors $\mathbf{1 1}$ and $\mathbf{2 7}$ were also tested as the increased 
lipophilicty of the Boc-group may aid in cell entry, with the possibility of Boc removal occurring once inside the cell.

The four synthesized compounds described above were all tested in Mycobacterium smegmatis by Nathanial Dasyam (from the natural products group at Victoria University of Wellington (VUW)). A green fluorescent protein (GFP) reporter and optical density (OD) were used to determine cell numbers and a resazurin reduction assay was used to determine the presence of metabolically active cells. The BCG assay was performed by Hilary Corkran (from the immunoglycomics research group at Malaghan Institute of Medical Research), using a resazurin-based detection. Activity against HL60 cells was assessed with assistance from Jessica Field (from the Centre for Biodiscovery at VUW), using an MTT assay. The results of these assays are shown in Table 4.1.

\section{Table 4.1. Activity of Synthesized Compounds Against Varying Cell Lines}

\begin{tabular}{|c|c|c|c|c|}
\hline Compound & Smegmatis (MIC) & BCG (MIC) & HL60 $\left(\mathrm{IC}_{50}\right)$ & $\begin{array}{c}\text { Selectivity } \\
\text { Index }^{b}\end{array}$ \\
\hline 11 & $>1000 \mu \mathrm{M}^{a}$ & $500-1000 \mu \mathrm{M}$ & $59.6 \pm 9.5 \mu \mathrm{M}$ & $0.12-0.24$ \\
\hline 27 & $>1000 \mu \mathrm{M}$ & $\geq 1000 \mu \mathrm{M}$ & $16.5 \pm 0.2 \mu \mathrm{M}$ & $>0.017$ \\
\hline 13 & $250-500 \mu \mathrm{M}$ & $62.5-125 \mu \mathrm{M}$ & $75.7 \pm 1.4 \mu \mathrm{M}$ & $1.2-0.6$ \\
\hline 28 & $250-500 \mu \mathrm{M}$ & $125-250 \mu \mathrm{M}$ & $112 \pm 18.2 \mu \mathrm{M}$ & $0.9-0.45$ \\
\hline
\end{tabular}

The results obtained demonstrated a few interesting points. The most important results in regards to the hypothesis were those pertaining to compound 13. Gratifyingly, this compound proved to have the highest MIC against both types of Mycobacterium tested, the most promising of which was the MIC of close to $62.5 \mu \mathrm{M}$ observed in BCG. Although not overly potent, this level of activity represents a good starting point for future development. Compound $\mathbf{1 3}$ also demonstrated the highest selectivity index (defined as 
the IC 50 of the HL60 cells divided by the MIC of BCG), at 0.6 to 1.2. However, this level of selectivity is lower than what would be deemed optimal, and may be indicative of potential for toxicity in a clinical setting. Nevertheless, it is worth pointing out again that the toxicity in HL60 cells is a very crude comparison and results against non-malignant cells and whole organisms may vary significantly. Regardless of its selectivity, the activity of compound 13 towards BCG suggests cell penetrance is not an issue. At the beginning of this thesis the high polarity of the original synthetic target 13 was identified as a potential problem in regards to cell penetrance. This was part of the motivation behind the proposed synthesis of the fluorescent compound $\mathbf{1 4}$ as an objective, as well as the testing of the Boc compounds 11 and 27. However, although it appears the drug is getting into the cell, the mechanism through which it is entering unclear. It is possible that $\mathbf{1 3}$ is getting is getting into the cell through an active transport mechanism, as is known to occur with mycothiol ${ }^{97}$. Regardless, as a result of the activity seen, the synthesis of fluorescent compound $\mathbf{1 4}$ to test cell entrance was no longer required.

Looking at compound $\mathbf{1 3}$ in isolation shows some promising results. However, when it is examined in context with the other three compounds some additional points of interest can be seen; particularly when compared to the compound that was originally designed to act as a negative control, i.e. 28. Surprisingly, this compound showed a similar level of activity to 13 in both the BCG and Mycobacterium smegmatis assays. This was unexpected, as it was hypothesized the change in stereochemistry at the anomeric centre would result in a significant conformational change, such that the compound would no longer be a substrate for Mca or MshB. Thus, the fact that activity is seen may indicate the streochemistry of the cyclohexane ring attachment only plays a very small role in recognition either by Mca or MshB. Alternatively, the toxicity observed may be independent of Mca/Msh B activity. With this in mind, one possibility is that the toxicity of these compounds is due to $\beta$-lysis of the compounds in their entirety. The mode of action will be tested in further studies. 
Comparing the Mycobacterium smegmatis and BCG assays shows that, in general, compounds show a higher level of activity in BCG. This suggests that, as stated above, the ability of Mycobacterium smegmatis to cope with oxidative stress may be contributing the lower level of activity seen, in comparison to $\mathrm{BCG}^{21}$. The other interesting result seen in the smegmatis assay was the activity of the $\alpha$-Boc 11, which showed contrasting results between the resazurin and GFP/OD detection methods. The resazurin results suggested $100 \%$ growth (relative to control) was occurring up to the $1 \mathrm{mM}$ concentration tested. In contrast, the OD and GFP detection methods both gave near identical I $C_{50}$ values of $4.6 \mu \mathrm{M}$ and 4.2 $\mu \mathrm{M}$ respectively. However, the OD and GFP data showed inhibition never dropped below $30 \%$ of maximal growth (relative to control). The reason for the apparent disparity may be due to the different ways each detection method determines cell growth. GFP and OD directly determine cell numbers through fluorescence and light scattering respectively, in comparison resazurin measures metabolic activity (through reduction of resazurin) ${ }^{98}$. One explanation of this effect is that $\mathbf{1 1}$ is bacteriostatic, leading to a reduction in cell numbers compared to the control, but retaining sufficient metabolic activity to reduce all the resazurin present. This could arise, for example, if $\alpha$-Boc $\mathbf{1 1}$ is inhibiting one or more of mycothiol's biosynthetic enzymes. As stated above Mycobacterium smegmatis does not require mycothiol to survive, however, if its ability to produce mycothiol is inhibited there is a concurrent reduction in the growth rate ${ }^{21}$. However, given the low level of activity exhibited by 11 in the BCG assay this theory seem unlikely and further testing will be required to determine the cause of the activity.

Finally, aside from providing a comparison to the mycobacterial assays, the HL60 assay had some interesting results of its own, particularly in regards to compound $\mathbf{2 7}$, which showed the highest level of activity, with an $\mathrm{IC}_{50}$ of $17 \mu \mathrm{M}$. Though the level of activity seen in $\mathbf{2 7}$ is well below what is seen in many natural products ${ }^{99,100}$, it may hold promise as a lead compound for future investigations; particularly given it's unique structural features.

In summary, the results obtained from the biological assays were satisfactory in terms of activity, with the original synthetic target 13 proving to have the highest MIC in both BCG 
and Mycobacterium smegmatis assays. Surprisingly, it corresponding $\beta$-anomer $\mathbf{2 8}$ showed similar activity. These results suggest further investigations into the mechanism of toxicity and optimization of the activity, through structural changes, may be warranted. 


\section{Chapter 5}

\section{Conclusions and Future Work}

\subsection{Concluding Remarks}

The original goal of this thesis was to explore whether the mycothiol and $\beta$-lyase pathways present in Mycobacterium tuberculosis could be exploited in order to produce an accumulation of harmful halothioketenes, ultimately resulting in cell death. This combination provides a novel target and mechanism towards the treatment of tuberculosis. The original synthetic target $\mathbf{1 3}$ was a derivatized version of a simplified mycothiol analogue developed by Knapp et al. (2002) ${ }^{18}$. However, their synthetic route proved to be extremely problematic in our hands. Gratifyingly, these problems were completely circumvented through a direct thioglycosidation of $\alpha$-glucosmaine pentaacetate to form the $\alpha$-thioglycoside 9 in 22\% yield, accompanied by formation of the $\beta$-thioglycoside 22, which had previously been identified as a desired control compound, in $11 \%$ yield. To avoid the use of hydrazine, the synthetic route to the deprotection of the thioglycosides $\mathbf{9}$ and 22 also involved deviation away from Knapp et al's (2002) synthesis. This was achieved by first activating the acetimide through addition of a Boc group, after which, a more facile deprotection involving $\mathrm{Na}^{0}$ in methanol followed by $\mathrm{HCl}$ was possible. The deprotected sugars $\mathbf{2 5 / 2 6}$ were coupled to TCVC, resulting in $\mathbf{1 1}$ and $\mathbf{2 7}$ in $\mathbf{2 6 \%}$ and $35 \%$ yield respectively. The final step in the synthesis involved the treatment of $\mathbf{1 1}$ and $\mathbf{2 7}$ with TFA to afford the original synthetic target in $35 \%$ yield, while the corresponding $\beta$-anomer was produced in $100 \%$ yield. The N-Boc-TCVC used in the formation of $\mathbf{1 1}$ and $\mathbf{2 7}$ was synthesized in $46 \%$ yield over two steps from L-cysteine. Whist some steps remain to be optimized, compounds $\mathbf{1 1}$ and $\mathbf{2 7}$ were produced in $3.2 \%$ and $1.7 \%$ yields respectively, over 
4 steps (longest linear sequence). While, 13 and 28 were synthesized in $1.1 \%$ and $1.7 \%$ yields respectively, over 5 steps (longest linear sequence).

Having successfully synthesized all the desired compounds, they were tested for their activity against Mycobacterium smegmatis, the BCG strain of Mycobacterium bovis and HL60 cells. The results obtained from these biological assays were satisfactory in terms of activity, with the original synthetic target 13 proving to have the MIC's of $250-500 \mu \mathrm{M}$ and 62.5 - $125 \mu \mathrm{M}$ in Mycobacterium smegmatis and BCG assays respectively. Surprisingly, the corresponding $\beta$-anomer 28 showed similar activity. These results suggest further investigations into the mechanism of toxicity and optimization of the activity, through structural changes, may be warranted.

\subsection{Future Directives}

This thesis describes the synthesis a mycothiol analogue $\mathbf{1 3}$ and three other structurally related variants $(\mathbf{1 1}, \mathbf{2 7}$ and $\mathbf{2 8})$. These were made to test whether mycothiol and $\beta$-Lyase metabolism could be selectively targeted in Mycobacterium tuberculosis, in order to produce an accumulation of harmful halothioketenes, with the end goal being cell death. Both interesting chemical and biological results were obtained on the way to achieving this goal that warrant future investigation.

From a chemical perspective, the most interesting result obtained was the synthesis of the $\alpha$-thioglycoside 9 directly from $\alpha$-glucosmaine pentaacetate. If the reaction was able to be optimized further to improve on the $33 \%$ yield $(\alpha: \beta, 2: 1)$ obtained, it would provide a very easy access to Knapp et al's (2002) analogue, along with the added advantage of producing the $\beta$-anomer concurrently. In regards to yield the only other reaction that warrants further optimization is the coupling of the deprotected thioglycoside salts $\mathbf{2 5}$ and 26 to $N$-Boc-TCVC. 
From a biological perspective there are a number of interesting results that warrant further investigation. Firstly, the $\beta$-Boc compound 27 had an IC 50 of $17 \mu \mathrm{M}$ in the HL60 MTT assay. This level of activity is sufficient to suggest it may be worthwhile examining the use of this compound as a lead for the development of related compounds that may further enhance the anti-cancer properties.

In regards to the Mycobacterium smegmatis assay, the activity of N-Boc- $\alpha$-thioglycoside 11 was promising $\left(\mathrm{IC}_{50}=4 \mu \mathrm{M}\right)$, despite its inability to cause complete cell death even at the highest concentration tested $(1 \mathrm{mM})$. These results suggested $\mathbf{1 1}$ may be exerting a bacteriostatic effect. As such, it would be interesting to ascertain whether this is the case, as well as determining if prolonged exposure leads to a bacteriocidal effect.

With respect to the original aim of this thesis, there are two main questions that remain unanswered. Firstly, although compound 13 (MIC 62.5-125 $\mu \mathrm{M}$ ) and, to a lesser extent 28 $(125-250 \mu \mathrm{M})$, show activity, the mechanism through which this activity occurs is unknown. Thus, testing should be performed to elucidate the mechanism that leads to toxicity. Secondly, a structure activity relationship could be explored in order to evaluate whether to antimicrobial activity could be enhanced and the toxicity to human cells reduced. Given the methodology developed, a library of compounds could be easily synthesized by substituting the cyclohexanethiol used in the glycosidation step with a range of other thiols, in combination with, switching of the substituent conjugated to the sulfur of cysteine. 


\section{Chapter 6}

\section{Experimental}

\subsection{General Experimental}

Unless otherwise stated, the following conditions apply. All reactions were performed with magnetic stirring. Moisture- and oxygen sensitive liquids and solutions were transferred using a stainless steel syringe. Before use, solvents were refluxed over the appropriate drying agent and distilled under nitrogen; acetonitrile (MeCN) and triethylamine ( $\left.\mathrm{NEt}_{3}\right)$ from calcium hydride; methanol $(\mathrm{MeOH})$ and toluene from sodium. Dichloromethane, toluene and THF were used directly from Innovative Technology Pure Solv MD-5 solvent purifier. Anhydrous $\mathrm{N}, \mathrm{N}$-dimethylformamide (DMF) and acetic anhydride were used as purchased, without further purification. All reagents were of commercial quality and used as received, without further purification. Analytical thin layer chromatography (TLC) was performed using plastic-backed pre-coated silica TLC plates (Polygram SilG/UV254). Visualisation was achieved by UV irradiation $(254 \mathrm{~nm}$ ) or by heating after treatment with a potassium permanganate dip $\left(1.5 \mathrm{~g} \mathrm{KMnO}_{4}, 10 \mathrm{~g} \mathrm{~K}_{2} \mathrm{CO}_{3}\right.$, $1.25 \mathrm{~mL}$ of $10 \%$ aqueous $\mathrm{NaOH}$ solution and $200 \mathrm{~mL}$ of water) or $p$-anisaldehyde dip (0.7 $\mathrm{mL} p$-anisaldehyde, $9.5 \mathrm{~mL}$ conc.

$\mathrm{H}_{2} \mathrm{SO}_{4}, 2.7 \mathrm{~mL}$ acetic acid and $250 \mathrm{~mL}$ of EtOH). The purification of products by flash column chromatography was conducted using silica gel 60 (220-240 mesh) with the solvent systems indicated. ${ }^{1} \mathrm{H}$ NMR spectra were recorded on either: a Varian Unity Inova 500 spectrometer at $500 \mathrm{MHz}$, or a Varian Inova 300 at $300 \mathrm{MHz}$. Data are listed as follows: chemical shift in ppm using chloroform as internal standard (7.26 ppm) or water $(4.79 \mathrm{ppm})$ or $\mathrm{d}_{4}-\mathrm{MeOH}(3.31)$, multiplicity $(\mathrm{s}=$ singlet, $\mathrm{d}=$ doublet, $\mathrm{t}=$ triplet, $\mathrm{q}=$ quartet, $\mathrm{m}=$ multiplet or overlap of non-equivalentresonances, $\mathrm{br}=$ broad, app. = apparent, obs. $=$ (partially) obscured), integration, peak assignment. ${ }^{13} \mathrm{C}$ NMR spectra 
were recorded on either: a Varian Unity Inova 500 spectrometer at $125 \mathrm{MHz}$ or a Varian DirectDrive 600 spectrometer at $150 \mathrm{MHz}$ and the data listed as follows: chemical shift in ppm using chloroform as internal standard (77.0 ppm) or $d_{4}-\mathrm{MeOH}(49.00)$. The assignment of atom connectivity and spatial relationships are exclusively based on 2D NMR correlations (NOESY, 1H/1H-COSY, 1H/13C-HMBC and 1H/13C-HSQC). IR bands were measured as either a thin film on a Bruker FT-IR Tensor 27 spectrometer with ATR sampling accessory or a Bruker ALPHA FT-IR spectrometer as a $\mathrm{KBr}$ disc on a Perkin-Elmer Spectrum One FT-IR spectrometer. High-resolution mass spectrometry (HRMS) was performed on a Agilent 6530 Accurate-Mass Q-TOF LC/MS mass spectrometer with Agilent Jet Stream ESI source. Melting points were measured on a Gallenkamp melting point apparatus and are uncorrected. Optical rotations were measured on an Autopol II polarimeter from Rudolph Research Analytical. The structure of each compound is presented with the corresponding method of preparation and spectroscopic data. 


\subsection{Experimental detail for chemical synthesis}

\section{2-acetamido-2-deoxy-1,3,4,6-tetra-O-acetyl- $\beta$-D-glucopyranose (6)}

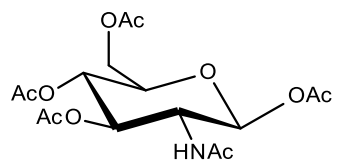

Sodium acetate $(4.18 \mathrm{~g}, 51.0 \mathrm{mmol})$ was stirred in acetic anhydride (40 mL, $424 \mathrm{mmol}$ ) at $100{ }^{\circ} \mathrm{C}$ for $5 \mathrm{~min}$, after which time $N$-acetyl glucosamine $(8.13 \mathrm{~g}, 36.7 \mathrm{mmol})$ was slowly added over a period of $10 \mathrm{~min}$ and the reaction allowed to stir at $100^{\circ} \mathrm{C}$ for an additional $1 \mathrm{~h}$. Water $(60 \mathrm{~mL})$ was then added to the reaction mixture and the compound extracted with dichloromethane ( 3 $x 60 \mathrm{~mL})$. The organic layer was then washed with brine $(200 \mathrm{~mL})$, dried with anhydrous anhydrous $\mathrm{MgSO}_{4}$ and concentrated in vacuo to produce a yellow oil, which was recrystallized from methanol to afford the title compound as a white solid (1.46 g, 10\%). $\mathrm{R}_{f} 0.36$ (EtOAc). ${ }^{1} \mathrm{HNMR}\left(500 \mathrm{MHz}, \mathrm{CDCl}_{3}\right) \delta: 5.69(\mathrm{~d}, J=8.5 \mathrm{~Hz}, 1 \mathrm{H}), 5.57(\mathrm{~d}, J=10.0 \mathrm{~Hz}, 1$ H), $5.14(\mathrm{~m}, 2 \mathrm{H}), 4.32(\operatorname{app~t}, J=9.5,1 \mathrm{H}), 4.27(\mathrm{dd}, J=4.5,12.5 \mathrm{~Hz}, 1 \mathrm{H}), 4.13(\mathrm{dd}, J=2.0$ Hz, 12.5 Hz, 1 H), 3.81 (m, 1 H), 2.12 (s, 3 H), 2.10 (s, 3 H), $2.05(\mathrm{~s}, 3 \mathrm{H}), 2.04(\mathrm{~s}, 3 \mathrm{H}), 1.94$ (s, 3 H). ${ }^{13}$ CNMR $\left(125 \mathrm{MHz}, \mathrm{CDCl}_{3}\right)$ $\delta: 171.23,170.69,170.07,169.57,169.24,92.61,72.93$, $72.58,67.44,61.62,53.04,23.22,20.91,20.74,20.65,20.60$.

Matched Literature data 62

$(3 \mathrm{a}, 5 R, 6 S, 7 R, 7 \mathrm{a} R)$-5-(Acetoxymethyl-6,7-diacetoxy-2-methyl-5,6,7,7a-tetrahydro-3aHpyrano[3,2-d]thiazole (7)

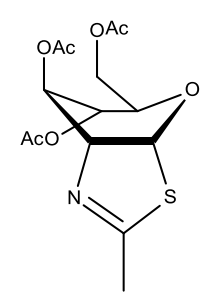

$\beta$-D-Glucosamine pentaacetate $(0.370 \mathrm{~g}, 0.95 \mathrm{mmol})$ and Lawesson's

reagent $(0.500 \mathrm{~g}, 1.20 \mathrm{mmol})$ were stirred in toluene $(4 \mathrm{~mL})$ at $90^{\circ} \mathrm{C}$ for $3 \mathrm{~h}$, after which time the reaction mixture was cooled and concentrated in vacuo to afford a yellow oil. The oil was then purified by flash chromatography on silica gel (eluent: ethyl acetate/dichloromethane, $3: 7$ ) to give the title compound as a yellow oil (222 mg, 68\%). $\mathrm{R}_{f} 0.24$ (1:3 EtOAc: $\mathrm{CH}_{2} \mathrm{Cl}_{2}$ ). ${ }^{1} \mathrm{HNMR}\left(500 \mathrm{MHz}, \mathrm{CDCl}_{3}\right)$ ): $6.24(\mathrm{~d}, J=7.0 \mathrm{~Hz}, 1 \mathrm{H}), 5.57$ (dd, J = 1.5, 3.0 Hz, $\left.1 \mathrm{H}\right), 4.95$ (d, $J=9.5 \mathrm{~Hz}$ ), $4.48(\mathrm{~s}, 1 \mathrm{H}), 4.12(\operatorname{app} d, J=11.0 \mathrm{~Hz}), 3.53-3.55(\mathrm{~m}, 1 \mathrm{H}), 2.32(\mathrm{~s}, 3 \mathrm{H}), 2.13(\mathrm{~s}$, 
3H), 2.08 (s, 6H). ${ }^{13} \mathrm{CNMR}\left(125 \mathrm{MHz} \mathrm{CDCl}_{3}\right.$ ) $\delta: 170.64,169.62,169.34,168.27,88.83$,

$76.66,70.72,69.31,68.42,63.30,20.99,20.91,20.78,20.71$.

Matched Literature data ${ }^{62}$

\section{2-Acetamido-2-deoxy-1-thio-3,4,6-tri-O-acetyl- $\beta$-D-glucopyranoside (8)}

GlcNAc-thiazoline triacetate $(66 \mathrm{mg}, 0.19 \mathrm{mmol})$ was dissolved in methanol $(3.0 \mathrm{~mL})$ and

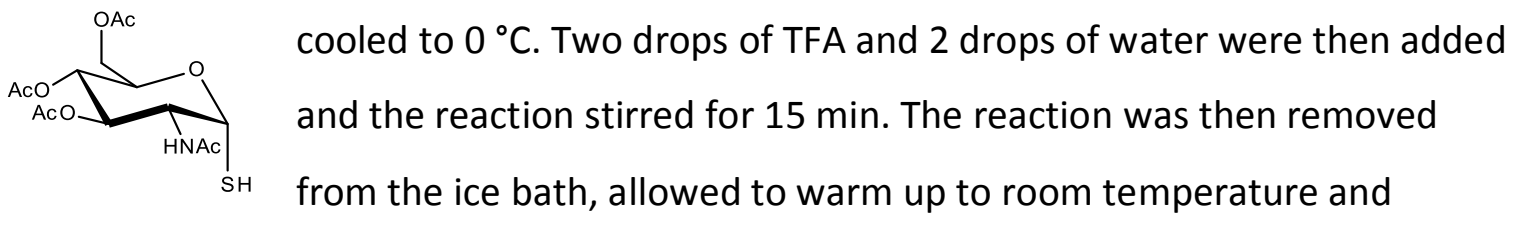
continued for an additional $2 \mathrm{~h}$, after which time the reaction was concentrated in vacuo to afford the title compound as a colourless oil (69 mg, 100\%). ${ }^{1} \mathbf{H} \mathbf{N M R}\left(500 \mathrm{MHz}, \mathrm{CDCl}_{3}\right)$ $\delta: 5.79(\mathrm{~m}, 2 \mathrm{H}), 5.13(\mathrm{t}, J=9.5 \mathrm{~Hz}, 1 \mathrm{H}), 5.09(\mathrm{t}, J=9.0 \mathrm{~Hz}, 1 \mathrm{H}), 4.32-4.51(\mathrm{~m}, 1 \mathrm{H}), 4.25-$ $4.31(\mathrm{~m}, 2 \mathrm{H}), 4.12(\mathrm{dd}, J=12.0,1.5 \mathrm{~Hz}, 1 \mathrm{H}), 2.07$ (s, $3 \mathrm{H}), 2.02(\mathrm{~s}, 3 \mathrm{H}), 2.01(\mathrm{~s}, 3 \mathrm{H})$, and 1.99 (s, $3 \mathrm{H}) .{ }^{13} \mathrm{C}$ NMR $\left(125 \mathrm{MHz} \mathrm{CDCl}_{3}\right) \delta: 171.7,171.4,170.8,169.3,78.5,70.5,68.9$, $67.9,61.7,52.6,22.9,20.6,20.5$.

Matched literature data ${ }^{74}$

\section{Cyclohexyl 2-Acetamido-2-deoxy-1-thio-3,4,6-tri-O-acetyl- $\alpha$-D-glucopyranoside (9)}

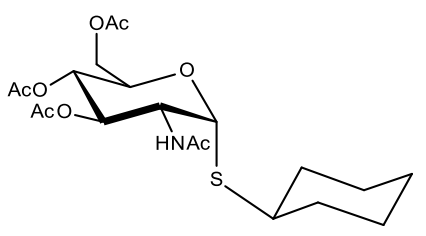

Method 1: AIBN (1.8 mg, $0.011 \mathrm{mmol})$ and thiol 8 (200 mg, $0.55 \mathrm{mmol})$ were dissolved in THF $(2.2 \mathrm{~mL})$ and cyclohexene (0.45 mL, $4.4 \mathrm{mmol})$ under a nitrogen atomosphere and stirred for $1 \mathrm{~h}$, after which time an addition aliquot of cyclohexene $(0.45 \mathrm{~mL}, 4.4 \mathrm{mmol})$ and AIBN $(1.8 \mathrm{mg}, 0.011 \mathrm{mmol})$ were added. The same quantity of AIBN and cyclohexene was added each hour, till the reaction had been stirring for 4 hours in total. The reaction was then stirred for an additional $1 \mathrm{~h}$, after which time AIBN (10.8 mg, $0.066 \mathrm{mmol}$ ) was added, the reaction stirred for an hour, and another portion of AIBN (10.mg, 0.066) added. The reaction was then allowed to stirred for one 
more hour, after which time the reaction was cooled and concentrated in vacuo. The resulting oil was then purified by flash chromatography on silica (eluent: ethyl acetate : dichloromethane $1: 3$ ) to afford the title compound as a colourless oil, that crystallized over time (71 mg, 29\%).

Method 2: $\alpha$-D-glucosamine pentaacetate 19 (1.01 g, $2.59 \mathrm{mmol})$ was dissolved in 1,2dichloroethane $(35 \mathrm{~mL})$. Cyclohexanethiol $(1.28 \mathrm{~mL}, 10.46 \mathrm{mmol})$ was then added and the reaction stirred under nitrogen for $20 \mathrm{~min}$ at room temperature. The reaction was then cooled to $0{ }^{\circ} \mathrm{C}$ and $\mathrm{BF}_{3} \cdot \mathrm{OEt}_{2}(0.643 \mathrm{~mL}, 5.21 \mathrm{mmol})$ added dropwise. The reaction was subsequently heated to $55^{\circ} \mathrm{C}$ and stirred for $3 \mathrm{~h}$, after which time the reaction was quenched with saturated aqueous sodium bicarbonate $(35 \mathrm{~mL})$ and extracted into the organic phase. The aqueous phase was then washed with additional dichloromethane $(2 \mathrm{x}$ $40 \mathrm{~mL}$ ). The organic fractions were then combined and washed with saturated brine (100 $\mathrm{mL}$ ), dried over anhydrous $\mathrm{MgSO}_{4}$ and concentrated in vacuo. The compound was then purified by flash chromatography on silica (eluent: petroleum ether/ethyl acetate, $1: 2$ ) to afford the title compound as a white solid (256 mg, 22\%). $\mathrm{R}_{f} 0.75$ (ethyl acetate). M.p. 119-121 ${ }^{\circ} \mathrm{C} .{ }^{1} \mathrm{H}$ NMR $(500 \mathrm{MHz}, \mathrm{CDCl} 3) \delta 5.69(\mathrm{brd}, J=9.2 \mathrm{~Hz}, 1 \mathrm{H}), 5.45(\mathrm{~d}, J=5.2 \mathrm{~Hz}, 1$ H), 5.09 (t, J = 9.6 Hz, 1 H), 5.02 (t, J= $10 \mathrm{~Hz}, 1 \mathrm{H}$ ), 4.49 (ddd, J= 5.6, 9.2, 10.8 Hz, $1 \mathrm{H}$ ), 4.38 (ddd, $J=2.2,4.8,10.0 \mathrm{~Hz}, 1 \mathrm{H}$ ), 4.24 (dd, $J=4.8,12.4 \mathrm{~Hz}, 1 \mathrm{H}$ ), 4.07 (dd, $J=2.4,12.4 \mathrm{~Hz}, 1$ H), $2.81(\mathrm{tt}, J=3.4,10.2 \mathrm{~Hz}, 1 \mathrm{H}), 2.07(\mathrm{~s}, 3 \mathrm{H}), 2.02(\mathrm{~s}, 3 \mathrm{H}), 2.01(\mathrm{~s}, 3 \mathrm{H}), 1.94(\mathrm{~s}, 3 \mathrm{H})$, 1.94-2.10 (m, $2 \mathrm{H}), 1.67-1.79(\mathrm{~m}, 2 \mathrm{H}), 1.54-1.63(\mathrm{~m}, 1 \mathrm{H}), 1.22-1.42$ (m, $5 \mathrm{H}) .{ }^{13} \mathrm{C}$ NMR (125 MHz, CDCl3) $\delta 171.1,170.3,169.5,169.0,83.5,71.4,68.3,68.2,61.0,52.1,44.9$, 34.2, 33.6, 25.9, 25.8, 25.5, 23.2, 20.7 (2 C), 20.6.

Matched data from literature ${ }^{18}$ 


\section{2-Acetamido-2-deoxy-1,3,4,6-tetra-0-acetyl- $\alpha$-D-glucopyranose (18)}

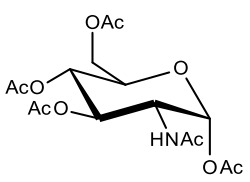

To a solution of D-glucosamine 1 (1.49g, $8.33 \mathrm{mmol})$ in pyridine $(8.3$ $\mathrm{mL}$ ) was added acetic anhydride $(7.8 \mathrm{~mL})$ and the mixture stirred for 18

$\mathrm{h}$, after which time the mixture was concentrated in vacuo to give a yellow/green syrup. Recrystallization of this oil using ethanol yielded the title compound as a white powder (1.83g, $4.63 \mathrm{mmol}, 56 \%) .{ }^{1} \mathrm{H}$ NMR $\left(500 \mathrm{MHz}, \mathrm{CDCl}_{3}\right) \delta: 6.18(\mathrm{~d}, J=3.0$ $\mathrm{Hz}, 1 \mathrm{H}), 5.56$ (d, J = 8.5 Hz), 5.17-5.27 (m, 2H), 4.46-4.51 (m, 1H), 4.26 (dd, J = 3.0, $9.0 \mathrm{~Hz}$, 1H), $4.06(\mathrm{~d}, J=7.5 \mathrm{~Hz}, 1 \mathrm{H}), 3.98-4.01(\mathrm{~m}, 1 \mathrm{H}), 2.16(\mathrm{~s}, 3 \mathrm{H}), 2.05(\mathrm{~s}, 3 \mathrm{H}), 2.02(\mathrm{~s}, 3 \mathrm{H}), 2.01$

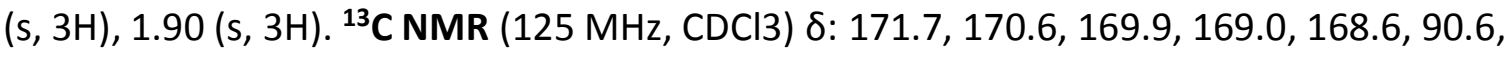
70.6, 69.6, 67.4, 61.4, 51.0.

\section{2-Acetamido-2-deoxy-3,4,6-tri-O-acetyl- $\alpha$-D-glucopyranose (19)}

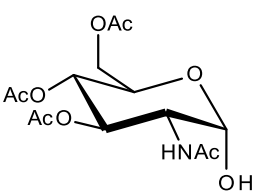

Glacial acetic acid $(0.31 \mathrm{~mL}, 5.43 \mathrm{mmol})$ was added to solution of ethylenediamine $(0.25 \mathrm{~mL}, 3.81 \mathrm{mmol})$ in THF $(80 \mathrm{~mL})$ and stirred under a nitrogen atomosphere for $5 \mathrm{~min}$ at room temperature. $\alpha-D$ -

Glucosamine pentaacetate $(1.06 \mathrm{~g}, 2.72 \mathrm{mmol})$ was then added to the solution and the reaction stirred for $30 \mathrm{~h}$, after which time water $(40 \mathrm{~mL})$ was added and the reaction extracted into the organic phase. The organic layer was then washed with $10 \% \mathrm{KHSO}_{4}(40$ $\mathrm{mL})$, saturated aqueous sodium bicarbonate $(40 \mathrm{~mL})$ and saturated brine $(40 \mathrm{~mL})$, dried over anhydrous $\mathrm{MgSO}_{4}$ and concentrated in vacuo. Purification was achieved by flash chromatography on silica (eluant: ethyl acetate) to afford the title compound as a white soild (666 mg, 70\%). $\mathrm{R}_{f} 0.33$ (ethyl acetate). ${ }^{1} \mathrm{H} \mathbf{N M R}\left(500 \mathrm{MHz}, \mathrm{CDCl}_{3}\right) \delta: 5.98$ (d, J = 9.5 $\mathrm{Hz}, 1 \mathrm{H}), 5.30(\mathrm{t}, J=10.0 \mathrm{~Hz}, 1 \mathrm{H}), 5.25(\mathrm{~d}, J=4.0 \mathrm{~Hz}, 1 \mathrm{H}), 5.12(\mathrm{t}, J=9.5 \mathrm{~Hz}, 1 \mathrm{H}), 4.28(\mathrm{td}, J$ = 3.0, $9.5 \mathrm{~Hz}, 1 \mathrm{H}), 4.17-4.23(\mathrm{~m}, 2 \mathrm{H}), 4.09-4.15(\mathrm{~m}, 1 \mathrm{H}) 2.09(\mathrm{~s}, 3 \mathrm{H}), 2.03(\mathrm{~s}, 3 \mathrm{H}), 2.02(\mathrm{~s}$, 3H), 1.96 (s, 3H). ${ }^{13} \mathrm{C} \mathrm{NMR}\left(125 \mathrm{MHz}, \mathrm{CDCl}_{3}\right)$ 8: 171.4, 171.0, 170.6, 169.5, 91.4, 71.0, 68.3, $67.3,62.1,52.3,23.0,20.7,20.6$

Matched literature data ${ }^{65}$ 


\section{2-Acetamido-2-deoxy-3,4,6-tri-0-acetyl- $\alpha$-D-glucopyranosyl trichloroacetimidate (20)}

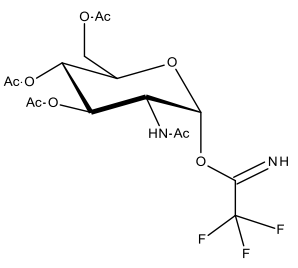

Glucosamine tetraacetate 19 (666 mg, $1.92 \mathrm{mmol}$ ) was dissolved in dichloromethane $(15 \mathrm{~mL})$, stirring under a nitrogen atmosphere, and subsequently cooled to $0^{\circ} \mathrm{C}$. DBU $(0.55 \mathrm{~mL}, 3.68 \mathrm{mmol})$ was then added, followed by trichloroacetonitrile $(0.76 \mathrm{~mL}, 7.58 \mathrm{mmol})$. The reaction mixture was then stirred for $2 \mathrm{~h}$ at $0^{\circ} \mathrm{C}$, after which time the solvent was removed in vacuo and the resulting oil purified by flash chromatography on silica (eluant : petroleum ether/ethyl acetate, $2: 1$ ) to afford the title compound as a yellow oil (633 mg, 67\%) $\mathrm{R}_{f} 0.71$ (ethyl acetate); ${ }^{1} \mathrm{H}$ NMR (300 MHz, CDCl 3 ) $\delta: 8.80(\mathrm{~s}, 1 \mathrm{H}), 6.36$ (d, J = $\left.3.9 \mathrm{~Hz}\right)$, $5.60(\mathrm{~d}, J=8.7 \mathrm{~Hz}), 5.32(\mathrm{t}, J=9.6 \mathrm{~Hz}), 5.26(\mathrm{t}, J=8.7 \mathrm{~Hz}), 4.41(\mathrm{td}, J=3.6,9.3 \mathrm{~Hz}, 1 \mathrm{H})$, $4.55(\mathrm{dd}, J=3.6,12.9 \mathrm{~Hz}, 1 \mathrm{H}) 4.11(\mathrm{~m}, 2 \mathrm{H}), 2.08(\mathrm{~s}, 3 \mathrm{H}), 2.07(\mathrm{~s}, 3 \mathrm{H}), 2.06(\mathrm{~s}, 3 \mathrm{H}), 1.94$ (s, 3 H). ${ }^{13}$ C NMR (125 MHz, $\left.\mathrm{CDCl}_{3}\right)$ $\delta: 171.59,170.62,169.17,160.25,94.74,70.66,70.22$, $67.24,61.41,51.74,23.07,20.74,20.68,20.58$.

Matched literature data ${ }^{65}$

Cyclohexyl 2-Acetamido-2-deoxy-1-thio-3,4,6-tri-O-acetyl- $\beta$-D-glucopyranoside (22)



Method 1: Cyclohexanethiol ( $25 \mu \mathrm{L}, 0.20 \mathrm{mmol})$ and trichloroacetimidate 20 (90 $\mathrm{mg}, 0.20 \mathrm{mmol}$ ) were stirred in dichloromethane $(1 \mathrm{~mL})$ under a nitrogen atomosphere at -

$42{ }^{\circ} \mathrm{C} . \mathrm{BF}_{3} \cdot \mathrm{OEt}_{2}(2.5 \mu \mathrm{L}, 0.02 \mathrm{mmol})$ was then added and the reaction stirred for $1 \mathrm{~h}$, after which time, the reaction was diluted with dichloromethane $(4 \mathrm{~mL})$ quenched with saturated aqueous sodium bicarbonate $(4 \mathrm{~mL})$ and extracted into the organic layer. The aqueous layer was then extracted with additional dichloromethane $(2 \times 5 \mathrm{~mL})$. The combined organic fractions were subsequently washed with saturated brine (15 $\mathrm{mL})$, dried over anhydrous $\mathrm{MgSO}_{4}$ and concentrated in vacou. The resulting oil was then purified by flash chromatography on silica (eluant: petroleum ether/ethyl acetate ,1:2) to afford the title compound as a white solid ( $28 \mathrm{mg}, 35 \%) \mathrm{R}_{f} 0.61$ (ethyl acetate) 
Method 2: $\alpha$-D-glucosamine pentaacetate 18 (1.01 g, $2.59 \mathrm{mmol})$ was dissolved in 1,2dichloroethane $(35 \mathrm{~mL})$. Cyclohexanethiol $(1.28 \mathrm{~mL}, 10.46 \mathrm{mmol})$ was then added and the reaction stirred under nitrogen for 20 minutes at room temperature. The reaction was then cooled to $0{ }^{\circ} \mathrm{C}$ in a ice salt bath and $\mathrm{BF}_{3} \cdot \mathrm{OEt}_{2}(0.643 \mathrm{~mL}, 5.21 \mathrm{mmol})$ added dropwise. The reaction was subsequently heated to $55^{\circ} \mathrm{C}$ and stirred for $3 \mathrm{~h}$, after which time the reaction was quenched with saturated aqueous sodium bicarbonate $(35 \mathrm{~mL})$ and extracted into the organic phase. The aqueous phase was then washed with additional dichloromethane $(2 \times 40 \mathrm{~mL})$. The organic fractions were then combined and washed with saturated brine $(100 \mathrm{~mL})$, dried over anhydrous $\mathrm{MgSO}_{4}$ and concentrated in vacuo. The compound was then purified by flash chromatography on silica (eluent: petroleum ether/ethyl acetate, $1: 2$ ) to afford the title compound as a white solid (128 mg, 11\%). $R_{f}$ 0.61 (ethyl acetate). ${ }^{1} \mathrm{H}$ NMR $\left(500 \mathrm{MHz}, \mathrm{CDCl}_{3}\right) \delta: 5.46(\mathrm{~d}, J=9 \mathrm{~Hz}, 1 \mathrm{H}), 5.23(\mathrm{t}, J=10.2 \mathrm{~Hz}$, $1 \mathrm{H}), 5.07$ (t, J = 10.2 Hz, $1 \mathrm{H}), 4.76(\mathrm{~d}, J=10.2 \mathrm{~Hz}, 1 \mathrm{H}), 4.21(\mathrm{dd}, J=5.7,12.3 \mathrm{~Hz}, 1 \mathrm{H}), 4.12$ (dd, $J=2.4,12.3 \mathrm{~Hz}, 1 \mathrm{H}$ ), 3.97 (q, J = 9.9 Hz, 1H), 3.69 (ddd, J=2.79, 5.7, $10.2 \mathrm{~Hz}, 1 \mathrm{H}$ ), $2.91(\mathrm{~m}, 1 \mathrm{H}), 2.07(\mathrm{~s}, 3 \mathrm{H}), 2.03(\mathrm{~s}, 6 \mathrm{H}), 1.95(\mathrm{~m}, 5 \mathrm{H}) 1.74(\mathrm{~m}, 2 \mathrm{H}), 1.60(\mathrm{~m}, 1 \mathrm{H}), 1.15-$ 1.47 (m, 5 H). ${ }^{13} \mathrm{C}$ NMR (125 MHz, CDCl $)$ ) $8: 171.0,170.6,170.1,169.3,83.6,75.6,73.7$, 68.6, 72.5, 53.8, 43.49, 34.0, 26.1, 25.9, 25.6, 23.3, 20.7 (2 C), 20.6. HRMS (ESI): $m / z$ $\mathrm{C}_{20} \mathrm{H}_{32} \mathrm{NO}_{8} \mathrm{~S}^{+}[\mathrm{M}+\mathrm{H}]^{+}$calculated 446.1843 , found 446.1846 
Cyclohexyl 2-(N-tert-butyloxycarbonylacetamido)-2-deoxy-3,4,6-tri-O-acetyl-1-thio- $\alpha$-Dglucopyranoside (24)

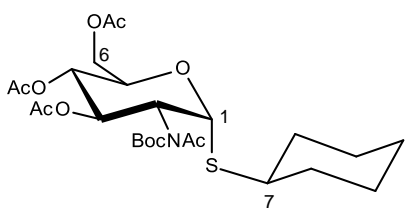

Thioglycoside 9 ( $960 \mathrm{mg}, 2.15 \mathrm{mmol}$ ), DMAP ( $25.3 \mathrm{mg}, 0.207$ $\mathrm{mmol}$ ) and di-tert-butyl dicarbonate $(2.57 \mathrm{~g}, 11.79 \mathrm{mmol})$ were dissolved in THF $(10 \mathrm{~mL})$ and stirred at reflux for $18 \mathrm{~h}$, after which time, the reaction mixture was concentrated in vacuo. The resulting oil was then purified by flash chromatography on silica (eluent: petroleum ether/ethyl acetate, $4: 1$ ) to afford the title compound as a colorless oil ( 1.18 g, 100 \%). $\mathrm{R}_{f} 0.8$ (3: $1 \mathrm{CH}_{2} \mathrm{Cl}_{2}:$ EtOAc). $[\alpha]_{D}^{26}=+106$. IR: 2958, 1742, 1691, 1450, 1368, 1221, 1148, $1040 \mathrm{~cm}^{-1} .{ }^{1} \mathrm{H}$ NMR (500 MHz, CDCl $)$ ) $: 5.93$ (app t, J = $10 \mathrm{~Hz}, 1 \mathrm{H}, \mathrm{C}-3$ ), 5.44 (d, J = $5 \mathrm{~Hz}, 1 \mathrm{H}, \mathrm{C}-1), 5.03(\mathrm{br} \mathrm{s}, 1 \mathrm{H}, \mathrm{C}-2), 4.94(\mathrm{t}, J=10 \mathrm{~Hz}, 1 \mathrm{H}, \mathrm{C}-4), 4.51$ (d, J $=10 \mathrm{~Hz}, 1$ H, C-5), 4.32 (d, J = 12.5 Hz, 1 H, C-6), 4.07 (d, J $=12.5 \mathrm{~Hz}, 1 \mathrm{H}, \mathrm{C}-6$ '), 2.72 (app t, J J $10 \mathrm{~Hz}$, $1 \mathrm{H}, \mathrm{C}-7), 2.41\left(\mathrm{~s}, 3 \mathrm{H}, \mathrm{COC} \underline{H}_{3}\right), 2.08\left(\mathrm{~s}, 3 \mathrm{H}, \mathrm{COCH}_{3}\right), 2.01\left(\mathrm{~s}, 3 \mathrm{H}, \mathrm{COCH}_{3}\right), 1.89-1.98(\mathrm{~m}, 5$ $\mathrm{H}, \mathrm{COCH}_{3}$ and cy), 1.71, (m, $\left.2 \mathrm{H}, \mathrm{cy}\right), 1.49-1.63\left(\mathrm{~m}, 10 \mathrm{H}, \mathrm{NHCOOC}\left(\mathrm{CH}_{3}\right)_{3}\right.$ and cy), 1.18-1.44

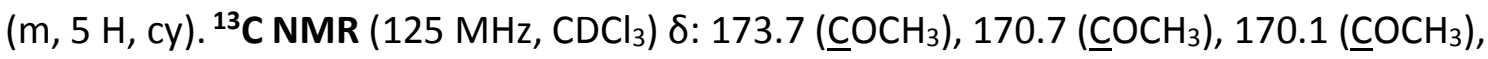
$169.5\left(\underline{\left.\mathrm{COCH}_{3}\right)}, 152.5\left(\mathrm{NHCOOC}\left(\mathrm{CH}_{3}\right)_{3}\right), 85.2\left(\mathrm{NHCOOC}_{\left.\left(\mathrm{CH}_{3}\right)_{3}\right)}\right) 82.9(\mathrm{C}-1), 70.8(\mathrm{C}-4), 70.7\right.$

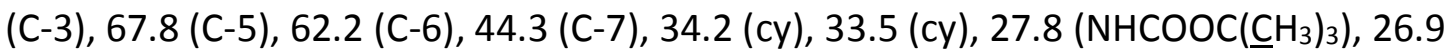

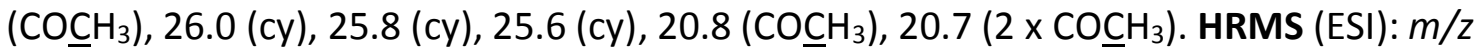
$\mathrm{C}_{25} \mathrm{H}_{40} \mathrm{NO}_{10} \mathrm{~S}^{+}[\mathrm{M}+\mathrm{H}]^{+}$calculated 546.2367 , found 546.2367 
Cyclohexyl 2-( $N$-tert-butyloxycarbonylacetamido)-2-deoxy-3,4,6-tri-O-acetyl-1-thio- $\beta$-Dglucopyranoside (25)

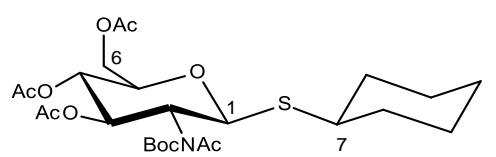

Thioglycoside 22 (360 mg, $0.81 \mathrm{mmol}$ ), DMAP (13.2 mg, $0.11 \mathrm{mmol}$ ) and di-tert-butyl dicarbonate $(955 \mathrm{mg}, 4.38$ mmol) were dissolved in THF (4 mL) and refluxed while stirring for $18 \mathrm{~h}$. The reaction mixture was subsequently concentrated in vacuo. The resulting oil was then purified by flash chromatography on silica (eluent: petroleum ether/ethyl acetate, $4: 1$ ) to afford the title compound as a yellow oil (360 mg, $82 \%$ ). $R_{f}$

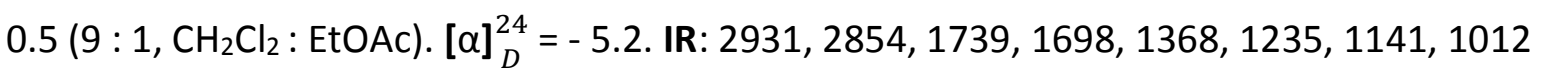
$\mathrm{cm}^{-1} .{ }^{1} \mathrm{H}$ NMR $\left(500 \mathrm{MHz}, \mathrm{CDCl}_{3}\right) \delta: 5.81(\mathrm{t}, J=10.0 \mathrm{~Hz}, 1 \mathrm{H}, \mathrm{H}-3), 5.70(\mathrm{t}, J=10.0 \mathrm{~Hz}, 1 \mathrm{H}$, $\left.\mathrm{H}^{\prime}-3\right), 5.57(\mathrm{~d}, J=10.0 \mathrm{~Hz}, 1 \mathrm{H}, \mathrm{H}-1), 5.33\left(\mathrm{~d}, J=10.0 \mathrm{~Hz}, 1 \mathrm{H}, \mathrm{H}^{\prime}-1\right), 5.07(\mathrm{t}, J=10.0 \mathrm{~Hz}, 1 \mathrm{H}$, $\left.\mathrm{H}^{\prime}-4\right), 5.01(\mathrm{t}, J=10.0 \mathrm{~Hz}, 1 \mathrm{H}, \mathrm{H}-4), 4.90\left(\mathrm{t}, J=10.0 \mathrm{~Hz}, \mathrm{H}^{\prime}-2\right), 4.22(\mathrm{~m}, 3 \mathrm{H}, \mathrm{H}-2, \mathrm{H}-6 \mathrm{a}$ and $\left.\mathrm{H}^{\prime}-6 \mathrm{a}\right), 4.09$ (t, $10.0 \mathrm{~Hz}, 2 \mathrm{H}, \mathrm{H}-6 \mathrm{~b}$ and H'-6b), 3.76 (m, $\left.1 \mathrm{H}, \mathrm{H}-5\right), 3.68\left(\mathrm{~m}, 1 \mathrm{H}, \mathrm{H}^{\prime}-5\right), 2.83$ (m, $2 \mathrm{H}, \mathrm{H}-7$ and $\left.\mathrm{H}^{\prime}-7\right), 2.41\left(\mathrm{~s}, 3 \mathrm{H}, \mathrm{COCH}_{3}\right), 2.33\left(\mathrm{~s}, 3 \mathrm{H}, \mathrm{COCH}_{3}\right), 2.06\left(\mathrm{~s}, 3 \mathrm{H}, \mathrm{COCH}_{3}\right)$, $2.05\left(\mathrm{~s}, 3 \mathrm{H}, \mathrm{COCH}_{3}\right), 2.00\left(\mathrm{~s}, 6 \mathrm{H}, 2 \times \mathrm{COC}_{3}\right), 1.87-1.97\left(\mathrm{~m}, 10 \mathrm{H}, 2 \times \mathrm{COC}_{3}\right.$ and cy), 1.71 (br s, $4 \mathrm{H}, \mathrm{cy}), 1.48-1.61\left(\mathrm{~m}, 20 \mathrm{H}, 2 \times \mathrm{NHCOOC}\left(\mathrm{CH}_{3}\right)_{3}\right.$ and cy), 1.15-1.39 $(10 \mathrm{H}, \mathrm{cy}) .{ }^{13} \mathrm{C}$ $\operatorname{NMR}\left(125 \mathrm{MHz}, \mathrm{CDCl}_{3}\right)$ 8: $173.9\left(\underline{\left.\mathrm{COCH}_{3}\right)}, 173.2\left(\mathrm{COCH}_{3}\right), 170.7\left(2 \times \underline{\mathrm{COCH}}_{3}\right), 170.3\right.$ $\left.(\underline{\mathrm{COCH}} 3), 170.0(\underline{\mathrm{COCH}} 3), 169.7(\underline{\mathrm{COCH}})_{3}\right), 169.4(\underline{\mathrm{COCH}} 3), 153.0\left(\mathrm{NH} \underline{\mathrm{COOC}}\left(\mathrm{CH}_{3}\right)_{3}\right), 151.7$ $\left(\mathrm{NH} \underline{\mathrm{COOC}}\left(\mathrm{CH}_{3}\right)_{3}\right), 84.7\left(\mathrm{NHCOO} \underline{(}\left(\mathrm{CH}_{3}\right)_{3}\right), 84.3\left(\mathrm{NHCOO}\left(\mathrm{CH}_{3}\right)_{3}\right), 82.7\left(\mathrm{C}-1^{\prime}\right), 82.0(\mathrm{C}-1), 75.7$ (C-5'), 75.4 (C-5), 71.8 (C-3'), 71.4 (C-3), 69.7 (C-4 and C-4'), 62.6 (C-6 and C-6'), 60.5 (C-2), 55.9 (C-2'), 44.1 (C-7), 43.5 (C'-7), 34.1 ( 2 x cy), 33.8 ( 2 x cy), $\left.28.1\left(\mathrm{NHCOOC}^{(} \mathrm{CH}_{3}\right)_{3}\right), 27.9$ $\left(\mathrm{NHCOOC}\left(\mathrm{CH}_{3}\right)_{3}\right), 27.5$ (cy), 26.9 ( $\left.2 \times \mathrm{COCH}_{3}\right), 26.1$ (cy), 26.0 (cy), 25.9 ( 2 x cy), 25.6 ( 2 x cy), $20.8\left(\mathrm{COC}_{3} 3\right), 20.7\left(3 \times \mathrm{COC}_{3}\right), 20.6\left(\mathrm{COC}_{3} 3\right), 20.5\left(\mathrm{COC} \underline{H}_{3}\right) . \mathrm{HRMS}(\mathrm{ESI}): \mathrm{m} / 2 \mathrm{C}_{25} \mathrm{H}_{40} \mathrm{NO}_{10} \mathrm{~S}^{+}$ $[\mathrm{M}+\mathrm{H}]^{+}$calculated 546.2367 , found 546.2367 . 


\section{Cyclohexyl 2-Amino-2-deoxy-1-thio- $\alpha$-D-glucopyranoside-HCl (26)}

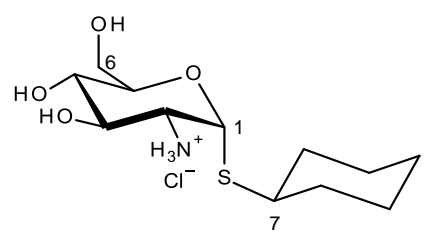

Sodium(33 mg, $1.5 \mathrm{mmol}$ ) was added to distilled methanol $(10 \mathrm{~mL})$ under the presence of a nitrogen atmosphere. Boc-

thioglycoside 24 (990 mg, $1.8 \mathrm{mmol}$ ) was subsequently added and the reaction stirred at room temperature for $2 \mathrm{hrs}$, after which time concentrated aqueous $\mathrm{HCl}(2 \mathrm{~mL})$ was added and the reaction stirred for an additional $18 \mathrm{~h}$. The compound was then concentrated in vacou to afford the title compound as a light yellow solid. This compound was characterized by ${ }^{1} \mathrm{H}$ and ${ }^{13} \mathrm{C} \mathrm{NMR}$ then a portion of it (5\%) carried through to the reaction directly below. ${ }^{1} \mathbf{H} \mathbf{~ N M R}(500 \mathrm{MHz}$, $\mathrm{D}_{2} \mathrm{O}$ ) $\delta: 5.65$ (d, $5.5 \mathrm{~Hz}, 1 \mathrm{H}, \mathrm{C}-1$ ), 4.08 (m, 1H, C-5), 3.84 (d, J=12.5 Hz, $\left.1 \mathrm{H}, \mathrm{C}-6\right), 3.79$ (dd, $\left.J=5.0,12.5 \mathrm{~Hz}, 1 \mathrm{H}, \mathrm{C}-6^{\prime}\right), 3.68$ (t, J=10.0 Hz, $1 \mathrm{H}, \mathrm{C}-3$ ), 3.55 (dd, J = 5.0, $11.0 \mathrm{~Hz}, \mathrm{C}-2$ ), 3.45 (t, J = 9.5 Hz, C-4), 2.98 (m, 1 H, C-7), 1.97 (m, 2 H, cy), 1.71 (m, 2 H, cy), 1.55 (m, 1 H, cy), 1.18-1.49 (m, $5 \mathrm{H}, \mathrm{cy}) ;{ }^{13} \mathrm{C}$ NMR (125 MHz, D $\mathrm{O}$ ) $\delta: 81.1$ (C-1), 72.7 (C-5), 70.1 (C-3), 69.8 (C-4), 60.1 (C-6), 53.7 (C-2), 45.0 (C-7), 33.7 (cy), 33.0 (cy), 25.2 (cy), 25.0 (cy). HRMS (ESI): $m / z \mathrm{C}_{12} \mathrm{H}_{24} \mathrm{NO}_{4} \mathrm{~S}^{+}[\mathrm{M}+\mathrm{H}]^{+}$calculated 278.1421, found 278.1421.

\section{Cyclohexyl 2-Amino-2-N-(N-tert-butylcarbonyl-S-trichlorovinyl -L-cysteinyl)-2-deoxy-1- thio- $\alpha$-D-glucopyranoside (11)}

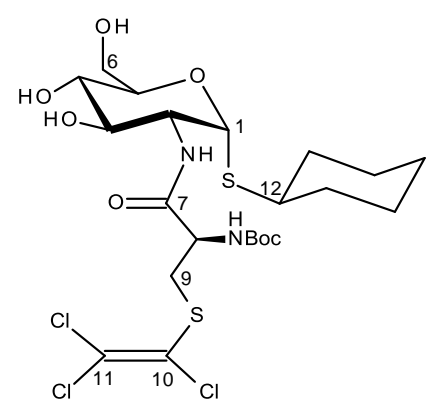

$\alpha$-thioglycoside $26\left(31 \mathrm{mg}^{a}\right)$ and potassium-tert butoxide (11 $\mathrm{mg}, 0.098 \mathrm{mmol})$ were stirred in DMF $(0.75 \mathrm{~mL})$ under a nitrogen atmosphere. This mixture was subsequently added to $\mathrm{EDCl}(37 \mathrm{mg}, 0.193 \mathrm{mmol})$ and Boc-TCVC (60 mg, 0.239 $\mathrm{mmol})$ in DMF $(0.75 \mathrm{~mL})$, which had been stirring under nitrogen at $0{ }^{\circ} \mathrm{C}$ for $10 \mathrm{~min}$ prior. The reaction was then allowed to warm up to room temperature and mixed for $2 \mathrm{~h}$, after which time the DMF was concentrated via distillation in vacuo. The reaction mixture was then passed through a silica column using a stepwise elution consisting of: petroleum ether; dichloromethane; 
diethyl ether; ethyl acetate and; dichloromethane : methanol ( $3: 2)$ as the eluents. The diethyl ether and ethyl acetate fractions were combined and concentrated in vacuu to afford a orange solid. Subsequent trituration with chloroform yielded the title compound as a white solid $\left(14.5 \mathrm{mg}, 26 \%^{b}\right) \mathrm{R}_{f} 0.51$ (ethyl acetate). M.p. $148-149^{\circ} \mathrm{C} .[\alpha]_{D}^{27}=+55$. IR: 3316, 2929, 2855, 1691, 1649, 1546, 1523, $1278 \mathrm{~cm}^{-1}$. ${ }^{1} \mathrm{H}$ NMR (500 MHz, CD ${ }_{3}$ OD) $\delta: 5.53$ (d, J = 5.0 Hz, $1 \mathrm{H}, \mathrm{H}-1), 4.30(\mathrm{~m}, 1 \mathrm{H}, \mathrm{H}-8), 3.96(\mathrm{~m}, 2 \mathrm{H}, \mathrm{H}-2$ and $\mathrm{H}-5), 3.79$ (d, J = $12.0 \mathrm{~Hz}$, $1 \mathrm{H}, \mathrm{H}-6), 3.72$ (dd, J = 5.0, $\left.12.0 \mathrm{~Hz}, 1 \mathrm{H}, \mathrm{H}-6^{\prime}\right), 3.51$ (t, J = 9.5 Hz, $1 \mathrm{H}, \mathrm{H}-3$ ), 3.44 (dd, J = 5.0, 14.0 Hz, $1 \mathrm{H}, \mathrm{H}-9), 3.35$ (t, J = 9.5 Hz, $1 \mathrm{H}, \mathrm{H}-4), 3.14$ (dd, J = 9.5, $14 \mathrm{~Hz}, 1 \mathrm{H}, \mathrm{H}-9$ '), 2.81 (m, $1 \mathrm{H}, \mathrm{H}-12), 1.98$ (m, $2 \mathrm{H}, \mathrm{cy}), 1.74$ (m, $2 \mathrm{H}, \mathrm{cy}), 1.59$ (m, $1 \mathrm{H}, \mathrm{cy}), 1.47$ (m, $9 \mathrm{H}$, $\left.\operatorname{NHCOOC}\left(\underline{\mathrm{C}}_{3}\right)_{3}\right), 1.21-1.43$ (m, $\left.5 \mathrm{H}, \mathrm{cy}\right) .{ }^{13} \mathrm{C}$ NMR (125 MHz, CD $\left.{ }_{3} \mathrm{OD}\right) \delta: 171.15$ (C-7), 156.15 ( $\left.\mathrm{NH} \underline{\mathrm{COOOC}}\left(\mathrm{CH}_{3}\right)_{3}\right), 127.07$ (C-11 or C-12), 121.07 (C-11 or C-12), 82.70 (C-1), 79.63 $\left(\mathrm{NHCOOC}\left(\mathrm{CH}_{3}\right)_{3}\right), 73.13$ (C-5), 71.59 (C-3), 71.02 (C-4), 61.11 (C-6), 54.55 (C-2), 54.05 (C-8),

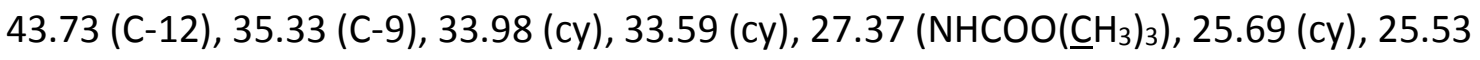
(cy), 25.47 (cy). HRMS (ESI): $\mathrm{C}_{22} \mathrm{H}_{36} \mathrm{Cl}_{3} \mathrm{~N}_{2} \mathrm{O}_{7} \mathrm{~S}_{2}^{+}[\mathrm{M}+\mathrm{H}]^{+}$calculated 609.1024 found 609.1036

${ }^{a} 5 \%$, by weight, of compound $\mathbf{2 6}$ synthesized above. ${ }^{b}$ Calculated over two steps starting from 24

\section{Cyclohexyl 2-Amino-2-deoxy-1-thio- $\beta$-D-glucopyranoside- $\mathrm{HCl}(27)$}

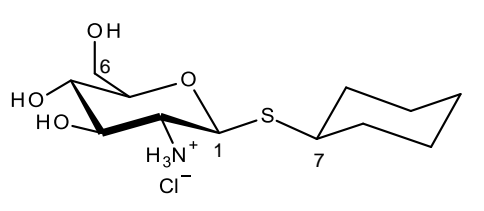

Sodium (12 mg, $0.55 \mathrm{mmol}$ ) was added to distilled methanol $(1.6 \mathrm{~mL})$ under the presence of a nitrogen atmosphere. Boc-thioglycoside 25 (342 $\mathrm{mg}, 0.63 \mathrm{mmol}$ ) was subsequently added and the reaction stirred at room temperature for $2 \mathrm{~h}$, after which time concentrated aqueous $\mathrm{HCl}(0.8 \mathrm{~mL})$ was added and the reaction stirred for an additional $18 \mathrm{~h}$. The compound was then concentrated in vacuo to afford the title compound as a light yellow solid. This compound was characterized by ${ }^{1} \mathrm{H}$ and ${ }^{13} \mathrm{C}$ NMR then a portion of it (32\%) carried through to the reaction directly below. ${ }^{1}$ H NMR (500 MHz, D ${ }_{2}$ ) $\delta: 4.90$ (d, J = $10.5 \mathrm{~Hz}, 1 \mathrm{H}, \mathrm{H}-1$ ), 3.90 (d, J = $\left.12.0 \mathrm{~Hz}, 1 \mathrm{H}, \mathrm{C}-6\right)$, 
$3.73\left(\mathrm{br} \mathrm{d}, J=11.0 \mathrm{~Hz}, 1 \mathrm{H}, \mathrm{C}-\mathrm{C}^{\prime}\right), 3.68(\mathrm{t}, J=9.0 \mathrm{~Hz}, 1 \mathrm{H}, \mathrm{C}-3), 3.51(\mathrm{~m}, 2 \mathrm{H}, \mathrm{C}-4$ and C-5), 3.14 (t, J=11.0 Hz, 1 H, C-2), 3.08 (m, 1 H, C-7), 1.99 (br s, 2 H), 1.74 (m, 2 H), 1.59 (m, 1 H), 1.19-1.51 (m, 5 H). ${ }^{13} \mathrm{C}$ NMR (125 MHz, D O) 8: 80.8 (C-1), 79.9 (C-5), 73.5 (C-3), 69.5, 60.5 (C-4), 55.1 (C-2), 44.6 (C-7), 33.7 (cy), 33.4 (cy), 25.5 (cy), 25.4 (cy), 24.9 (cy). HRMS (ESI): $m / z \mathrm{C}_{12} \mathrm{H}_{24} \mathrm{NO}_{4} \mathrm{~S}^{+}[\mathrm{M}+\mathrm{H}]^{+}$calculated 278.1421, found 278.1420.

Cyclohexyl 2-Amino-2-N-(N-tert-butylcarbonyl-S-trichlorovinyl -L-cysteinyl)-2-deoxy-1thio- $\beta$-D-glucopyranoside (28)

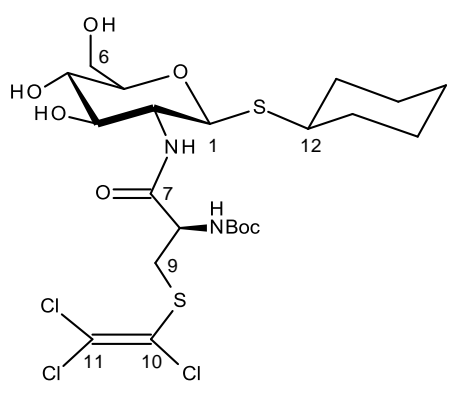

$\beta$-thioglycoside $27\left(67 \mathrm{mg}^{a}\right)$ of and potassium-tert butoxide (25 mg, $0.22 \mathrm{mmol})$ were stirred in DMF $(2 \mathrm{~mL})$ under a nitrogen atomoshpere. This mixture was subsequently added to $\mathrm{EDCl}(84 \mathrm{mg}, 0.54 \mathrm{mmol})$ and Boc-TCVC (119 mg, $0.33 \mathrm{mmol})$ in DMF (2 mL), which had been stirring under nitrogen at $0^{\circ} \mathrm{C}$ for $10 \mathrm{~min}$ prior. The reaction was then allowed to warm up to room temperature and mixed for $2 \mathrm{~h}$, after which time the DMF was concentrated via distillation in vacuo. The reaction mixture was then passed through a silica column using a stepwise elution consisting of: petroleum ether; dichloromethane; diethyl ether; ethyl acetate; and dichloromethane : methanol ( $3: 2)$ as the eluents. The diethyl ether and ethyl acetate fractions were combined and concentrated in vacuo to afford an orange solid. Subsequent trituration with chloroform yielded the title compound


$=-2.89$. IR: $3316,2930,2854,1690,1654,1541,1529,1205,1141 \mathrm{~cm}^{-1} .{ }^{1} \mathbf{H}$ NMR $(500$ $\mathrm{MHz}, \mathrm{CD}_{3} \mathrm{OD}$ ) $\delta: 4.73$ (d, J=10 Hz, $\left.1 \mathrm{H}, \mathrm{H}-1\right), 4.27$ (dd, J = 4.5, 8.5 Hz, $\left.1 \mathrm{H}, \mathrm{H}-8\right), 3.85$ (d, J = $12 \mathrm{~Hz}, 1 \mathrm{H}, \mathrm{H}-6), 3.67(\mathrm{dd}, J=7.0,12.0 \mathrm{~Hz}, 1 \mathrm{H}, \mathrm{H}-6$ '), $3.56(\mathrm{~m}, 2 \mathrm{H}, \mathrm{H}-2$ and H-3), 3.48 (dd, 4.5, $14 \mathrm{~Hz}, \mathrm{H}-9), 3.25-3.37$ (m, $2 \mathrm{H}, \mathrm{H}-4$ and H-5), 3.13 (dd, 8.5, $14 \mathrm{~Hz}, \mathrm{H}-9$ '), 2.93 (m, $1 \mathrm{H}$, H-12), 2.00 (m, $1 \mathrm{H}, \mathrm{cy}), 1.93$ (m, 1H, cy), 1.73 (m, $2 \mathrm{H}, \mathrm{cy}), 1.59$ (m, $1 \mathrm{H}, \mathrm{cy}), 1.45$ (s, $9 \mathrm{H}$,

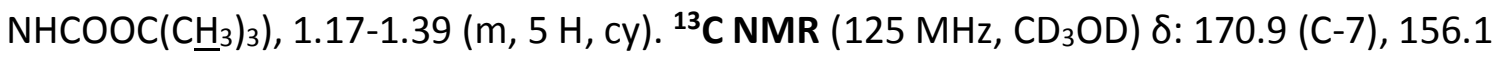
$\left(\mathrm{NH} \underline{\mathrm{COOC}}\left(\mathrm{CH}_{3}\right)_{3}\right), 127.2$ (C-10 or C-11), 120.9 (C-10 or C-11), 83.0 (C-1), 80.4 
$\left(\mathrm{NHCOOC}_{(}\left(\mathrm{CH}_{3}\right)_{3}\right), 79.9$ (C-5), 75.25 (C-3), 70.62 (C-3), 61.62 (C-6), 55.78 (C-2), 54.33 (C-8), 42.88 (C-12), 35.93 (C-9), 33.96 (cy), 33.77 (cy), $27.67\left(\mathrm{NHCOOC}\left(\mathrm{CH}_{3}\right)_{3}\right), 25.81$ (cy), 25.63 (cy), 25.53 (cy). HRMS (ESI): $m / z \mathrm{C}_{22} \mathrm{H}_{36} \mathrm{Cl}_{3} \mathrm{~N}_{2} \mathrm{O}_{7} \mathrm{~S}_{2}^{+}[\mathrm{M}+\mathrm{H}]^{+}$calculated 609.1024 found 609.1032.

${ }^{a} 32 \%$, by weight, of compound $\mathbf{2 7}$ that synthesized above). ${ }^{b}$ Calculated over two steps starting from 25

Cyclohexyl 2-Amino-2-N-(S-trichlorovinyl -L-cysteinyl)-2-deoxy-1-thio- $\alpha-D-$ glucopyranoside·Trifluoroacetic acid (13)

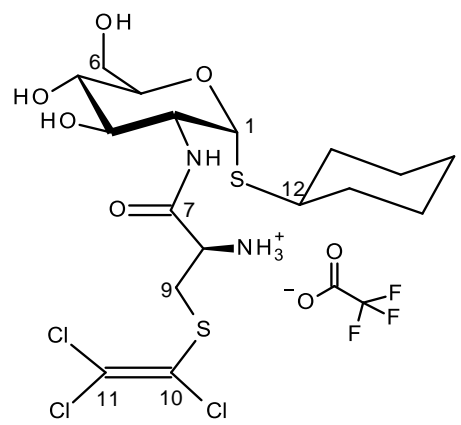

Anhydrous TFA ( $1 \mathrm{~mL}$ ) was cooled to $0{ }^{\circ} \mathrm{C}$ and added to $\beta-\mathrm{N}$ Boc-TCVC thoglycoside 28 (9.5 $\mathrm{mg}, 0.014 \mathrm{mmol})$. The reaction was stirred at $0{ }^{\circ} \mathrm{C}$ for $5 \mathrm{~min}$, after which time the reaction was warmed up to room temperature over a 20 min period. The reaction was then concentrated to afford an orange oil. The compound was then triturated with chloroform to afford the title compound an orange oil (3 mg, 35\%) $R_{f} 0.52$ (19 : 1, EtOAc : Methanol). $[\alpha]_{D}^{26}=+77$. IR: 3350, 2999, 2845, 1672, 1563, 1448, 1201, $1092 \mathrm{~cm}^{-1} .{ }^{1} \mathbf{H}$ NMR (500 MHz, CD $\left.{ }_{3} \mathrm{OD}\right)$ 8: 5.56 (d, J = 5.0 Hz, 1H, C-1), 3.95-4.11 (m, $3 \mathrm{H}, \mathrm{H}-2, \mathrm{H}-5$ and H-8), $3.80(\mathrm{dd}, J=2.4,12.5 \mathrm{~Hz}, 1 \mathrm{H}, \mathrm{H}-6), 3.73\left(\mathrm{dd}, J=6.5,12 \mathrm{~Hz}, 1 \mathrm{H}, \mathrm{H} 6^{\prime}\right), 3.59\left(\mathrm{~m}, 2 \mathrm{H}, \mathrm{H} 9^{\prime}\right.$ and H-3), 3.36 (t, J = $10 \mathrm{~Hz}, 1 \mathrm{H}, \mathrm{H}-4$ ), 3.32 (obs m, $1 \mathrm{H}, \mathrm{H}-9$ '), 2.84, (m, $1 \mathrm{H}), 1.99$ (m, $2 \mathrm{H}$ ), 1.74 (m, $2 \mathrm{H}), 1.60(\mathrm{~m}, 1 \mathrm{H}), 1.22-1.44(\mathrm{~m}, 5 \mathrm{H}) .{ }^{13} \mathrm{C}$ NMR (125 MHz, CD $\mathrm{CD}_{3}$ ) $\delta: 166.6$ (C-7), 125.3 (C-10 or C-11), 123.2 (C-10 or C-11), 82.5 (C-1), 72.9 (C-5), 71.3 (C-3 and C-4), 61.0 (C-6), 54.8 (C-2), 52.2 (C-8), 43.5 (C-12), 35.2 (су), 34.0 (су), 33.4 (су), 25.7 (сy), 25.6 (сy), 25.5 (cy). HRMS (ESI): $m / z \mathrm{C}_{17} \mathrm{H}_{28} \mathrm{Cl}_{3} \mathrm{~N}_{2} \mathrm{O}_{5} \mathrm{~S}_{2}^{+}[\mathrm{M}+\mathrm{H}]^{+}$calculated 509.0500 found 509.0495. 


\section{Cyclohexyl 2-Amino-2-N-(S-trichlorovinyl -L-cysteinyl)-2-deoxy-1-thio- $\beta$-D-}

glucopyranoside-Trifluoroacetic acid (29)

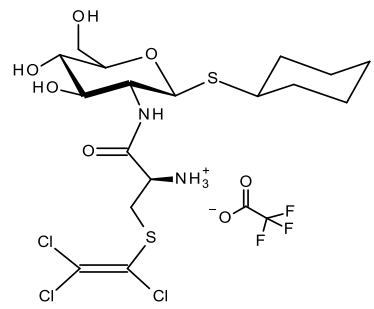

Anhydrous TFA ( $2 \mathrm{~mL}$ ) was cooled to $0{ }^{\circ} \mathrm{C}$ and added to $\beta-\mathrm{N}-\mathrm{Boc}-$ TVCV thioglycoside $28(20.4 \mathrm{mg}, 0.033 \mathrm{mmol})$. The reaction was stirred at $0{ }^{\circ} \mathrm{C}$ for $5 \mathrm{~min}$, after which time the reaction was warmed up to room temperature over a 20 min period. The reaction was then concentrated to afford the title compound as an orange oil $(21 \mathrm{mg}$, 100\%) ${ }^{1} \mathrm{H}$ NMR (500 MHz, CD ${ }_{3} \mathrm{OD}$ ) $\delta: 4.82$ (obs d, $\left.J=11.5 \mathrm{~Hz}, 1-\mathrm{H}\right), 4.03(\mathrm{~m}, 1 \mathrm{H}), 3.86$ (d, $J=12 \mathrm{~Hz}, 1 \mathrm{H}$ ), 3.58-3.71 (m, $3 \mathrm{H}$ ), 3.54 (t, J = $10 \mathrm{~Hz}, 1 \mathrm{H}$ ), 3.25-3.38 (obs, 3H), 3.00 (br s, 1 $\mathrm{H}), 2.00(\mathrm{~m}, 2 \mathrm{H}), 1.20-1.74$ (obs by degradation product, $8 \mathrm{H}) .{ }^{13} \mathrm{C}$ NMR $\left(125 \mathrm{~Hz}, \mathrm{CD}_{3} \mathrm{OD}\right)$

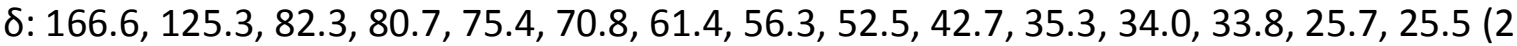
C). HRMS (ESI): $m / z \mathrm{C}_{17} \mathrm{H}_{28} \mathrm{Cl}_{3} \mathrm{~N}_{2} \mathrm{O}_{5} \mathrm{~S}_{2}^{+}[\mathrm{M}+\mathrm{H}]^{+}$calculated 509.0500 found 509.0508 .

\section{N-Boc-L-Cystine (15)}

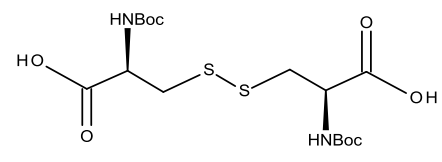

L-cystine $(2.12 \mathrm{~g}, 8.88 \mathrm{mmol})$ was dissolved sodium hydroxide (0.5 M, $25 \mathrm{~mL}$ ). Subsequently, di-tert-butyl dicarbonate (4.30 $\mathrm{g}, 19.7 \mathrm{mmol})$ in THF $(7.6 \mathrm{~mL})$ was added slowly over a period of $30 \mathrm{~min}$. The reaction was then stirred for $18 \mathrm{hr}$, after which time, ethyl acetate ( $40 \mathrm{~mL}$ ) was added and the reaction cooled in an ice-salt bath to $0^{\circ} \mathrm{C}$. The $\mathrm{pH}$ was then dropped to approximately 2 using $\mathrm{HCl}(1 \mathrm{M})$ and the organic layer seperated. The organic layer was subsequently washed with saturated brine, dried over Anhydrous MgSO and concentrated to afford the title compound as a white solid (3.51 g, 93\%) $\mathrm{R}_{f} 0.68$ (3:1 $\mathrm{CH}_{2} \mathrm{Cl}_{2}$ : EtOAc). ${ }^{1} \mathrm{H}$ NMR $\left(500 \mathrm{MHz}, \mathrm{CDCl}_{3}\right) \delta: 5.56(\mathrm{~d}, J=8.5 \mathrm{~Hz}, 1 \mathrm{H}), 4.77(\mathrm{br} \mathrm{s}, 1 \mathrm{H}), 3.31(\mathrm{~d}, J=10 \mathrm{~Hz}, 1$ H), $3.20(\mathrm{~d}, J=10 \mathrm{~Hz}, 1 \mathrm{H})$. 


\section{N-Boc-L-Cysteine (2)}

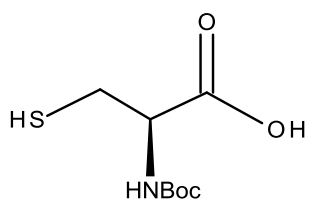

Method 1: N-Boc-cystine ( $270 \mathrm{mg}, 0.62 \mathrm{mmol}$ ) was dissolved in $5 \%$ glacial acetic acid in THF $(10 \mathrm{~mL})$ at $0^{\circ} \mathrm{C}$, Zinc dust $(2.27 \mathrm{~g})$ was added slowly over a period of $20 \mathrm{~min}$. The reaction was then allowed to warm to room temperature over a $1 \mathrm{~h}$ period and left

stirring for an additional $3 \mathrm{~h}$. The reaction was then filtered through celite and washed with glacial acetic acid. The filtrate was subsequently concentrated in vacuo and the resulting residue taken up in $1 \mathrm{M} \mathrm{HCl}(8 \mathrm{~mL})$ the aqueous phase was extracted with ethylacetate $(8 \mathrm{~mL})$, washed with saturated brine and dried over Anhydrous MgSO. The organic was then concentrated in vacuo to produce the title compound as a colourless oil (131 mg, 97\%)

Method 2: L-Cysteine hydrochloride monohydrate $(2.09 \mathrm{~g}, 11.9 \mathrm{mmol})$, sodium bicarbonate (1.96 g, $23.3 \mathrm{mmol}$ ) and di-tert-butyl dicarbonate (654 mg, $3.0 \mathrm{mmol})$ were placed in a round bottom flask under a nitrogen atmosphere. In two additional, separate, round bottom flasks, water $(50 \mathrm{~mL})$ and THF $(10 \mathrm{~mL})$ were bubbled through with nitrogen for $30 \mathrm{~min}$ each. Aliquots of $43 \mathrm{~mL}$ and $3 \mathrm{~mL}$ of water and THF respectively, were added to the flask containing the L-cysteine hydrochloride monohydrate, sodium bicarbonate)and di-tert-butyl dicarbonate and the reaction stirred at room temperature for $18 \mathrm{~h}$. Ethyl acetate $\left(50 \mathrm{~mL}\right.$ ) was then added and the reaction acidified to $\mathrm{pH} 3$ using $\mathrm{H}_{2} \mathrm{SO}_{4}(1 \mathrm{M})$. The organic layer was then washed with saturated brine, dried over Anhydrous MgSO and concentrated to afford the title compound as a colorless oil (440 mg, 66\%) $\mathrm{R}_{f} 0.68$ (3: 1 $\mathrm{CH}_{2} \mathrm{Cl}_{2}$ : EtOAc) ${ }^{1} \mathrm{H}$ NMR (500 MHz, CDCl3) $\delta: 5.47$ ( app d, J = $6.5 \mathrm{~Hz}, 1 \mathrm{H}$ ), $4.65($ br s, $1 \mathrm{H}$ ), 2.95-3.10 (m, $2 \mathrm{H})$. 


\section{N-Boc-S-triclorovinyl Cysteine (3)}<smiles>NC(CSC(Cl)=C(Cl)Cl)C(=O)O</smiles>

$N$-Boc-L-cysteine 2 (440 mg, $1.25 \mathrm{mmol}$ ) was dissolved in tetrachloroethylene $(10 \mathrm{~mL}, 97.6 \mathrm{mmol})$ and acetonitrile

(6.4 $\mathrm{mL})$. The reaction mixture was then stirred under a

nitrogen atmosphere for $45 \mathrm{~min}$, after which time DBN $(0.64 \mathrm{~mL}, 5.18 \mathrm{mmol})$ was added dropwise and the reaction allowed to stir for an additional $30 \mathrm{~min}$. Dichloromethane (50 $\mathrm{mL})$ and water $(20 \mathrm{~mL})$ was then added and the reaction mixture acidified to approximately $\mathrm{pH} 2$ using $\mathrm{H}_{2} \mathrm{SO}_{4}(1 \mathrm{M})$. The organic layer was then extracted, washed with brine, dried over Anhydrous MgSO and concentrated in vacuo to afford the title compound as a colourless oil (480 mg, 69\%). ${ }^{1} \mathbf{H}$ NMR (500 MHz, CDCl3) $\delta: 5.35$ (d, $J=7$ Hz), 4.66 (d, J=6 Hz), 3.56 (dd, $J=3.5,14.5 \mathrm{~Hz}), 3.36$ (dd, J = 4.5 Hz, $14.5 \mathrm{~Hz}), 1.46$ (s, $9 \mathrm{H})$. ${ }^{13} \mathrm{C}$ NMR $\left(125 \mathrm{MHz}, \mathrm{CDCl}_{3}\right) \delta: 174.35,155.03,126.76,122.49,80.92,53.62,35.80,28.28$

\subsection{Experimental Details for Macromodel Calculations}

Lowest energy conformers of the compounds studied were obtained by molecular mechanics and methodology. Each structure was subjected to exhaustive conformational searching using the mixed torsional/low mode sampling routine as implemented in MacroModel version 9.7 (Mohamadi, 1990) ${ }^{101}$ and visualised in Maestro 9.0. The simulation was continued until the five lowest energy structures reported had been replicated at least 25 times. Structures obtained were minimized using the OPLS_2005 forcefield using the chloroform model (Still, 1990) and the Polak-Ribiere conjugate gradient (PRCG) conjugate gradients method and terminated on a gradient threshold of $0.01 \mathrm{~kJ} \mathrm{~mol}^{-1} \AA^{-1}$. 


\subsection{Experimental Detail for MTT Cell Proliferation Assay}

MTT (3-(4,5-dimethylthiazol-2-yl)-2,5 diphenyltetrazolium) and the solubilizer were prepared according to Berridge et al. (1996). An HL60 cell suspension ( 1 x $10^{6}$ cells $/ \mathrm{mL}$ ) was added to 2-fold dilutions of the compounds in RPMI 1640 in sterile 96-well plates, giving final concentrations ranging from 250 to $1.2 \mu \mathrm{M}$. The volume was brought up to 100 $\mu \mathrm{L}$ with RPMI 1640. Cells were incubated for either for $24 \mathrm{~h}$ at $37^{\circ} \mathrm{C}$. After the incubation, MTT (20 $\mu \mathrm{l}$ per well) was added and allowed to react for $2 \mathrm{~h}$ at $37^{\circ} \mathrm{C}$, solubilizer $(200 \mu \mathrm{l}$ per well) was added and the plates incubated overnight at $37^{\circ} \mathrm{C}$. The absorbance was read in a microplate reader at $570 \mathrm{~nm}^{102}$. 


\section{Appendix}

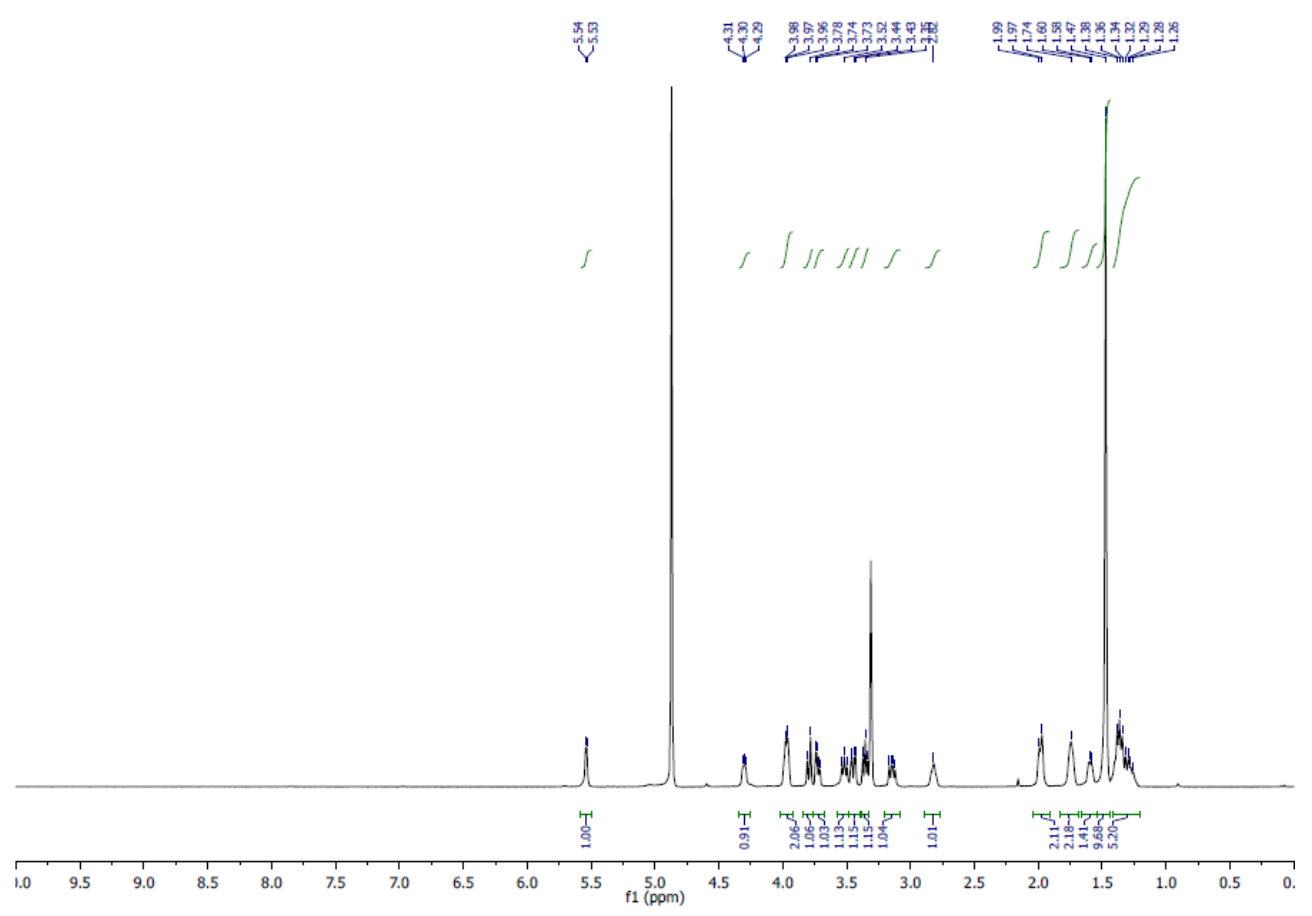

$\begin{array}{llll}2 & 0 \\ 1 & 1 & 1\end{array}$
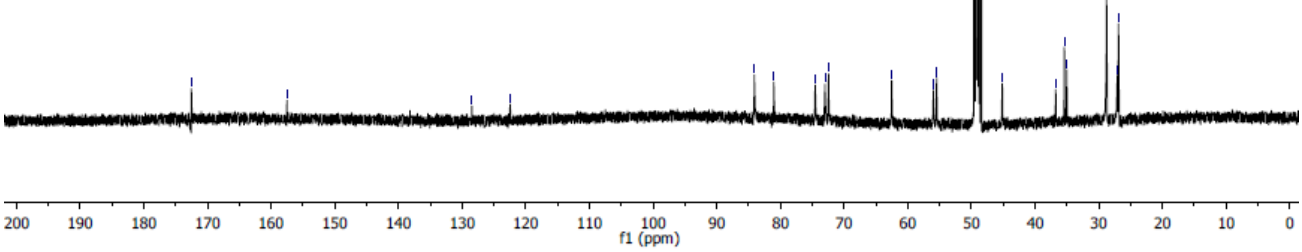

${ }^{1} \mathrm{H}$ NMR and ${ }^{13} \mathrm{C}$ NMR spectrum of $\mathbf{1 1}$ 




$\begin{array}{llllllllllllllllllllllll}230 & 220 & 210 & 200 & 190 & 180 & 170 & 160 & 150 & 140 & 130 & 120 & 110 & 100 & 90 & 80 & 70 & 60 & 50 & 40 & 30 & 20 & 10 & \mathrm{c}\end{array}$

${ }^{1} \mathrm{H}$ NMR and ${ }^{13} \mathrm{C}$ NMR spectrum of $\mathbf{2 7}$ 

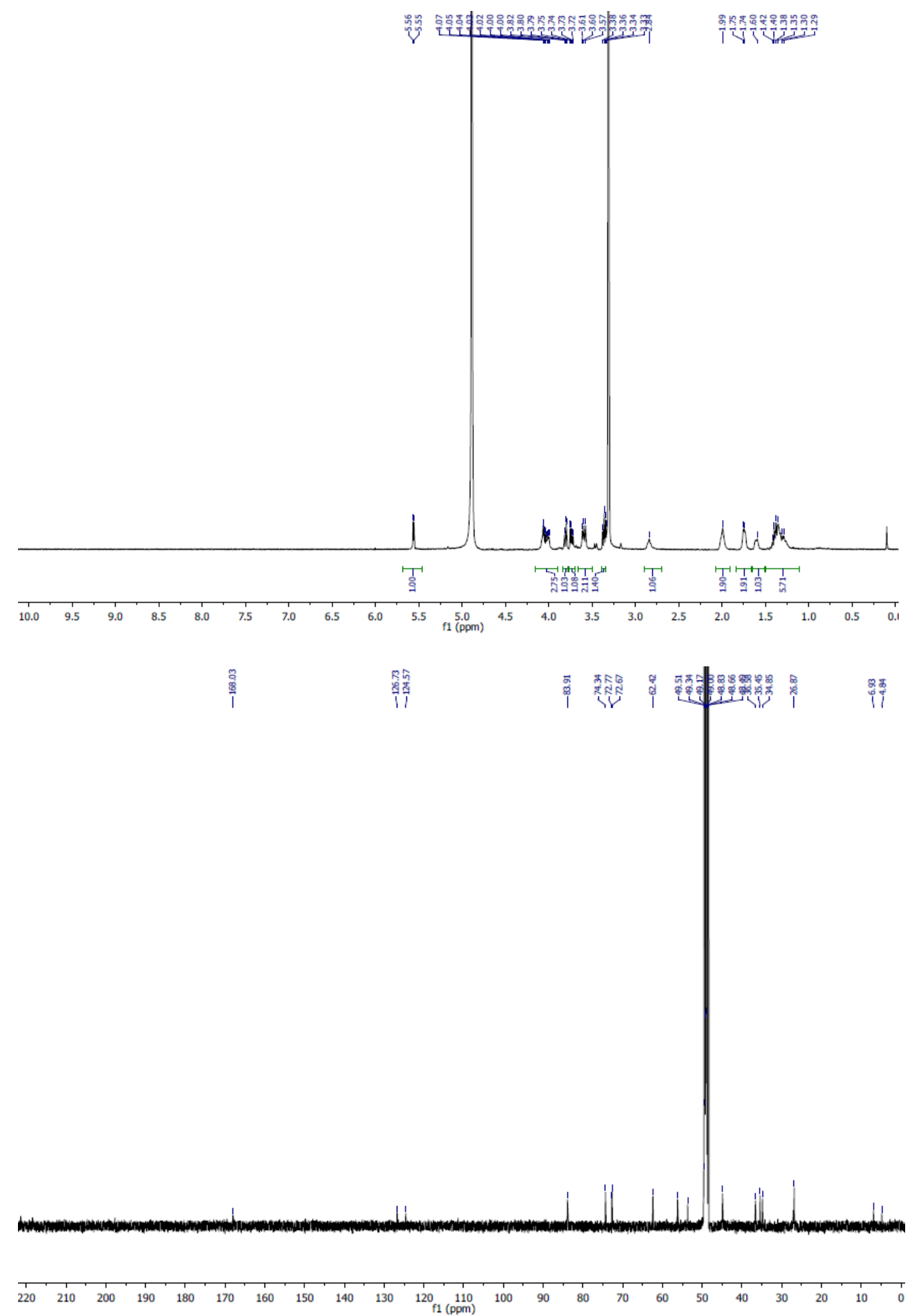

${ }^{1} \mathrm{H}$ NMR and ${ }^{13} \mathrm{C}$ NMR spectrum of 13 

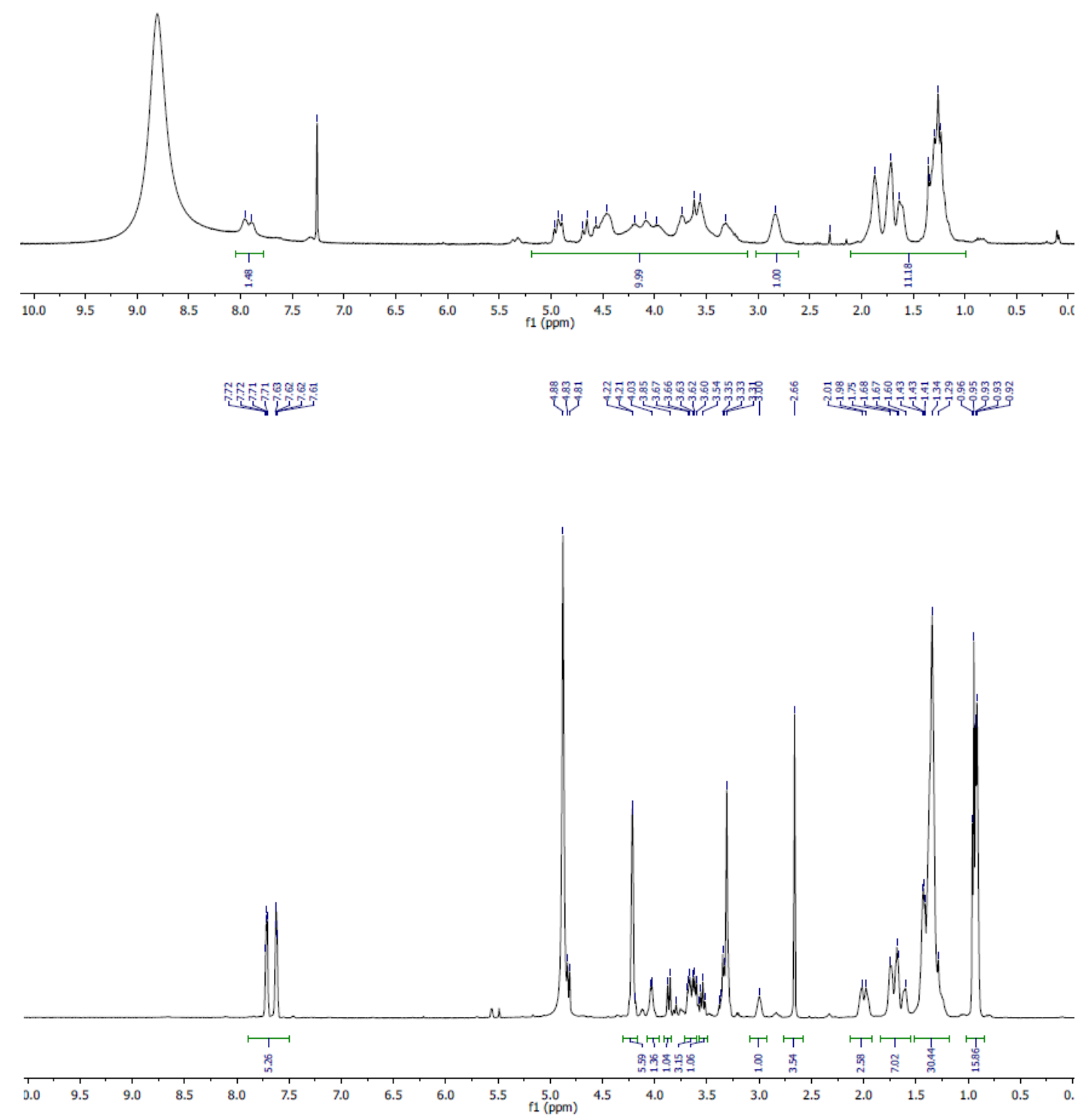

${ }^{1} \mathrm{H}$ NMR (CDCl 3 /TFA)(Top) and ${ }^{1} \mathrm{H}$ NMR (MeOD)(Bottom) spectrum of 28 


\section{References}

1. Huebner, R. E.; Castro, K. G. The changing face of tuberculosis. Annu. Rev. Med. 1995, 46, 47-55.

2. Frieden, T. R.; Sterling, T. R.; Munsiff, S. S.; Watt, C. J.; Dye, C. Tuberculosis. Lancet 2003, 362, 887-899.

3. Parrish, N. M.; Dick, J. D.; Bishai, W. R. Mechanisms of latency in Mycobacterium tuberculosis. Trends Microbiol. 1998, 6, 107-112.

4. Tufariello, J. M.; Chan, J.; Flynn, J. L. Latent tuberculosis: mechanisms of host and bacillus that contribute to persistent infection. Lancet Infect. Dis. 2003, 3, 578-590.

5. Brennan, M. J.; Stone, M. R.; Evans, T. A rational vaccine pipeline for tuberculosis. Int. J. Tuberc. Lung Dis. 2012, 16, 1566-1573.

6. Rowland, R.; McShane, H. Tuberculosis vaccines in clinical trials. Expert Rev. Vaccines 2011, 10, 645-658.

7. Andersen, P.; Doherty, T. M. The success and failure of BCG - implications for a novel tuberculosis vaccine. Nat. Rev. Microbiol. 2005, 3, 656-662.

8. Kaufmann, S. H. E.; Gengenbacher, M. Recombinant live vaccine candidates against tuberculosis. Curr. Opin. Biotechnol. 2012, 23, 900-907.

9. Janssen, S.; Jayachandran, R.; Khathi, L.; Zinsstag, J.; Grobusch, M. P.; Pieters, J. Exploring prospects of novel drugs for tuberculosis. Drug. Des. Devel. Ther. 2012, 6, 217-224.

10. Dover, L. G.; Coxon, G. D. Current status and research strategies in tuberculosis drug development. J. Med. Chem. 2011, 54, 6157-6165.

11. Gandhi, N. R.; Nunn, P.; Dheda, K.; Schaaf, H. S.; Zignol, M.; van Soolingen, D.; Jensen, P.; Bayona, J. Multidrug-resistant and extensively drug-resistant tuberculosis: a threat to global control of tuberculosis. Lancet 2010, 375, 1830-1843.

12. Villemagne, B.; Crauste, C.; Flipo, M.; Baulard, A. R.; Deprez, B.; Willand, N. Tuberculosis: The drug development pipeline at a glance. Eur. J. Med. Chem.2012, 51, 1-16.

13. Ajayi, K.; Thakur, V. V.; Lapo, R. C.; Knapp, S. Intramolecular alpha-glucosaminidation: synthesis of mycothiol. Org.Lett. 2010, 12, 2630-2633.

14. Garcia, A.; Bocanegra-Garcia, V.; Palma-Nicolas, J. P.; Rivera, G. Recent advances in antitubercular natural products. Eur. J. Med. Chem.2012, 49, 1-23. 
15. Cole, S. T.; Riccardi, G. New tuberculosis drugs on the horizon. Curr. Opin. Microbiol.2011, $14,570-576$.

16. Metaferia, B. B.; Ray, S.; Smith, J. A.; Bewley, C. A. Design and synthesis of substrate-mimic inhibitors of mycothiol-S-conjugate amidase from Mycobacterium tuberculosis. Bioorg. Med.

Chem. Lett. 2007, 17, 444-447.

17. Slattegard, R.; Gammon, D. W.; Oscarson, S. Synthesis of fused bicyclic thioglycosides of Nacylated glucosamine as analogues of mycothiol. Carbohydr. Res. 2007, 342, 1943-1946.

18. Knapp, S.; Gonzalez, S.; Myers, D. S.; Eckman, L. L.; Bewley, C. A. Shortcut to mycothiol analogues. Org.Lett. 2002, 4, 4337-4339.

19. Newton, G. L.; Fahey, R. C.; Cohen, G.; Aharonowitz, Y. Low-molecular-weight thiols in Streptomycetes and their potential role as antioxidants. J. Bacteriol. 1993, 175, 2734-2742.

20. Newton, G. L.; Av-Gay, Y.; Fahey, R. C. A novel mycothiol-dependent detoxification pathway in mycobacteria involving mycothiol S-conjugate amidase. Biochemistry 2000, 39, 1073910746.

21. Jothivasan, V. K.; Hamilton, C. J. Mycothiol: synthesis, biosynthesis and biological functions of the major low molecular weight thiol in actinomycetes. Nat. Prod. Rep. 2008, 25, 1091-1117.

22. Buchmeier, N.; Fahey, R. C. The mshA gene encoding the glycosyltransferase of mycothiol biosynthesis is essential in Mycobacterium tuberculosis Erdman. FEMS Microbiol. Lett. 2006, 264, 74-79.

23. Newton, G. L.; Ta, P. L.; Sareen, D.; Fahey, R. C. A coupled spectrophotometric assay for Lcysteine: 1-D-myo-inosityl 2-amino-2-deoxy-alpha-D-glucopyranoside ligase and its application for inhibitor screening. Anal. Biochem. 2006, 353, 167-173.

24. Hayward, D.; Wiid, I.; van Helden, P. Differential expression of mycothiol pathway genes: Are they affected by antituberculosis drugs? IUBMB Life 2004, 56, 131-138.

25. Kohanski, M. A.; Dwyer, D. J.; Hayete, B.; Lawrence, C. A.; Collins, J. J. A common mechanism of cellular death induced by bactericidal antibiotics. Cell 2007, 130, 797-810.

26. Steffek, M.; Newton, G. L.; Av-Gay, Y.; Fahey, R. C. Characterization of Mycobacterium tuberculosis mycothiol S-conjugate amidase. Biochemistry 2003, 42, 12067-12076.

27. Nicholas, G. M.; Eckman, L. L.; Newton, G. L.; Fahey, R. C.; Ray, S.; Bewley, C. A. Inhibition and kinetics of Mycobacterium tuberculosis and Mycobacterium smegmatis mycothiol-Sconjugate amidase by natural product inhibitors. Bioorg. Med. Chem. 2003, 11, 601-608.

28. Lock, E. A.; Reed, C. J. Trichloroethylene: Mechanisms of renal toxicity and renal cancer and relevance to risk assessment. Toxicol. Sci. 2006, 91, 313-331. 
29. McKinney, L. L.; Weakley, F. B.; Campbell, R. E.; Eldridge, A. C.; Cowan, J. C.; Picken, J. C.; Jacobson, N. L. Toxic protein from trichloroethylene-extracted soybean oil meal. J. Am. Oil Chem. Soc. 1957, 34, 461-466.

30. McKinney, L. L.; Picken, J. C.; Weakley, F. B.; Eldridge, A. C.; Campbell, R. E.; Cowan, J. C.; Biester, H. E. Possible toxic factor of trichloroethylene-extracted soybean oil meal. J. Am. Chem. Soc. 1959, 81, 909-915.

31. Bruning, T.; Bolt, H. M. Renal toxicity and carcinogenicity of trichloroethylene: Key results, mechanisms, and controversies. Crit. Rev. Toxicol. 2000, 30, 253-285.

32. Wartenberg, D.; Reyner, D.; Scott, C. S. Trichloroethylene and cancer: Epidemiologic evidence. Environ. Health Persp. 2000, 108, 161-176.

33. Lash, L. H.; Fisher, J. W.; Lipscomb, J. C.; Parker, J. C. Metabolism of trichloroethylene. Environ. Health Persp. 2000, 108, 177-200.

34. Goeptar, A. R.; Commandeur, J. N. M.; Vanommen, B.; Vanbladeren, P. J.; Vermeulen, N. P. E. Metabolism and kinetics of trichloroethylene in relation to toxicity and carcinogenicity relevance of the mercapturic acid pathway. Chem. Res. Toxicol. 1995, 8, 3-21.

35. Lash, L. H.; Putt, D. A.; Parker, J. C. Metabolism and tissue distribution of orally administered trichloroethylene in male and female rats: Identification of glutathione- and cytochrome P-450-derived metabolites in liver, kidney, blood, and urine. J. Toxicol. Environ. Health, Part A 2006, 69, 1285-1309.

36. Lash, L. H.; Putt, D. A. Identification of S-(1,2-dichlorovinyl)glutathione in the blood of human volunteers exposed to trichloroethylene. J. Toxicol. Environ. Health, Part A 1999, 56, 1-21.

37. Clang, C. M. W.; Aleo, M. D. Mechanistic analysis of S-(1,2-dichlorovinyl)-L-cysteineinduced cataractogenesis in vitro. Toxicol. Appl. Pharmacol. 1997, 146, 144-155.

38. Groves, C. E.; Hayden, P. J.; Lock, E. A.; Schnellmann, R. G. Differential cellular effects in the toxicity of haloalkene and haloalkane cysteine conjugates to rabbit renal proximal tubules. $J$. Biochem. Toxicol. 1993, 8, 49-56.

39. Shirai, N.; Ohtsuji, M.; Hagiwara, K.; Tomisawa, H.; Ohtsuji, N.; Hirose, S.; Hagiwara, H. Nephrotoxic effect of subchronic exposure to S-(1,2-dichlorovinyl)-L-cysteine in mice. J. Toxicol. Sci. 2012, 37, 871-878.

40. Newman, D.; Abuladze, N.; Scholz, K.; Dekant, W.; Tsuprun, V.; Ryazantsev, S.; Bondar, G.; Sassani, P.; Kurtz, I.; Pushkin, A. Specificity of aminoacylase III-mediated deacetylation of mercapturic acids. Drug Metab. Dispos. 2007, 35, 43-50.

41. Birner, G.; Bernauer, U.; Werner, M.; Dekant, W. Biotransformation, excretion and nephrotoxicity of haloalkene-derived cysteine S-conjugates. Arch. Toxicol. 1997, 72, 1-8. 
42. Bhattach.Rk; Schultze, M. O. Enzymes from bovine and turkey kidneys which cleave S-(1,2dichlorovinyl)-I-cysteine. Comp. Biochem. Physiol. 1967, 22, 723-\&.

43. Tateishi, M.; Suzuki, S.; Shimizu, H. Cysteine conjugate beta-lyase in rat-liver - novel enzyme catalyzing formation of thiol-containing metabolites of drugs. J. Biol. Chem. 1978, 253, 8854-8859.

44. Cooper, A. J. L.; Krasnikov, B. F.; Niatsetskaya, Z. V.; Pinto, J. T.; Callery, P. S.; Villar, M. T.; Artigues, A.; Bruschi, S. A. Cysteine S-conjugate beta-lyases: important roles in the metabolism of naturally occurring sulfur and selenium-containing compounds, xenobiotics and anticancer agents. Amino Acids 2011, 41, 7-27.

45. Anders, M. W.; Dekant, W. Glutathione-dependent bioactivation of haloalkenes. Annu. Rev. Pharmacol. Toxicol. 1998, 38, 501-537.

46. Dekant, W.; Vamvakas, S.; Berthold, K.; Schmidt, S.; Wild, D.; Henschler, D. Bacterial betalyase mediated cleavage and mutagenicity of cysteine conjugates derived from the nephrocarcinogenic alkenes trichloroethylene, tetrachloroethylene and hexachlorobutadiene. Chem.-Biol. Interact. 1986, 60, 31-45.

47. Stevens, J. L.; Robbins, J. D.; Byrd, R. A. A purified cysteine conjugate beta-lyase from ratkidney cytosol - requirement for an alpha-keto acid or an amino-acid oxidase for activity and identity with soluble glutamine transaminase-K. J. Biol. Chem. 1986, 261, 5529-5537.

48. Dekant, W. Biosynthesis of toxic glutathione conjugates from halogenated alkenes. Toxicol. Lett. 2003, 144, 49-54.

49. Volkel, W.; Dekant, W. Chlorothioketene, the ultimate reactive intermediate formed by cysteine conjugate beta-lyase-mediated cleavage of the trichloroethene metabolite $S$-(1,2dichlorovinyl)-L-cysteine, forms cytosine adducts in organic solvents, but not in aqueous solution. Chem. Res. Toxicol. 1998, 11, 1082-1088.

50. Chen, Q.; Jones, T. W.; Stevens, J. L. Early cellular events couple covalent binding of reactive metabolites to cell-killing by nephrotoxic cysteine conjugates. J. Cell. Physiol. 1994, 161, 293-302.

51. Newton, G. L.; Ko, M.; Ta, P.; Av-Gay, Y.; Fahey, R. C. Purification and characterization of Mycobacterium tuberculosis 1D-myo-inosityl-2-acetamido-2-deoxy- $\alpha$-D-glucopyranoside deacetylase, MshB, a mycothiol biosynthetic enzyme. Protein Expression Purif. 2006, 47, 542-550.

52. Nicholas, G. M.; Kovac, P.; Bewley, C. A. Total synthesis and proof of structure of mycothiol bimane. J. Am. Chem. Soc. 2002, 124, 3492-3493.

53. Lee, S.; Rosazza, J. P. N. First total synthesis of mycothiol and mycothiol disulfide. Org.Lett. 2004, 6, 365-368. 
54. Bornemann, C.; Jardine, M. A.; Spies, H. S. C.; Steenkamp, D. J. Biosynthesis of mycothiol: elucidation of the sequence of steps in Mycobacterium smegmatis. Biochem. J. 1997, 325, 623629.

55. McConnell, M. S.; Yu, F.; Nguyen, H. M. Nickel-catalyzed $\alpha$-glycosylation of C(1)-hydroxyl D-myo-inositol: a formal synthesis of mycothiol. Chem. Commun. 2013, 49, 4313-4315.

56. Yanagisawa, H.; Ishihara, S.; Ando, A.; Kanazaki, T.; Miyamoto, S.; Koike, H.; lijima, Y.; Oizumi, K.; Matsushita, Y.; Hata, T. Angiotensin-converting enzyme-inhibitors - perhydro-1,4thiazepin-5-one derivatives. J. Med. Chem. 1987, 30, 1984-1991.

57. Petra, D. G. I.; Kamer, P. C. J.; Spek, A. L.; Schoemaker, H. E.; Van, L. P. W. N. M. Aminosulf(ox)ides as ligands for iridium(I)-catalyzed asymmetric transfer hydrogenation. J. Org. Chem. 2000, 65, 3010-3017.

58. Euerby, M. R.; Partridge, L. Z.; Gibbons, W. A. Study of the chromatographic behavior and resolution of alpha-amino-acid enantiomers by high-performance liquid-chromatography utilizing pre-column derivatization with ortho-phthaldialdehyde and new chiral thiols. J. Chromatogr. 1989, 483, 239-252.

59. Olsen, R. K.; Kini, G. D.; Hennen, W. J. Conversion of thiosulfinate derivatives of cystine to unsymmetrical cystines and lanthionines by reaction with tris(dialkylamino)phosphines. J. Org. Chem. 1985, 50, 4332-4336.

60. Roth, G. A. Synthesis of cysteine and homoglutathione conjugates of crop protection agents containing electrophilic centers. J. Org. Chem. 1995, 60, 8105-8109.

61. Bartels, M. J.; Miner, V. W. Synthesis of stable isotope-labeled analogs of the cysteine and $\mathrm{N}$-acetylcysteine conjugates of tetrachloroethylene. J. Labelled Compd. Radiopharm. 1990, 28, 209-14.

62. Knapp, S.; Huhn, R. A.; Amorelli, B. Thionation: GlaNAc-thiazoline triacetate. Org. Synth. 2007, 84, 68-76.

63. Beckmann, H. S. G.; Niederwieser, A.; Wiessler, M.; Wittmann, V. Preparation of carbohydrate arrays by using Diels-Alder reactions with inverse-electron-demand. Chem. - Eur. J. 2012, 18, 6548-6554.

64. Bhatt, B.; Bohm, R.; Kerry, P. S.; Dyason, J. C.; Russell, R. J. M.; Thomson, R. J.; von, I. M. Exploring the interactions of unsaturated glucuronides with influenza virus sialidase. J. Med. Chem. 2012, 55, 8963-8968.

65. Sudibya, H. G.; Ma, J.; Dong, X.; Ng, S.; Li, L.-J.; Liu, X.-W.; Chen, P. Interfacing glycosylated carbon-nanotube-network devices with living cells to detect dynamic secretion of biomolecules. Angew. Chem., Int. Ed. 2009, 48, 2723-2726. 
66. Chaplin, D.; Crout, D. H. G.; Bornemann, S.; Hutchinson, D. W.; Khan, R. Conversion of 2acetamido-2-deoxy- $\beta$-D-glucopyranose ( $N$-acetylglucosamine) into 2 -acetamido-2-deoxy- $\beta$-Dgalactopyranose ( $N$-acetylgalactosamine using a biotransformation to generate a selectively deprotected substrate for $\mathrm{S}_{\mathrm{N}} 2$ inversion. J. Chem. Soc., Perkin Trans. 1 1992, 235-7.

67. Hoebartner, C.; Pradeepkumar, P. I.; Silverman, S. K. Site-selective depurination by a periodate-dependent deoxyribozyme. Chem. Commun. 2007, 2255-2257.

68. Meinjohanns, E.; Meldal, M.; Paulsen, H.; Bock, K. Dithiasuccinoyl (Dts) amino-protecting group used in syntheses of 1,2-trans-amino sugar glycosides. J. Chem. Soc., Perkin Trans. 1 1995, 405-15.

69. Greig, I. R.; Macauley, M. S.; Williams, I. H.; Vocadlo, D. J. Probing Synergy between Two Catalytic Strategies in the Glycoside Hydrolase $O$-GlcNAcase Using Multiple Linear Free Energy Relationships. J. Am. Chem. Soc. 2009, 131, 13415-13422.

70. Kiso, M.; Anderson, L. Protected glycosides and disaccharides of 2-amino-2-deoxy-Dglucopyranose by ferric chloride-catalyzed coupling. Carbohydr. Res. 1985, 136, 309-23.

71. Perez, E. M. S.; Avalos, M.; Babiano, R.; Cintas, P.; Light, M. E.; Jimenez, J. L.; Palacios, J. C.; Sancho, A. Schiff bases from D-glucosamine and aliphatic ketones. Carbohydr. Res. 2010, 345, 2332.

72. Horton, D. The anomeric 1,3,4,6-tetra-O-acetyl-2-deoxy-2-(2,4-dinitro-anilino)-Dglucopyranoses. J. Org. Chem. 1964, 29, 1776-82.

73. Himanen, J. A.; Pihko, P. M. Synthesis of Trisaccharides by Hetero-Diels-Alder Welding of Two Monosaccharide Units. Eur. J. Org. Chem. 2012, 3765-3780.

74. Knapp, S.; Myers, D. S. $\alpha-G I c N A c$ Thioconjugates. J. Org. Chem. 2001, 66, 3636-3638.

75. Wang, L. Polymer Handbook, 4th Edition Edited by J. Brandrup, E. H. Immergut, E. A. Grulke, A. Abe and D. R. Bloch (eds). Z. Metallkd. 2000, 91, 618-619.

76. Zhu, X.; Schmidt, R. R. Synthesis of $\alpha$-S-linked glycopeptides in water containing solution. Tetrahedron Lett. 2003, 44, 6063-6067.

77. Schmidt, R. R.; Michel, J. Simple syntheses of $\alpha$ - and $\beta$-O-glycosyl imidates; preparation of glycosides and disaccharides. Angew. Chem. Int. Ed. 1980, 92, 763-4.

78. Schmidt, R. R.; Castro-Palomino, J. C.; Retz, O. New aspects of glycoside bond formation. Pure Appl. Chem. 1999, 71, 729-744.

79. Schmidt, R. R.; Kinzy, W. Anomeric-oxygen activation for glycoside synthesis: the trichloroacetimidate method. Adv. Carbohydr. Chem. Biochem. 1994, 50, 21-123. 
80. Kumar, A.; Schmidt, R. R. Reversal of anomeric selectivity with O-glycosyl trichloroacetimidates as glycosyl donors and thiols as acceptors under acid/base catalysis. Eur. J. Org. Chem. 2012, 2715-2719.

81. Heuckendorff, M.; Pedersen, C. M.; Bols, M. Quantifying electronic effects of common carbohydrate protecting groups in a piperidine model system. Chem. - Eur. J. 2010, 16, 1398213994.

82. Mootoo, D. R.; Konradsson, P.; Udodong, U.; Fraser-Reid, B. Armed and disarmed npentenyl glycosides in saccharide couplings leading to oligosaccharides. J. Am. Chem. Soc. 1988, 110, 5583-4.

83. Jensen, H. H.; Nordstrom, L. U.; Bols, M. The disarming effect of the 4,6-acetal group on glycoside reactivity: torsional or electronic? J. Am. Chem. Soc. 2004, 126, 9205-9213.

84. Crich, D.; Li, M. Revisiting the armed-disarmed concept: the importance of anomeric configuration in the activation of S-benzoxazolyl glycosides. Org. Lett. 2007, 9, 4115-4118.

85. Xu, C.; Liu, H.; Li, X. Thioglycosylation of 1,2-cis-glycosyl acetates: a long-standing overlooked issue in preparative carbohydrate chemistry. Carbohydr. Res. 2011, 346, 1149-1153.

86. Chu, A.-H. A.; Nguyen, S. H.; Sisel, J. A.; Minciunescu, A.; Bennett, C. S. selective synthesis of 1,2-cis- $\alpha$-glycosides without directing groups. Application to iterative oligosaccharide synthesis. Org. Lett. 2013, 15, 2566-2569.

87. Xue, J. L.; Cecioni, S.; He, L.; Vidal, S.; Praly, J.-P. Variations on the SnCl4 and CF3CO2Agpromoted glycosidation of sugar acetates: a direct, versatile and apparently simple method with either $\alpha$ or $\beta$ stereocontrol. Carbohydr. Res. 2009, 344, 1646-1653.

88. Buskas, T.; Garegg, P. J.; Konradsson, P.; Maloisel, J.-L. Facile preparation of glycosyl donors for oligosaccharide synthesis: 2-azido-2-deoxyhexopyranosyl building blocks. Tetrahedron: Asymmetry 1994, 5, 2187-94.

89. Dasgupta, F.; Garegg, P. J. Synthesis of ethyl and phenyl 1-thio-1,2-trans-Dglycopyranosides from the corresponding per-O-acetylated glycopyranoses having a 1,2-transconfiguration using anhydrous ferric chloride as a promoter. Acta Chem. Scand. 1989, 43, 471-5.

90. Calosso, M.; Charpentier, D.; Vaillancourt, M.; Bencheqroun, M.; St-Pierre, G.; Wilkes, B. C.; Guindon, Y. A New approach to explore the binding space of polysaccharide-based ligands: selectin antagonists. ACS Med. Chem. Lett. 2012, 3, 1045-1049.

91. Heng, L.; Li, Z. Non-natural active oligosaccharide compounds, preparing process and application. Chinese Patent Application Number 200510020578, 2005. 
92. Weng, S.-S. Diastereoselective thioglycosylation of peracetylated glycosides catalyzed by in situ generated iron(III) iodide from elemental iodine and iron. Tetrahedron Lett. 2009, 50, 64146417.

93. Pilgrim, W.; Murphy, P. V. SnCl4- and TiCl4-catalyzed anomerization of acylated $O$ - and Sglycosides: analysis of factors that lead to higher $\alpha: \beta$ anomer ratios and reaction rates. J. Org. Chem. 2010, 75, 6747-6755.

94. Malik, S.; Shah, K. J.; Ravindranathan, K. K. P. lodine-hexamethyldisilane (HMDS)-mediated anomerization of peracetylated 1,2-trans-linked alkyl and aryl glycosides. Carbohydr. Res. 2010, $345,867-871$.

95. Painter, E. P. The anomerization of sugar acetates. Glucose pentaacetates in acetic acidacetic anhydride mixtures catalyzed by sulfuric and perchloric acids. J. Am. Chem. Soc. 1953, 75, 1137-46.

96. Benakli, K.; Zha, C.; Kerns, R. J. Oxazolidinone protected 2-amino-2-deoxy-D-glucose derivatives as versatile intermediates in stereoselective oligosaccharide synthesis and the formation of $\alpha$-linked glycosides. J. Am. Chem. Soc. 2001, 123, 9461-9462.

97. Bzymek, K. P.; Newton, G. L.; Ta, P.; Fahey, R. C. Mycothiol import by Mycobacterium smegmatis and function as a resource for metabolic precursors and energy production. J. Bacteriol. 2007, 189, 6796-6805.

98. Miller, C. H.; Nisa, S.; Dempsey, S.; Jack, C.; O'Toole, R. Modifying culture conditions in chemical library screening identifies alternative inhibitors of mycobacteria. Antimicrob. Agents Chemother. 2009, 53, 5279-5283.

99. Hood, K. A.; West, L. M.; Rouwe, B.; Northcote, P. T.; Berridge, M. V.; Wakefield, S. J.; Miller, J. H. Peloruside A, a novel antimitotic agent with paclitaxel-like microtubule-stabilizing activity. Cancer Res. 2002, 62, 3356-3360.

100. Tanaka, J.-i.; Higa, T. Zampanolide, a new cytotoxic macrolide from a marine sponge. Tetrahedron Lett. 1996, 37, 5535-5538.

101. Mohamadi, F.; Richards, N. G. J.; Guida, W. C.; Liskamp, R.; Lipton, M.; Caufield, C.; Chang, G.; Hendrickson, T.; Still, W. C. MacroModel - an integrated software system for modeling organic and bioorganic molecules using molecular mechanics. J. Comput. Chem. 1990, 11, 440-67.

102. Berridge, M. V.; Tan, A. S.; McCoy, K. D.; Wang, R. The biochemical and cellular basis of cell proliferation assays that use tetrazolium salts. Biochemica 1996, 14-19. 